\title{
Quality of sleep in hospital settings
}

Citation for published version (APA):

Cox, C. M. M. (1992). Quality of sleep in hospital settings. [Doctoral Thesis, Maastricht University]. Datawyse / Universitaire Pers Maastricht. https://doi.org/10.26481/dis.19921009cc

Document status and date:

Published: 01/01/1992

DOI:

10.26481/dis.19921009cc

Document Version:

Publisher's PDF, also known as Version of record

\section{Please check the document version of this publication:}

- A submitted manuscript is the version of the article upon submission and before peer-review. There can be important differences between the submitted version and the official published version of record.

People interested in the research are advised to contact the author for the final version of the publication, or visit the DOI to the publisher's website.

- The final author version and the galley proof are versions of the publication after peer review.

- The final published version features the final layout of the paper including the volume, issue and page numbers.

Link to publication

\footnotetext{
General rights rights.

- You may freely distribute the URL identifying the publication in the public portal. please follow below link for the End User Agreement:

www.umlib.nl/taverne-license

Take down policy

If you believe that this document breaches copyright please contact us at:

repository@maastrichtuniversity.nl

providing details and we will investigate your claim.
}

Copyright and moral rights for the publications made accessible in the public portal are retained by the authors and/or other copyright owners and it is a condition of accessing publications that users recognise and abide by the legal requirements associated with these

- Users may download and print one copy of any publication from the public portal for the purpose of private study or research.

- You may not further distribute the material or use it for any profit-making activity or commercial gain

If the publication is distributed under the terms of Article $25 \mathrm{fa}$ of the Dutch Copyright Act, indicated by the "Taverne" license above, 


\section{Quality of sleep in hospital settings}

\section{Karen Cox}

Faculteit der Gezondheidswetenschappen

Rijksuniversiteit Limburg 



\title{
QUALITY OF SLEEP IN HOSPITAL SETTINGS
}

\author{
Proefschrift
}

ter verkrijging van de graad van doctor aan de Rịkksuniversiteit Limburg te Maastricht, op gezag van de Rector Magnificus, Prof. mr. M.J. Cohen, volgens het besluit van het College van Dekanen, in het openbaar te verdedigen op vrijdag, 9 oktober 1992 om 16.00 uur

door

Catharina Mathea Maria Cox

geboren te Sittard in 1964 


\section{Promotores:}

Prof. dr. H. Huijer Abu-Saad

Prof. dr. H. Philipsen

Co-promoter:

Dr. R.J.G. Halfens

Beoordelingscommissie:

Prof, dr. J.J.C.B. Bremer, voorzitter

Prof. dr. J.A. Floyd, Wayne State University Detroit, U.S.A.

Prof. dr. G.J. Kok

Prof. dr. L.M. Shortridge, Pace University New York, U.S.A.

Prof. dr. E.F.M. Wouters

CIP-GEGEVENS KONINKLIJKE BIBLIOTHEEK, DEN HAAG

Cox, Catharina, Mathea, Maria

Quality of sleep in hospital settings / Catharina Mathea Maria Cox.

Maastricht: Universitaire Pers Maastricht. - III

Thesis Maastricht. - With ref. - With summary in Dutch.

ISBN 90-5278-036-6

NUGI 750

Subject headings: sleep / sleep problems; hospitals / sleep problems; nursing.

produktie: Datawyse Maastricht

druk: Krips Repro Meppel

Aan dit promotie-onderzoek is financieel bijgedragen door het Praeventiefonds. 


\section{CONTENTS}

Dankwoord 9

Introduction $\quad 11$

Part I Quality of sleep: Its definition, appraisal and 15 measurement

$\begin{array}{ll}\text { Literature review } & 17\end{array}$

$\begin{array}{lll}1.1 & \text { Introduction } & 17\end{array}$

$\begin{array}{lll}1.2 & \text { Structure and physiology of sleep } & 17\end{array}$

$\begin{array}{lll}1.3 & \text { Appraisal of sleep quality } & 21\end{array}$

1.4 Biophysiological measurements, observations 22

$\begin{array}{lll}1.5 & \text { Conclusions } & 25\end{array}$

$2 \quad$ The Subjective Sleep Quality Scale 27

$\begin{array}{lll}2.1 & \text { Introduction } & 27\end{array}$

$\begin{array}{lll}2.2 & \text { Measuring sleep } & 27\end{array}$

2.3 Subjective Sleep Quality Scale (SSOS) 28

2.4 Reliability and validity of the SSOS 30

2.5 Research design $\quad 32$

2.5.1 Population $\quad 32$

2.5.2 Variables $\quad 32$

2.5.3 Analysis 33

2.6 Results 33

2.6.1 Dimensionality 33

$\begin{array}{ll}2.6 .2 & \text { Internal consistency } \\ 2.6 .3 & 34\end{array}$

$\begin{array}{lll}2.6 .3 & \text { Stability } & 34\end{array}$

2.6.4 Concurrent validity $\quad 35$

$\begin{array}{ll}2.6 .5 & \text { Construct validity } \\ 2.7 & 37\end{array}$

2.7 Conclusions and discussion 38 

its determinants

$3 \quad$ Literature review on sleep in hospital settings

3.1 Introduction

3.2 Sleep quality and quantity in the hospital 44

3.3 Etiology of sleep problems

3.3.1 Environmental variables

3.3.2 Personal characteristics

3.3.3 Disease-related variables 50

3.4 Conclusions 51

$4 \quad$ Research methods of Part II 53

4.1 Introduction 53

4.2 Research design 54

4.2.1 Methods $\quad 54$

4.2.2 Population 54

4.2.3 Variables and instruments $\quad 55$

4.2.4 Procedure 60

$\begin{array}{lll}4.2 .5 & \text { Analysis } & 60\end{array}$

5 An inventory of sleep problems in hospitals 63

5.1 Introduction 63

5.2 Changes in sleep pattern 63

5.3 The extent of sleep problems 65

$\begin{array}{lll}5.4 & \text { Conclusions and discussion } & 67\end{array}$

6 Determinants of sleep problems 69

$\begin{array}{lll}6.1 & \text { Introduction } & 69\end{array}$

6.2 Factors patients experience as disturbing their sleep 69

$\begin{array}{lll}6.3 & \text { Demographic variables } & 73\end{array}$

$\begin{array}{lll}6.4 & \text { Environmental variables } & 74\end{array}$

$\begin{array}{lll}6.5 & \text { Personal characteristics } & 76\end{array}$

6.6 Disease-related variables $\quad 80$

$\begin{array}{lll}6.7 & \text { Regression analysis } & 82\end{array}$

$\begin{array}{ll}\text { 6.8 Conclusions and discussion } & 87\end{array}$ 
7 Sleep medication in a general hospital

7.1 Introduction

7.2 Sleep medications

7.3 Sleep medication in hospital

7.4 Research design

7.4.1 Methods

7.4.2 Population

7.4.3 Instruments

7.4.4 Procedure

7.4.5 Analysis

7.5 Results

7.6 Conclusions and discussion

8 Problem-solving in nursing

8.1 Introduction

103

8.2 The nursing process

103

8.3 Why a nursing process?

105

8.4 The diagnostic process

106

8.5 Nursing process and nursing care plans

8.6 Conclusions

9 The management of sleep: An intervention study

9.1 Introduction

9.2 Research design

9.2.1 Methods

9.2.2 Population

9.2.3 Instruments

114

9.2.4 Procedure

114

9.2.5 Analysis

115

9.3 Results

115

9.3.1 Sleep quality and quantity

9.3.2 Nursing interventions on sleep

9.4 Conclusions and discussion 
10 The nursing process in practice

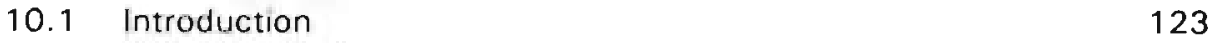

$\begin{array}{ll}10.2 \text { Research design } & 123\end{array}$

$\begin{array}{ll}\text { 10.2.1 Methods } & 123\end{array}$

$\begin{array}{ll}\text { 10.2.2 Population } & 124\end{array}$

10.2.3 Instruments $\quad 124$

10.2.4 Procedure $\quad 124$

10.2.5 Analysis $\quad 125$

$\begin{array}{lll}10.3 \text { Results } & 125\end{array}$

10.3. 1 Correspondence between patients' view and nursing care plans 125

$\begin{array}{ll}\text { 10.3.2 Nursing diagnoses } & 127\end{array}$

10.3.3 Nursing interventions 129

10.3.4 Nursing interventions based on nursing diagnoses 130

10.4 Conclusions and discussion 132

$\begin{array}{ll}\text { Part IV Conclusions and discussion } & 135\end{array}$

11 Conclusions and discussion 137

$\begin{array}{lll}11.1 & \text { Introduction } & 137\end{array}$

$\begin{array}{lll}11.2 & \text { Summary of the results } & 137\end{array}$

11.3 Methodological reflections 138

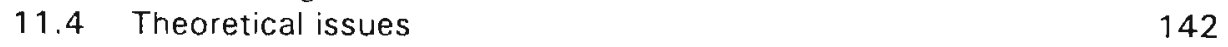

$\begin{array}{lll}11.5 & \text { Practical implications } & 144\end{array}$

$\begin{array}{lll}11.6 & \text { Recommendations for further study } & 145\end{array}$

$\begin{array}{ll}\text { Summary } & 147\end{array}$

$\begin{array}{ll}\text { Samenvatting } & 151\end{array}$

$\begin{array}{ll}\text { References } & 154\end{array}$

$\begin{array}{ll}\text { Appendices } & 164\end{array}$

$\begin{array}{ll}\text { Curriculum vitae } & 176\end{array}$ 


\section{Dankwoord}

Nadat dit onderzoek twee eerdere starts had gekend, is het dan nu toch eindelijk afgerond. Dit was echter niet mogelijk geweest zonder de inzet van een aantal personen. Enkelen wil ik hier met naam noemen.

Op de eerste plaats wil ik mijn promotoren, Hans Philipsen en Huda Huijer AbuSaad en co-promotor Ruud Halfens noemen. Hans, je had zeker aan het einde van dit onderzoek een inspirerende invloed, waardoor het proefschrift de vorm heeft gekregen die het nu heeft. Ook de inbreng van jou, Huda, had ik zeker niet willen missen, ook al ben je pas nadat het onderzoek had plaatsgevonden erbij betrokken geraakt. Ruud wil ik ervoor danken dat hij altijd tijd voor me had en zelfs niet schuwde om mee te gaan interviewen.

Ook wil ik de patiënten op de afdelingen danken, want zonder hun medewerking was dit onderzoek uiteraard niet mogelijk geweest. De verpleegkundigen wil ik danken voor hun inzet die ze getoond hebben, ondanks het feit dat ze verrast waren, dat dit onderzoek niet hun slaapproblemen betrof maar die van de patiënten.

Tegen Miriam Janssen wil ik zeggen, dat ze niet alleen in theorie veel afweet van sociale netwerken maar die kennis ook nog heel goed weet toe te passen in de praktijk. Miriam, ik hoop dat ik ook nog na de promotie deel mag blijven uitmaken van je netwerk en de gelegenheid krijg de balans weer in evenwicht te brengen. Van Neeltje Mosterd heb ik, zonder dat ze zich daar zo van bewust was, ontzettend veel geleerd en wat ik bijzonder gewaardeerd heb, is dat ze altijd tijd voor me had als het eens even tegen zat.

Op deze plaats wil ik ook Henk Janssen noemen. Henk, je bent niet alleen een $s$ ter ín de keuken maar ook vóór de pc. Je enthousiasme werkte zeer aanstekelijk en heeft ervoor gezorgd dat het proefschrift deze lay-out heeft gekregen.

De heer Janssen wil ik danken voor zijn aanbod om de Nederlandse teksten te lezen. Ik heb dit aanbod graag aangenomen.

In dit dankwoord wil ik ook mijn ouders vermelden, ze hebben me altijd gestimuleerd om verder te studeren en ik ben hun daar dan ook zeer dankbaar voor. Tegen Fons zeg ik: Dank je voor je onvoorwaardelijke steun die je al die jaren verleend hebt. Eindelijk kunnen we nu aan onze toekomst samen gaan denken zonder proefschrift, want, hoe je het ook wendt of keert, een promotie-onderzoek beheerst in belangrijke mate jouw leven en dat van je partner. 



\section{Introduction}

When people are admitted to the hospital several things change, among them the daily routines. Ordinary daily routines which are disrupted by a hospital admission include eating habits, elimination pattern and also the sleep-wake pattern. Patients are expected to adapt to different rules and routines. "I didn't sleep a wink in the hospital", "You won't sleep in the hospital" or "You'll get addicted to sleep medication in the hospital" are statements commonly cited by patients. However, these are personal statements. Very little research has been done on the extent of sleep problems among patients in hospital settings.

Although the function of sleep is still surrounded by much controversy, a restful sleep is considered as necessary for recovery. Experience shows, as is generally known, that a poor sleep has its influence on day time functioning and gives an unsatisfied feeling. As a consequence promoting and maintaining sleep is generally recognized as a nursing function. Nightingale (1859) in her Notes on Nursing stated that "never to allow a patient to be waked, intentionally or accidentally, is a sine qua non of all good nursing. If he is roused out of his first sleep, he is almost certain to have no more sleep" (1947, p. 25). The acceptance of the nursing diagnosis "Sleep pattern disturbance" by the North American Nursing Diagnosis Association underscored the fact that the phenomenon of sleep as described above belongs to the domain of nursing. "Sleep pattern disturbance" is defined as the state in which disruption of sleep time causes discomfort or interferes with an individual's desired life-style (McLane, 1987). This definition encompasses the four types of sleep disorders in the classification of the Association of Sleep Disorder Centers (ASDC, 1979). These categories are: disorders of initiating and maintaining sleep (DIMS), disorders of excessive somnolence (DOES), disorders of the sleepwake schedule, and the dysfunctions associated with sleep, sleep stages or partial arousals. Sleep problems due to hospital admissions belong to the first and third type of sleep disorders. Chronic sleep problems are not expected to be solved during a regular hospital admission.

Sleep has been conceptualized as a basic human need (Henderson, 1966, Maslow, 1970), a survival need (Yura \& Walsh, 1988). Orem (1985) identified the balance between activity and rest as one of the eight universal self-care requisites of human beings. Effectively meeting these requisites is essential "when there is pathology in order to maintain human structure and functioning and to promote development and thereby contribute to rehabilitation" (1985, p. 90). Roy (1984, p. 153) states that "the physical and psychological stresses commonly experienced by hospitalized patients augment the importance of providing a suitable environment for meeting rest and sleep needs".

Nurses are, because of their 24-hour contact with patients in the best position to recognize and resolve or alleviate these sleep problems. Unfortunately, nursing education books contain only limited information on sleep, sleep problems and possible interventions on sleep. 
The question is whether nurses have the abilities to assess the sleep problems of patients accurately, and what care do they provide to enhance the hospitalized patients' sleep.

This dissertation focuses on the following aspects of sleep in hospital. How patients experience sleep in hospital settings and what do nurses do about the sleep of patients? The purpose of this study is to explore the sleep problems experienced by hospitalized patients and the nursing interventions provided to prevent sleep problems.

For this reason four studies were executed in five participating hospitals. For each of the four studies the problem to be studied was formulated as follows:

Study I: What is the extent of use of sleep medication in a general hospital?

Study II: What is the extent of sleep problems in a general hospital?

Study III: Does using the nursing process by nurses lead to an improvement of sleep quality and quantity and a decrease in use of sleep medication on hospital wards?

Study IV: Do the nurses of a general hospital accurately assess patients'sleep problems and what diagnoses and interventions do they formulate with respect to sleep problems?

In this dissertation the quality and quantity of sleep is estimated by means of a solf-report, the Subjective Sleep Quality Scale. It has been shown that self-reports of sleep correlate with the biophysiological measurements of sleep. The patient's own perception of sleep is an important source of information for nurses to asses. a nursing diagnosis. Besides, in nursing practice nurses mostly do not have access to biophysiological instruments.

Sleep medications are frequently used to alleviate sleep problems. Study I comprises an inventarization of the prescriptions of sleep medication and their actual use in three general hospitals. A considerable percentage of sleep medication orders are "as needed" prescriptions, leaving the decision to the discretion of the nurse, together with the patient, to provide sleep medications or not. However, without knowledge of the cause of the sleep problem no rational decision can be made. Study II consequently was an inventarization of sleep problems patients experience during their hospital stay and the possible causes of these sleep problems. Once the causes of the sleep problems are known, nursing interventions can be planned to improve the sleep quality of patients in hospital settings.

In Study III nurses were instructed to use the nursing process in preventing and solving sleep problems in a general hospital. To accomplish this, extra forms were added to the nursing records. By using the nursing process, it was hypothesized that interventions would be planned based on the diagnosis, and would lead to an improvement of sleep or to the prevention of a deterioration of sieep quality in the hospital.

Study IV evaluated the use of the nursing process in Study III. Besides it provided more knowledge on the kind of diagnoses nurses formulated and the interventions they used to relieve sleep problems. 
This dissertation contains four parts. The results of the four studies are not presented separately per study; instead they are presented within a diagnosis part (Part II), a description of the extent and nature of sleep problems and possible related factors, and an intervention part (Part III), nursing interventions instituted for sleep problems. Part I presents a general introduction to the subject and Part IV concludes this dissertation.

Data from Studies II and III are used in Part II as well as in Part III, and only those facets of the research design which are relevant to the current chapter are presented. As a result the reader is at some points in the text referred to other chapters for additional information on the research design. A description of the chapters follows.

Chapter 1 presents a review of the literature on sleep in general; it contains a discussion of how to appraise sleep quality and about whether to use biophysiological instruments, observations or self-reports to measure sleep quality. The instrument used in these studies, the Subjective Sleep Quality Scale, is presented in Chapter 2, which reports tests conducted on reliability and validity.

Part II, the diagnosis part, consists of four chapters. In Chapter 3 the literature on sleep in hospital settings and etiological factors is reviewed. Chapter 4 describes the research methods of Study II and Study III, in so far as they are related to the aim of this part. The results are presented in two chapters, with Chapter 5 focusing on the extent of the sleep problems in hospital and Chapter 6 concentrating on the etiological factors.

In Part III, the intervention part, the link between diagnoses and interventions is established. In Chapter 7, the literature on the use of sleep medication in general hospitals is reviewed. Data on the use of sleep medication in hospital are taken from Studies I, II and III. The research design of Study I is described in this chapter. Chapter 8 illustrates the use of the nursing process as a guide for decision-making in nursing. In Study III the nursing process was introduced on some hospital wards to guide this process of clinical decision-making. The expectation was that it would improve the care provided with regard to sleep resulting in better sleep and less use of sleep medication in hospital. The research methods and results of Study III, a quasi-experiment, are presented in Chapter 9 . The last chapter in Part III, Chapter 10, presents a secondary analysis (Study IV) of the forms added to the nursing care plans in Study III. Because information was available from the patients, by means of interviews, as well as from the nurses, from these nursing care plans, an impression could be formed of the diagnostic skills of the nurses. An overview is presented of the diagnoses formulated and interventions planned and whether these two steps of the nursing process are related or not.

This dissertation concludes with a chapter on methodological and theuretical reflections, practical implications and recommendations for further research. 
In summary, the results of the four studies are presented as follows:

\begin{tabular}{||l|l|l||}
\hline Problem statements: & $\begin{array}{l}\text { Results present- } \\
\text { ed in: }\end{array}$ & Data used from: \\
\hline \hline $\begin{array}{l}\text { What is the extent of use of sleep } \\
\text { medication in a general hospital? }\end{array}$ & Chapter 7 & $\begin{array}{l}\text { Studies I, II and } \\
\text { III }\end{array}$ \\
\hline $\begin{array}{l}\text { What is the extent of sleep problems } \\
\text { in a general hospital? }\end{array}$ & Chapters 5 and 6 & Studies II and III \\
\hline $\begin{array}{l}\text { Does using the nursing process by } \\
\text { nurses lead to an improvement of } \\
\text { sleep quality and quantity and a de- } \\
\text { crease in use of sleep medication on } \\
\text { hospital wards? }\end{array}$ & Chapter 9 & Study III \\
\hline $\begin{array}{l}\text { Do the nurses of a general hospital } \\
\text { accurately assess patients' sleep } \\
\text { problems and what diagnoses and } \\
\text { interventions do they formulate with } \\
\text { respect to sleep problems? }\end{array}$ & Chapter 10 & Study IV \\
\hline
\end{tabular}




\section{Part I}

Quality of sleep: Its definition, appraisal and measurement 



\section{Literature review}

\section{$1.1 \quad$ Introduction}

Although sleep is considered to be a subjective experience and the individual person is the only authority on the quality of sleep, nurses are expected to do something about sleep problems. In general a restorative function is ascribed to sleep and as a result the promotion of sleep is considered as a goal of nursing care in hospital settings. In order to do that, a nurse has to know whether someone has sleep problems. In other words, nurses need the tools to assess sleep.

Biophysiological instruments, observations and self-reports are means to collect information on sleep. Information from observations and self-reports by the patients is accessible to nurses. The nurse on the night shift can observe when a patient does not sleep or has difficulties falling asleep, while nurses during the day are confronted with patients who are feeling sleepy or who report they slept poorly the previous night.

It is generally stressed that objectively measuring sleep is the most reliable and valid means to gain accurate information about sleep. In hospital settings it is not always feasible to measure sleep biophysiologically: the means to do this are often lacking. As a result the question arises as to what extent these three means of estimating sleep correlate with each other.

Since it is important to institute appropriate nursing interventions, the assessment of sleep problems should be accurate, based on information from observations and self-reports.

In this chapter the literature on the appraisal of sleep quality is reviewed. What makes a person say that he had a good sleep last night? A good night's sleep does not mean the same thing for everybody. The review is followed by a comparison of biophysiological measurements, observations and self-reports on sleep. A short summary on sleep theories, structure and physiology of sleep are presented and discussed to the extent that they are related to the present research.

\section{$1.2 \quad$ Structure and physiology of sleep}

Much has been published on sleep but still not all facets of sleep are clear, including the function and physiology of sleep. Several sleep theories address the function and physiology of sleep. Most sleep theories, however, focus more on the mechanisms (the physiology) of sleep and less on the purpose or function of sleep (Horne, 1989).

Why do we sleep? What is the purpose of sleep? These are common questions but are still difficult to answer in view of the limited information that is presently available. In general it is held that sleep has a restorative function. Theories on the functions of sleep are also often limited to restorative theories (Oswald, 1984). The 
deep sleep (slow-wave sleep) restores the physical effects of wakefulness (Akerstedt \& Gillberg, 1981, Czeisler, Weitzman, Moore-Ede, Zimmerman, \& Knauer, 1980, Webb \& Agnew, 1971) and the REM sleep (Rapid Eye Movernents) the emotional processing of the previous day (Hartmann, Baekeland, Zwilling, and Hoy, 1971, Hartmann, 1973, Schirmer, 1983). However, empirical data to support these theories is limited. Sleep is considered to have a restorative function as supported by the fact that ai rise in the release of growth hormone occurs especially in the beginning of the night which is linked with mitosis and protein synthesis.

The effect of sleep deprivation can shed more light on the functions of sleep. Experiments with sleep deprivation in humans show, however, minor effects of sleep deprivation. Horne (1989) argues the function of sleep for body restitution considering the results of the deprivation studies. In his view the functions of sleep alter as the night's sleep progresses, initially serving more important purposes, then changing to those of lesser benefit. The last two hours of sleep may be superfluous. Other theories on the functions of sleep describe sleep as energy conservation, a form of adaptive behavior or as an instinct (Canavan, 1984, Meddis, 1977).

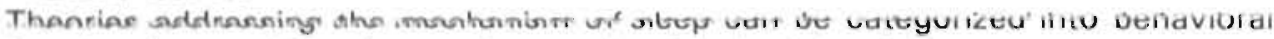
theories, humoral theories, and neurophysiological theories.

Behavioral theories were popular in the nineteenth century until the turn of the century. Sleep was first thought of as a consequence of a lack of external stimuli. Without stimulation, the organism will fall asleep. Another behavioral theory viewed sleep as an instinct. Organisms sleep in order to avoid exhaustion and awaken when they have enough.

The beginning of the twentieth century marked the beginning of humoral sleep theories and since the 1960 s interest in the subject has been increasing. According to these theories various sleep inducing substances accumulate in the brain during wakefulness.

Around the same time the development of neurophysiological sleep theories started. After the discovery of arousal centers in the brain by Moruzzi and Mogoun in 1947, the sleep-inducing centers in the brain became the center of sleep research (Mendelson, 1989).

There are two sorts of sleep the NREM sleep (Non Rapid Eye Movements) also called the orthodox sleep, and the REM sleep also called the paradoxical sleep. Within the NREM sleep four stages can be recognized, stages 1 and 2, light sleep, and stages 3 and 4, deep sleep or delta sleep. The EEG (electroencephalogram) has facilitated the discovery of the stages of sleep (Figure 1). Determination of sleep stage is based on the information obtained from the EEG, EMG (electromyogram). and EOG (electro-oculogram). Records are scored in periods of 20 to 30 seconds for the dominant sleep stage.

Stage 1 is a transitional phase between wakefulness and sleep, and occupies only $5 \%$ of sleep time in a normal young adult (Table 1, 1). About $45 \%$ of sleep is made up of stage 2 sleep. Stage 3 is a transition between stage 2 and stage 4 sleep and constitutes only $7 \%$ of the sleep in a young adult. Stage 4 sleep constitutes around $10 \%$ of the sleep of a young adult (Anch, Browman, Mitler, \& Walsh, 1988). Stages 3 and 4 are also called the slow wave sleep (SWS). 
During REM sleep an EEG shows similarity with stage 1 sleep and is therefore as a result called the paradoxical sleep. The EMG indicates a decrease in muscle tone and rapid eye movements are visible on the EOG. REM sleep makes up about 25 to $30 \%$ of the total sleep.

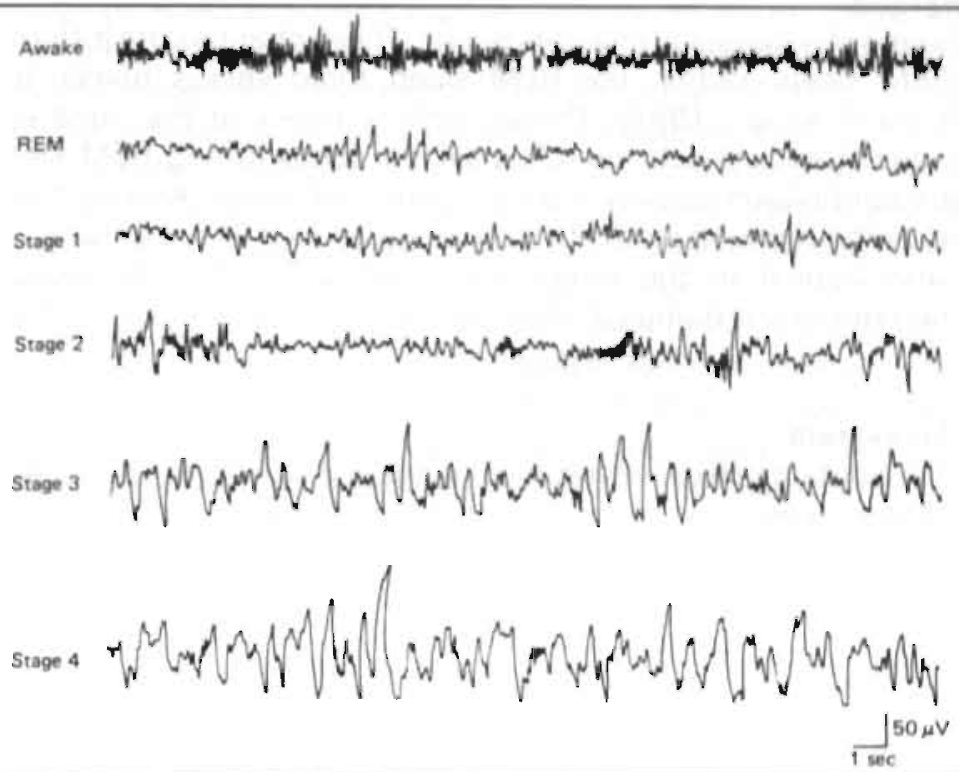

Figure 1 Polysomnographic recordings illustrating wakefulness and sleep (Anch et al., 1988).

Table 1.1 Distribution of sleep stages in a young adult.

\begin{tabular}{lr}
\hline Stage 1 & $5 \%$ \\
Stage 2 & $45-50 \%$ \\
Stage 3 & $7 \%$ \\
Stage 4 & $10 \%$ \\
REM & $25-30 \%$ \\
\hline
\end{tabular}

These sleep stages occur in cycles. A normal young adult goes from waking into a period of NREM sleep, starting with stage 1 to stage 4 . From stage 4 the sleeper returns to stage 1 or 2 and REM sleep occurs. After this REM sleep period the cycle starts over again. Each cycle lasts about 90 minutes, varying between 70 and 120 minutes (Mendelson, 1989). The duration and the content of the sleep cycle change during the night. Subsequent sleep cycles show less delta sleep and the REM sleep periods become longer.

The total sleep time and the number of sleep stages are age dependent, with stage 1 and 2 gradually increasing with age and stage 4 disappearing in some cases completely. After puberty the REM sleep retains the same number of episodes but the duration of each episode declines (Colling, 1983). As people grow older, the. 
total sleep time decreases although the time in bed remains the same or even increases. Sleep in the elderly is more fragmented and less deep.

Pharmacological and neuroanatomical manipulation in animals has shown that certain areas in the brain are involved in the regulation of the sleep-wake cycle. The physiological and anatomical mechanisms of sleep are still, however, not completely understood.

During sleep some physiological changes occur. These changes are different for the NREM and REM sleep. Within the REM sleep tonic versus phasic activity is distinguished (Anch et al., 1988). Phasic activity refers to the rapid eye movements or the facial and muscle twitches which occur during REM sleep. Tonic activity means continuous activity during a phase of sleep. Among the systems most affected by the sleeping state are the cardiovascular and respiratory systems. Differences also appear in the temperature regulation. The following section focuses on the normal physiological changes during sleep and not on the pathological ones.

\section{Cardiovascular system}

During the first hours of sleep which mainly consist of stages 3 and 4 of NREM sleep, blood pressure declines. An increase in variability of blood pressure occurs during REM sleep, the highest and lowest values for the night being recorded during this phase (Snyder, Hobson, Moneson, \& Goldfrank, 1964). Heart rate decreases during the transition from wakefulness to sleep, with large variability in REM sleep which may trigger nocturnal angina or infarction (Robinson, 1986).

\section{Respiratory system}

During the transition from wakefulness to slow wave sleep the respiratory rate decreases. Slower, deeper, but regular breathing characterizes NREM sleep. Respiration becomes rapid and irregular during REM sleep. In this stage respiration resembles that seen in the awake-behavior pattern (Anch et al., 1988).

\section{Thermoregulation}

Core body temperature is closely linked with the sleep-wake cycle. Body temperature peaks before sleep onset and falls during the night reaching its trough during the last third of the sleep phase. During REM sleep a close relationship exists between ambient temperature and body temperature because the body does not thermoregulate during REM sleep, with both sweating and shivering absent (Anch et al., 1988).

It is thus evident that sleep is connected to various physiological systems but it is not clear what the interactive effects of these systems are on sleep. Apparently, there is no organ and no function in the body which does not exhibit rhythmicity (Aschoff, 1965). Depending on the period it takes to complete a cycle, these rhythms are classified as either ultradian (less than 24 hours), circadian (24 hours) or infradian (greater than 24 hours). The sleep-wake cycle is an example of a circadian rhythm (Anch et al., 1988). The REM-NREM cycle has a period less than 24 hours which makes it an ultradian rhythm. These rhythmic activities were first thought of as passive responses to environmental fluctuations such as light, dark, 
and temperature. However, experiments without those environmental cues (Zeitgebers) (Aschoff, 1965, Czeisler et al., 1980) demonstrated the presence of endogenous rhythms in humans, implicating a biological clock controlling these events. The periods of the free-running rhythms (without time cues) were not necessarily the same as the normal entrained rhythms. The sleep-wake rhythm was a little slower than the entrained rhythm, namely 25 hours. Thus, environmental cues (Zeitgebers), such as social contacts, light, temperature, timing of the sleepwake cycle reset the body clocks to run in synchrony with day and night. Besides the environmental cues there are endogenous variables which influence the sleepwake cycle. As reported above, the temperature cycle is highly correlated with the sleep-wake cycle. However, in free-running (without Zeitgebers) subjects, the temperature cycle and sleep-wake cycle desynchronize (Aschoff, 1965, Czeisier et al., 1980) indicating two separate internal clocks.

Bedtime most frequently chosen by free-running subjects is just after the trough of the temperature cycle (Czeisler et al., 1980). Bedtimes chosen at the trough of the average temperature cycle resulted in a shorter sleep episode and an accumulation of REM sleep in the beginning of the sleep compared to bedtimes at or after the peak of the temperature cycle. The desynchronization of the temperature cycle and sleep-wake cycle and the fact that there are circadian (sleep-wake cycle) and ultradian (REM-NREM cycle) rhythms related to sleep are indications of more than one internal clock (Anch et al., 1988). The suprachiasmatic nucleus in the hypothalamus has been isolated as the primary internal clock in humans (Anch et al., 1988). It is not known, however, where other internal clocks are located (Mendelson, 1989)

\subsection{Appraisal of sleep quality}

A good quality of sleep will have different meanings for different people. Some people are satisfied with five hours of sleep and others are not satisfied until they had at least seven hours of sleep. According to Monroe (1967), people have definite impressions about whether they are good or poor sleepers. This is partly determined by sleep latency, by subjective feelings of how "soundly" or "deeply" one sieeps, and on how well rested one feels on awakening.

In estimating sleep pattern disturbances the following characteristics of sleep problems find frequent mention in the literature:

* difficulty falling asleep

* difficulty remaining asleep

* early awakening (Davignon \& Bruno, 1982, Jenkins, Stanton, Niemcryk, \& Ross, 1988, Johns, 1975, Merica \& Gaillard, 1985, Snyder-Halpern \& Verran, 1987).

Other facets mentioned by some authors included not feeling well rested (Davignon \& Bruno, 1982), movements (Knab \& Engel-Sittenfeld, 1983, Merica \& Gaillard, 1985 ), and the depth of sleep (Snyder-Halpern \& Verran, 1987).

Which of these facets are relevant for the judgement of the quality of sleep is not clear. According to Knab and Engel-Sittenfeld (1983), there are three important criteria for the appraisal of sleep quality. The first criterion is the sleep latency, the time span people remember having been awake before falling asleep. The second 
criterion is the number of arousals during the night, and the third is the amount of total sleep time. The sleep quality is often also judged by the feeling of how rested one is during the following day which is determined by the subject's feelings about his/her own performance and mood. This relationship has not, however, been proven.

Comparing the sleep of people who complain about sleep with non-complaining individuals is a way to determine how people judge their sleep. Several studies have examined the polysomnographic differences between good sleepers and insomniacs (Coates, Killen, George, Marchini, Silverman, Hamilton, \& Thoresen, 1982, Frankel, Coursey, Buchbinder, \& Snyder, 1976, Monroe, 1967$).$

Although differences in sleep exist between complainers and non-complainers these were substantially less than expected (Meddis, 1977). Insomniacs consistently had a significantly longer sleep latency, more arousals during the night, more time awake after sleep onset and a lower sleep efficiency. Inconsistent results were found on the variables total sleep time and the structure of sleep, such as percentage of REM sleep and SWS (Anch et al., 1988). In Carskadon's et al. study (Carskadon, Dement, Mitler, Guilleminault, Zarcone, \& Spiegel, 1976) a group of subjects complaining of insomnia had a total sleep time which was 30 minutes shorter and a sleep latency which was approximately 30 minutes longer than the group of non-complainers. Only half of the complaining group could be distinguished from the non-complaining subjects.

The problem with these studies is that the subjects were not asked whether their judgement of the quality of sleep was based on the factors measured with the polysomnography. Only Herbert, Johns and Dore (1976) asked the subjects what caused them to feel that they had slept badly.

The perception of the quality of sleep seems to be based upon an analysis of what is remembered about sleep (Meddis, 1977). Things remembered are the periods of wakefulness, the difficulty in falling asleep, and the number of awakenings (Baekeland \& Hoy, 1971, Herbert et al., 1976, Johns, 1975, Parrot \& Hindmarch, 1978).

It appears from the literature that it is still not clear what determines the quality of sleep. The waking periods during sleep seem to be important in the appraisal of sleep.

\section{$1.4 \quad$ Biophysiological measurements, observations and self-reports}

The appraisal of sleep quality occurs subjectively and therefore requires measurement techniques such as self-reports. Observation methods are often used when communication with patients is not feasible, for instance in critical care units. Nurses have then to rely on their observational skills.

A brief overview of reliability and validity issues in the measurement of sleep will be presented.

Testing the reliability and validity of the different subjective instruments can be done by comparing them with objective measurements. Johns (1971), however, advised caution in interpreting sleeping EEGs in the absence of other measures of sleep. Certain drugs and metabolic disturbances may cause dissociation between 
behavioral and EEG signs of sleep and wakefulness. Although there is a manual with standardized nomenclature and methods for recording and scoring sleep EEGs, the interpretation of the EEG may not always be as objective as frequently claimed because the different stages overlap (Johns, 1971).

Subjective measurements of the quality and quantity of sleep appear to be accurate. Despite the fact that insomniacs and sometimes healthy subjects overestimated their sleeping problems, subjective measurements were significantly correlated with objective measurements (Carskadon et al., 1976, Lewis, 1969). Double-blind studies on the effects of sleep medication showed significant cor. relations between objective and subjective measures (Kripke, Hauri, Ancoli-Israel, \& Roth, 1990, Mamelak, Csima, \& Price, 1990).

The different studies on subjective and objective sleep reports are difficult to compare because of the different populations studied, the different definitions used of sleep latency and arousals, and the different length of the drug-free period before testing the subjects.

In general studies with insomniacs show the same results. Insomniacs overestimate the time it takes them to fall asleep, the sleep latency (Carskadon et al., 1976, Coates et al., 1982, Frankel et al,, 1976), underestimate the total sleep time (Carskadon et al., 1976, Frankel et al., 1976), and overestimate the nocturnal arousals (Carskadon et al., 1976). Sleep quality varies considerably for insomniacs on a night to night basis, while sleep for noninsomniacs is basically the same every night (Anch et al, 1988). Therefore insomniacs are able to describe their sleep more accurately on a night to night basis than in a more unfocused interview or questionnaire (Carskadon et al., 1976).

Studies with healthy subjects show different results when comparing self-reports with biophysiological records of sleep.

Baekeland and Hoy (1971) reported that healthy young male subjects (mean age 26.5 years) correctly estimated the sleep latency, and the prolonged awakenings (more than 4 minutes). These results were confirmed by Browman and Tepas (1976) but not by Frankel et al. (1976) who concluded that their subjects (mean age 44) underestimated the sleep latency, and overestimated total sleep time. In Johns' study (1977) subjects were able to give valid and reliable estimates of usual sleep latencies at night. According to Thornby, Karacan, Beutler, Booth, Anch, Williams, Salis, \& Blackburn (1974), individual subjects are capable of determining changes in their sleep latency and sleep length.

Lewis (1969), however, did find that young male adults using sleep medication or withdrawing from sleep medication, were similar to insomniacs in overestimating their sleep latency, underestimating their total sleep time and overestimating the awakening which lasted longer than one minute. The reported and recorded values correlated significantly except for the drug-free control group. A study with healthy older subjects revealed that the elderly are accurate in estimating their sleep (Hoch, Reynolds III, Kupfer, Berman, Houck, \& Stack, 1987).

Of concern is the operationalization of the concepts used. For example, when is an arousal according to the EEG counted as an arousal? Different durations have been used, 15 seconds (Coates et al., 1982), 30 seconds (Hoch et al., 1987), and a minute (Lewis, 1969). 
Some subjects are unable to discriminate brief periods of sleep from wakefulness (Agnew \& Webb, 1971). Short arousals may be experienced by the subjects as one longer arousal or a continuation of unbroken wakefulness at the beginning of the night (Carskadon et al., 1976). NREM stage 1 sleep will be scored as sleep by investigators but insomniacs may experience this as arousal or latency (Coates et al., 1982). Scoring onset of consolidated sleep, for example more than five minutes of continuous stage 2 sleep, did lead to an increase in the correlations between objective and subjective measurements in insomniacs (Schneider-Helmert \& Kumar, 1986). Healthy subjects soon descend into stage 3 or 4 of the NREM sleep, stage 2 playing a minor role for their subjective sleep experience. However, insomniacs remain in stage 2 or 1 or alternate between these two stages (Knab \& Engel-Sittenfeld, 1983). Therefore short latencies tended to be underestimated and longer latencies ( > 30 minutes) were significantly overestimated. This is consistent with studies that showed that insomniacs usually overestimate their sleep latencies (Johns, 1977). In the study conducted by Johns (1977) subjects woke up on several occasions within 5 to 10 minutes of falling asleep. Apparently they were not aware of having been asleep. The subjective reports of sleep latencies corresponded more closely with the total delay before finally going to sleep than with the shorter delay before dozing off initially. Knab and Engel's (1988) study showed that not all possible physiological arousals at night are perceived, but all perceived arousals are recalled in the morning, both by good sleepers and by insomniacs. In Rosekind \& Schwartz' (1988) study good sleepers were accurate in discriminating between wakefulness and REM sleep, while the discrimination between stages 2 and 4 were less accurate, a fact, according to the authors, due to absence of information from the sleepers.

The length of the drug-free period varied in the studies from one week (Carskadon et al., 1976) to 4 weeks (Coates et al., 1982, Frankel et al., 1976) or no medication at all (Baekeland \& Hoy, 1971, Johns, 1977). According to Lewis (1969), withdrawal of sleep medication leads to exaggeration of the extent of the poor quality of sleep. It would be of interest to discover how long this effect will continue.

The methods most commonly used to assess patients' sleep are nurses' observations, accompanied by patients' self-reports. Variables which are observed to assess sleep are whether the eyes are closed or not, regular respiration, immobility and a lack of response to minor environmental variables. In research these variables are often dichotomized in sleep or wakefulness (Closs, 1988a).

Several studies have been performed on the reliability and validity of observation techniques used in sleep research. However, the results of these studies vary. Moreover, these studies are difficult to compare because of differences in populations, such as trauma patients (Fontaine, 1989), burn patients (Dotson, 1986), or institutionalized elderly people (Gress, Bahr, \& Hassanein, 1981), and differences in designs. The interrater reliability was not estimated in every study. Observational assessment of sleep was compared with polysomnographic recordings (Fontaine, 1989), and with self-reports (Dotson, 1986, Richards, 1987a). Fontaine (1989) and Richards (1987a) concluded that observations were reliable and valid estimates of sleep while Dotson (1986) found that nurses' assessment did not correlate with patients' reports. Fontaine (1989) stressed that 
studies which failed to show correlations between observations and polysomnographic recordings or self-reports, often used observation intervals of up to 30 minutes. Carroll, Bliwise and Dement (1989) also concluded that observations are a reliable approach in the study of sleep. They used a 15-minute interval in their observations. In Coates et al.'s (1982) study it was found that spouses reported valid information for estimates of minutes to sleep onset for good and poor sleepers and minutes awake after sleep onset for insomniacs.

In conclusion, for normal subjects a general subjective sleep report is relatively accurate, but subjective reports on a night to night basis are relatively more accurate when dealing with insomniacs.

\subsection{Conclusions}

Although the function of sleep is not clear, it is generally accepted that it has a restorative function. It seems reasonable therefore that persons recovering from surgery or illness need this restorative function even more. It is essential therefore that nurses assess sleep problems accurately.

Another facet of sleep beset by many questions is what determines the quality of sleep. Since sleep is a subjective phenomenon, the person is the best authority on evaluating the quality and quantity of his/her sleep. In view of the above, selfreport measures provide the nurse with accurate information on the quality of sleep experienced by patients. Further, self-report measures have been shown to correlate significantly with polysomnographic recordings.

The next chapter presents a self-report method in measuring sleep quality with emphasis on validity and reliablility. 



\section{The Subjective Sleep Quality Scale}

\section{$2.1 \quad$ Introduction}

Sleep quality and quantity can be measured by biophysiological instruments, by observations and by means of self-reports (Beck, 1988). Most evaluation of sleep quality has taken place within laboratory settings. Biophysiological monitoring is, however, difficult to use in settings outside the laboratory. In addition observations and self-reports are more practical when working with a large population of patients. As shown in the previous chapter, subjective appraisal of sleep quality by self-reports is often significantly correlated with biophysiological measurements of sleep. As a result self-reports have been utilized more often in nursing studies.

In this study self-reports have been used to measure sleep quality. One of the instruments was the Subjective Sleep Quality Scale (SSQS), an instrument developed by Mulder-Hajonides van der Meulen, Wijnberg, Hollander, DeDiana, and Van den Hoofdakker (1980). Since the SSaS has not been utilized in hospital settings, its psychometric properties will be discussed here.

The SSQS has been used in Studies II and III to measure the sleep quality at home and in the hospital. A description of the research designs of these two studies can be found in Chapters 4 and 9 . An overview of methods available in measuring sleep quality and quantity will be first presented.

\section{$2.2 \quad$ Measuring sleep}

There are several different methods to measure sleep which can be grouped in three categories, biophysiological methods, observations and self-reports. One of the most commonly used biophysiological devices in sleep research is polysomnography. Multiple sleep parameters can be estimated, based on the results of the polysomnography. Brain activity, for example, is monitored by an electroencephalogram (EEG), an electro-oculogram (EOG) measures the eye movements, and an electromyogram (EMG) registers the loss of the muscle activity of the chin, an indicator of REM-sleep. Other objective methods are the measurement of body movements, the measurement of skin resistance (Beck, 1988) and arousal thresholds (Closs, 1988a). Determining the arousal thresholds by arousing someone from sleep is a method to measure the depth of sleep but is obviously unsuitable for the study of sleep in hospital patients. Tests devised to assess daytime vigilance, the Wilkinson Auditory Vigilance test, and sleepiness, the Multiple Sleep Latency Test (Carskadon \& Dement, 1982), reflecting the quality of previous sleep are both objective measurements, but are time-consuming and require specialized equipment and are therefore not appropriate for hospital patients (Closs, 1988a). 
As reported in the previous chapter, more reliable information about certain asperts of sleep is provided by subjective reports such as the subjective aspects of sleep quality than by polysomnographic laboratory recordings of sleep quality (Johns, 1971, Knab \& Engel-Sittenfeld, 1983). Evaluation of the state of rest and satisfaction with sleep demand subjective estimation (Closs, 1988b, Johns, 1971). One person can be satisfied with just a few hours of sleep while another person needs at least eight hours of sleep.

Self-reports can have different forms, such as visual analogue scales (Oswald, 1980, Richards, 1987a, Snyder-Halpern \& Verran 1987), subjective rating scales (Hoddes, Zarcone, Smythe, Phillips, \& Dement, 1973), questionnaires (Baekeland \& Hoy, 1971, Carskadon et al., 1976, Ellis, Johns, Lancaster, Raptopoulos, Angelopoulos, \& Priest, 1981, Lamb, 1982, Monroe, 1967, Moore, 1989), and diaries or sleep charts (Floyd, 1984, Lewis \& Masterton, 1957, Tune, 1969).

Nursing observations are, together with self-reports, the traditional means nurses use to assess patients' sleep. It is, however, difficult to distinguish periods of quiet wakefulness from sleep and as a result it is difficult to observe the period of falling asleep accurately. In addition the observations should be sufficiently frequent in order to be reliable (Closs, 1988a). Different instruments are used in studies such as Echol's Patient Sleep Behavior Observational Tool (Fontaine, 1989), Richards Campbell Sleep Questionnaire (Richards, 1987a), scoring sleep/wakefulness (Carroll, Bliwise, \& Dement, 1989, Dotson, 1986, Gress, Bahr, \& Hassanein, 1981), or a computer-compatible method for recording behavior data (White, Wear, \& Stephenson, 1983).

Whichever method is chosen to assess sleep quality depends on several aspects such as the research question, the costs and equipment needed and the population. In this study a questionnaire was used to estimate the quality of sleep in hospital patients.

\subsection{Subjective Sleep Quality Scale (SSOS)}

DeDiana (1976) developed two almost parallel scales for the measurement of sleep quality in a healthy population, a general scale (10 items) and a specific scale (11 items). From the specific scale 8 items were reformulated for the general scale. The reliabilities of those scales were high and the scales formed were unidimensional. Both scales were sensitive to experimental changes in the environment (Visser, Hofman, Kumar, Cluydts, DeDiana, Marchant, Bakker, Van Diest, \& Poelstra, 1978).

Mulder et al. (1980) used 6 items of DeDiana's general scale and 7 of the specific one to construct two new parallel scales each consisting of 14 items, applicable for a depressive population. Both scales were highly reliable and valid (Mulder et al., 1980). The scales developed by Mulder et al. (1980) retained their unidimensionality in other populations. Four items could be omitted when used in a population of shift workers (Kampman, 1981).

In this study the complete scale from Mulder et al. (1980) was selected to assess the sleep status of hospital patients. This tool has not been used in 
hospital settings before. Two versions of this tool exist, one for measuring the sleep quality of a specific night and a general version (Table 2.1). The scales used contain 15 items. These are statements about sleep with which one can agree or disagree.

The range of the scores is from 0 to 15 , with 0 indicating a very poor sleep and 15 a very good sleep. One item was added to the specific scale by accident by other researchers who did use the scales. It concerned the item "I slept deeply last night". This item was meant to be an example item. In this study the general scale was also extended by the same but reformulated item. In the specific SSOS the same items are used, only reformulated for a specific night. For example "I didn't sleep a wink last night" and "I tossed and turned all night" (Appendix A).

Table 2.1 The subjective sleep quality scale (general version).



It should be mentioned that the scales presented here, in their English version, have not yet been tested. The results presented in this chapter are only applicable to the Dutch version.

The facets which seem to be relevant to estimate the quality of sleep were mentioned in Chapter 1 . They include:

* difficulty in falling asleep

* difficulty in remaining asleep

* early awakening

* not feeling rested

* movements

* the depth of sleep

All these sleep characteristics are represented in the SSQS supporting the content validity of the scales. 


\subsection{Reliability and validity of the SSOS}

Reliability and validity are not a property of an instrument but are dependent on the sample and the conditions when administered (Polit \& Hungler, 1987). Therefore the Subjective Sleep Quality Scale, which had not been used in hospital settings before, needed to be investigated for its reliability and validity. The following problem statement is formulated.

Is the Subjective Sleep Quality Scale a reliable and valid instrument to measure sleep quality in hospital settings?

Internal consistency reliability, stability, content, concurrent and construct validity were investigated for the SSOS. Eleven hypotheses were derived to test the reliability and validity of the SSOS.

As indicated in paragraph 2.3, facets of sleep, found in the literature, which are probably important for the appraisal of sleep quality, were all represented in the SSOS, supporting the content validity of the scale. What is not clear, however, is whether the SSOS measures an unidimensional construct "sleep quality", with all facets of sleep represented, or whether it measures the separate facets as individual constructs such as "problems falling asleep" or "frequent awakenings". This leads to the first hypothesis.

\section{Hypothesis 1: The SSOS measures a unidimensional construct, sleep quality.}

Cronbach's alpha indicates the extent of the unidimensionality of the construct "sleep quality" as it is measured with the SSQS. Instruments with a Cronbach's alpha $\geq .80$ have strong internal consistency (Carmines \& Zeller, 1981) which means that all items measure the same construct, are homogeneous, and correlate in the same direction. This leads to the second hypothesis for both the total scale and the probable separate facets of sleep quality as found in the literature.

\section{Hypothesis 2: Cronbach's $a$ for the SSQS is $\geq .80$.}

In general sleep patterns are stable, presumably constrained by day schedules (Sharpley, Solomon, \& Cowen, 1990). However, in a laboratory setting the occurrence of the sleep stages during two different nights were significantly correlated but the correlation was not higher than .54 indicating that sleep can vary within a subject (Moses, Lubin, Naitoh, \& Johnson, 1972). Hospitalization causes changes in environment and in sleep routines. Thus it is expected that the correlation between the scores on two specific SSOS's will be low.

The general SSOS is a sort of re-test of the specific SSOS and probably even more a re-test of the mean of the subjective sleep quality of two specific nights. The specific SSOS is expected to correlate more strongly with the general SSaS in hospital. The test-retest is a procedure to assess the stability of an instrument. In this case it is difficult to separate stability and construct validity. Construct validity is concerned with the extent to which a particular measure relates to other measures consistent with theoretically derived hypotheses 
concerning the concepts that are being measured (Carmines \& Zeller, 1981). Strong theoretical foundations to support construct validity are missing.

The following hypotheses were generated to test the stability of the SSOS.

Hypothesis 3: The scores on the SSOS for two specific nights correlate positively but weakly $(.20 \leq r \leq .40)$.

Hypothesis 4: The subjective sleep quality for a specific night correlates positively but moderately with the general subjective sleep quality in hospital (.40 $\leq \mathrm{r} \leq .60)$.

Hypothesis 5: The mean of the SSQS for two specific nights correlates positively and highly with the general SSOS in hospital $(r \geq .60)$.

Concurrent validity is a type of criterion-related validity in which the emphasis is on establishing the relationship between the instrument and some kind of criterion (Polit \& Hungler, 1987). A 5-point scale on the quality of sleep used in study $\mathrm{II}$, is used as the criterion. Unfortunately the validity of this instrument is not known. Four hypotheses were formulated to test the concurrent validity. Because the instruments used in this study lack a strong theoretical basis, it would be inadmissable to call this construct validity.

Hypothesis 6: The scores on specific items of the SSOS are negatively and moderately correlated with the sleep problems mentioned by the patients $(-.40 \leq r \leq-.60)$.

Hypothesis 7: The scores on the SSQS are strongly correlated with the scores on a 5 -point scale $(\geq .60)$.

Hypothesis 8: The qualitative aspects of sleep, sleep latency and number of awakenings, are negatively and moderately correlated with the scores on the SSQS $(-.40 \leq r \leq-.60)$.

Hypothesis 9: Sleep quantity is positively and moderately correlated with the scores on the SSQS $(.40 \leq r \leq .60)$.

A common approach to construct validation is the known-group technique (Polit \& Hungler, 1987). This aspect of construct validity is tested by comparing the scores on the different SSQS's with different age groups, and male and female groups. In the literature it is often mentioned that sleep quality decreases with increasing age (Carskadon et al., 1976, Dement, Miles, \& Carskadon, 1982) and that women complain more about sleep than men (Hoch et al., 1987, Ruler \& Lack, 1988, Tune, 1968). The following hypotheses were therefore formulated.

Hypothesis 10: Older people will have a significantly lower sleep quality than younger people.

Hypothesis 11: Women will have a significantly lower sleep quality than men. 


\section{$2.5 \quad$ Research design}

To validate the SSOS, data were used from two studies. One was Study II, a descriptive correlational study concerning an inventarization of the sleep problems and possible related variables on surgical and medical wards in three general hospitals. The other, Study III, a quasi-experimental design, tested the effects of using the nursing process on sleep quality and quantity and the use of sleep medication by patients on surgical and medical wards in one of the general hospitals of Study II. More details of the designs of these studies are given in Chapter 4.

\subsubsection{Population}

In Study II all participating patients $(n=141)$ were women between 30 and 70 years of age, who were not seriously ill. In study III, however, both men ( $\mathrm{n}=$ 253) and women $(n=229)$, who were at least 30 years of age and without serious diagnoses participated. In both studies the patients had to be admitted to the wards for at least two nights.

The population of Study III was significantly older (Mean $59, s d=14$ ) than that of Study II (Mean 52, $s d=12)(t=5.3 d f=621 \mathrm{p} \leq .001)$. In both studies the population was almost equally distributed between medical and surgical patients.

These differences in population contribute to the validation of the scale. The data from the subjects of the pretest as well as the posttest were used in testing the reliability and validity of the SSOS. Because it concerned different people the experiment was not expected to have influence on the administration of the SSQS's.

\subsubsection{Variables}

The variables described in this section have been used to validate the SSOS. They concern sleep quality, sleep quantity and sleep problems, and the demographic variables age and gender.

In Study II sleep quality was estimated by means of two different instruments, the SSOS and a 5-point scale. The SSOS scale was completed by the patients four times and the 5-point scale (very poor, poor, moderate, good, very good) was administered three times, as shown in Table 2.2. These measurements took place on two alternate days.

Information on sleep problems (problems experienced by the patient) and sleep quantity (in hours) was obtained using open-ended interview questions. In addition, data on other qualitative sleep characteristics such as sleep latency (estimated minutes it took the patient to fall asleep) and number of nocturnal awakenings were also collected in the interview. 
Table 2.2 Sleep variables of Study II used to validate the Subjective Sleep Quality Scale.

\begin{tabular}{|c|c|c|c|c|}
\hline & SSOS & 5-point scale & sleep quantity & sleep problem \\
\hline $\begin{array}{l}\text { Sleep at home } \\
\text { Sleep in hospital }\end{array}$ & $\mathrm{x}$ & $x$ & $x$ & $x$ \\
\hline $\begin{array}{l}* \text { in general } \\
* \text { night } 1\end{array}$ & $\begin{array}{l}x^{1} \\
x\end{array}$ & $x^{\prime}$ & & $x^{\prime}$ \\
\hline * night 2 & $x$ & $x$ & $x$ & $x$ \\
\hline
\end{tabular}

in the first interview

t until the second interview

the night prior to the first interview

$\square$ the night prior to the second interview

In Study III only the general version of the SSQS was administered, about the sleep at home and the sleep in hospital in general, during the pretest as well as the posttest. Information about the night prior to the interview was collected by means of open-ended questions about sleep latency, total sleep time and num ber of arousals during the night. The interview questions are presented in Table 4.3 in Chapter 4.

\subsubsection{Analysis}

Mostly univariate analyses were performed to test the hypotheses formulated. The populations of Study II and III were kept separate because they differnd in gender and age distribution. Study III is in fact a replication of Study II with a different population. As a result the robustness of the SSOS can be testr.n (Brinberg \& McGrath, 1985).

\section{$2.6 \quad$ Results}

\subsubsection{Dimensionality}

Factor analysis of the SSQS did not identify the sieep characteristics mentioned in the literature. The factor loadings for the SSOS in general are shown in Table 2.3 and those for the two specific scales and sleep at home are presented in Appendix A.

The first factor extracted with the principal component analysis explained 40 to $50 \%$ of the variance, $41 \%$ for night $1,45 \%$ for night $2,48 \%$ for the general sleep quality in hospital, and $50 \%$ for the sleep at home indicating that both scales, general and specific, are unidimensional. 
Table 2.3 The SSOS in general in hospital in Study II $(n=141)$ : Distribution of answers on the separate items in percentages and factor loadings without rotation.

\begin{tabular}{lccc}
\hline & agree & disagree & fac 1' \\
\hline I feel that I mostly sleep well. & 51 & 49 & .87 \\
I feel that I often get only a couple & & & \\
of hours sleep during the night. & 49 & 51 & .85 \\
I feel that I sleep poorly most of the time. & 41 & 59 & .83 \\
After awaking at night it is difficult to fall asleep again. & 53 & 47 & .78 \\
I feel that I don't get enough sleep most of the time. & 47 & 53 & .77 \\
Mostly I feel rested after awaking in the morning. & 56 & 44 & .73 \\
I often fall asleep easily. & 52 & 48 & .67 \\
It often takes longer than half an hour to fall asleep. & 59 & 41 & .65 \\
Often I awake several times a night. & 71 & 29 & .65 \\
Often I don't sleep a wink. & 24 & 76 & .63 \\
I often feel tired and exhausted after awaking in the morning. 53 & 47 & .61 \\
I don't sleep more than 5 hours. & 48 & 52 & .61 \\
Mostly I toss and turn all night. & 38 & 62 & .59 \\
I think I have a deep sleep most nights. & 46 & 54 & .55 \\
Often I get up in the middle of the night. & 26 & 74 & .53 \\
\hline
\end{tabular}

eigenvalue 7.24 variance $48 \%$

\subsubsection{Internal consistency}

Table 2.4 shows the Cronbach's alphas for the individual SSQS's in the two studies. Because the SSOS apparently measures a unidimensional construct, only the internal consistencies of the total scales had to be calculated.

In both studies the Cronbach's alphas vary between .88 and .92 . This implies that all the items are measuring the same concept and correlate in the same direction. Therefore hypothesis 2 is supported.

Table 2.4 Cronbach's alphas of the subjective sleep quality scales for Study II ( $n=141$ ) and Study III ( $\mathrm{n}=482$ ).

\begin{tabular}{lcc}
\hline & Study II & Study III \\
\hline At home & .92 & .90 \\
Night 1 & .88 & $\ldots$ \\
Night 2 & .90 & $\ldots$ \\
Hospital in general & .92 & .90 \\
\hline
\end{tabular}

\subsubsection{Stability}

There was a significant but weak correlation between the scores on the SSOS for the two specific nights as predicted $(r=.23, p \leq .01)$. The specific nights are moderately correlated with the general sleep quality in the hospital (night 1 $r=.57, p \leq .001$, night $2 r=.51, p \leq .001)$, and the mean scores of the sleep quality of these two nights are strongly correlated with the general sleep quality $\{r=.69, p \leq .001)$. Therefore hypotheses 3,4 and 5 are all supported. 
Table 2.5 Mean scores on the general and specific SSOS in study II $(n=141)$.

\begin{tabular}{lrrrrr}
\hline & \multicolumn{5}{c}{ Study II } \\
\cline { 2 - 6 } & mean & sd & mode & median skewness \\
\hline At home & 9.2 & 5.0 & 15.0 & 11.0 & $-.49^{\circ}$ \\
Hospital in general & 7.9 & 5.1 & 14.0 & 8.0 & -.13 \\
Night 1 & 8.4 & 4.5 & 12.0 & 9.0 & -.31 \\
Night 2 & 8.9 & 4.8 & 14.0 & 10.0 & -.32 \\
\hline
\end{tabular}

\footnotetext{
'significant skewness
}

The subjective sleep quality (SSQ) at home in Study II does not differ significantly from the SSQ at home in the comparable female patients in Study III (Tables 2.5 and 2.6). In addition the correlation coefficients between the scores on the SSOS at home and in hospital in general are almost the same for Study II $(r=.45, p \leq .001)$ and Study $I I I(r=.48, p \leq .001)$. Both findings support the robustness of the SSQS's.

Table 2.6 Mean scores on the general SSOS in Study III for the total population ( $\mathrm{n}=482$ ) and only for women $(\mathrm{n}=229$ ).

\begin{tabular}{|c|c|c|c|c|c|c|c|c|c|c|}
\hline & \multicolumn{5}{|c|}{ Study III women } & \multicolumn{5}{|c|}{ Study III total } \\
\hline & mean & sd & mode & median & kewness & mean & sd & mode & median & skewness \\
\hline \multirow{2}{*}{$\begin{array}{l}\text { At home } \\
\text { Hospital } \\
\text { in general }\end{array}$} & 10.0 & 4.6 & 15.0 & 12.0 & $-.75^{\prime}$ & $10.7^{*}$ & 4.3 & 15.0 & 12.0 & $-.99^{\dagger}$ \\
\hline & 7.9 & 4.6 & 3.0 & 8.0 & -.03 & 7.9 & 4.8 & 3.0 & 8.0 & -.02 \\
\hline
\end{tabular}

'significant skewness

'significantly different from sleep quality at home in Study $1 /(t=-2.97, p \leq .05)$.

\subsubsection{Concurrent validity}

In Study II patients were asked what sort of sleeping problems they experience at home and in the hospital. The sleeping problems mentioned most frequently were difficulty in falling asleep and difficulty in staying asleep (See Table 5.4, Chapter 5).

It was expected that patients who reported a sleeping problem would score significantly lower on the items about that sleeping problem than those who did not. Table 2.7 presents the correlation coefficients between the sleep problems mentioned and the scores of the two or three items concerning these problems. 
Table 2.7 Correlation coefficients (Kendall's tau) between sleep problems mentioned and the scores on the specific items of the SSOS in Study II ( $n=141)$.

\begin{tabular}{llll}
\hline & \multicolumn{3}{c}{ SSQS } \\
\cline { 2 - 4 } As reported by patients: & & Night2 & Hospital in general \\
\hline Difficulty in falling asleep & $-.47^{*}$ & $-.27^{*}$ & $-.39^{*}$ \\
Difficulty in staying asleep & $-.34^{*}$ & $-.35^{*}$ & $-.34^{*}$ \\
Early awakening & $-.27^{*}$ & $-.28^{*}$ & -.06 \\
Total sleep problems & $-.52^{*}$ & $-.54^{*}$ & $-.44^{*}$ \\
\hline
\end{tabular}

p $\mathrm{p} 5.001$

Those patients who reported a specific sleeping problem answered in the expected direction on the items of the SSOS concerning that sleeping problem, except for one sleeping problem in the hospital, namely early awakening. All the sleep problems, except one, are weakly but significantly correlated with the specific items of the SSQS's (Table 2.7). Hypothesis 6 is, as a result, supported with exception of the items related to "early awakening".

The total sum of problems patients experience at home and in hospital correlated significantly with the items of the SSOS concerning these problems.

Table 2.8 shows the correlation coefficients between the 5 -point scales and the score on the SSQS. All judgements of sleep are highly correlated with the SSOS, thus supporting hypothesis 7 .

Table 2.8 Correlation coefficients (Pearson) between the scores on the 5-point scales and the SSOS in Study II $(n=141)$.

SSOS

5-Point scales

\begin{tabular}{ll}
\hline At home & $.76^{*}$ \\
Night 2 & $.83^{*}$ \\
Hospital in general & $.70^{*}$
\end{tabular}

p $\mathrm{p} .001$

Although the 5-point scales correlated strongly with the scores on the SSQS, the latter has a greater discriminatory ability. The SSQS is more able to detect a change in the quality of sleep than the 5-point scale. This is important when the effect of a sleep intervention has to be tested. The difference between the mean scores of the general SSOS in hospital and sleep at home were significantly larger than between the means of the 5 -point scales $(t=1.65, p \leq .05)$. As shown in Table 2.9, and in support of hypotheses 8 and 9, duration of sleep is positively and moderately correlated with sleep quality in Study $I I$ as well as Study III, and sleep latency and number of awakenings are negatively and moderately correlated with sleep quality. Those qualitative characteristics were only measured in Study III. These results further support the concurrent validity of the SSQS. 
Table 2.9 Correlation coefficients (Pearson) between qualitative, quantitative sleep characteristics and the scores on the SSQS in Study II $(n=141)$ and Study III $(n=482)$.

\begin{tabular}{lccc}
\hline & \multicolumn{2}{c}{ Study II } & Study III \\
\cline { 2 - 4 } & At home & Night 2 & Hospital in general \\
\hline Duration of sleep & $.47^{*}$ & $.63^{*}$ & $.55^{*}$ \\
Number of awakenings ${ }^{+}$ & & & $-.45^{*}$ \\
Sleep latency ${ }^{+}$ & & & $-37^{*}$ \\
\hline
\end{tabular}

not measured in Study $\|$

$p \leq .001$

\subsubsection{Construct validity}

For the construct validity the population was divided in three age groups (20-35, 36-50, older than 50 years) (Table 2.10 ). A one-way analysis of variance performed on the SSOS scores revealed that patients 50 years and older in comparison to the other two age groups had a better sleep quality in hospital ( $F=3.29$, $S S=162.4, d f=2, p \leq .05)$ in Study II. In Study III, again older patients tended to sleep better in the hospital but had a significantly lower sleep quality at home than the younger patients $(F=4.21, S S=156.1, d f=2$, $p \leq .01$ ). Hypothesis 10 is therefore only partly supported.

Table 2.10 The mean SSaS scores for three age groups in Studies II and III.

\begin{tabular}{|c|c|c|c|c|c|c|c|c|}
\hline & \multicolumn{5}{|c|}{ Study II } & \multicolumn{3}{|c|}{ Study III } \\
\hline & & $\begin{array}{l}\text { t home } \\
\text { Mean }\end{array}$ & $\begin{array}{l}\text { Night } 1 \\
\text { hospital } \\
\text { Mean }\end{array}$ & $\begin{array}{l}\text { Night } 2 \\
\text { hospital } \\
\text { Mean }\end{array}$ & $\begin{array}{l}\text { In general in } \\
\text { hospital } \\
\text { Mean }\end{array}$ & & $\begin{array}{l}\text { At home } \\
\text { Mean }\end{array}$ & $\begin{array}{c}\text { In general in } \\
\text { hospita! } \\
\text { Mean }\end{array}$ \\
\hline $20-35$ & $n=18$ & 9.9 & 7.5 & 8.2 & 7.1 & $n=43$ & 12.4 & 7.7 \\
\hline $36-50$ & $n=45$ & 9.3 & 8.1 & 8.8 & 6.6 & $\mathrm{n}=72$ & 10.1 & 6.9 \\
\hline older than 50 & $n=77$ & 9.0 & 8.8 & 9.1 & 9.0 & $n=364$ & 10.6 & 8.1 \\
\hline
\end{tabular}

A one-way analysis of variance was also performed for the male and female groups (Table 2.11).

Table 2.11 The mean SSOS scores for men and women and age distribution in Study III.

\begin{tabular}{lcc}
\hline & $\begin{array}{c}\text { At home } \\
\text { Mean }\end{array}$ & $\begin{array}{c}\text { In general in hospital } \\
\text { Mean }\end{array}$ \\
\hline men & 11.2 & 7.9 \\
women & 10.0 & 7.9 \\
\hline
\end{tabular}

As expected, women had a significantly lower sleep quality at home than men $(F=9.14, S S=168.7, d f=2, p \leq .01)$. However, no difference in sleep quality in the hospital could be detected. Again hypothesis 11 is only partly supported. 


\subsection{Conclusions and discussion}

In general, subjective sleep quality instruments prove to be accurate in estimating sleep latency, total sleep time, and number of awakenings. Subjective scales are especially useful in detecting changes in sleep quality.

The SSOS used in this study showed sufficient reliability and validity. The instrument does, however, need further construct validation. The majority of the hypotheses formulated at the beginning of this chapter have been accepted except hypotheses 10 and 11, dealing with the construct validity. The SSQS showed evidence of content validity. Both versions of the SSOS measured a unidimensional construct "sleep quality" and they are both internally consistent. Qualitative and quantitative sleep characteristics correlated significantly with the scores on the SSOS. The sleeping problems mentioned by the subjects correlated significantly with the scores on the scales. The specific scales showed, as expected, fluctuation in sleep quality over two nights. Correlations found in the two studies are often comparable. Therefore it may be concluded that the SSOS possesses robustness.

Several reasons can be advanced for the lack of support for the hypotheses on construct validity. It is possible that the theoretical framework used to generate the hypotheses is not correct or the method or procedure used to test the hypotheses is inappropriate (Carmines \& Zeller, 1981). Older adults who are sick and in a dependent situation are possibly less likely to complain about the hospital stay and they may feel safer in the hospital than at home.

In this study older people tended to have a higher sleep quality in the hospital in comparison to the quality of sleep at home than younger hospitalized people. Snyder-Halpern and Verran (1987) also found that older people in a hospital reported a higher sleep quality and a feeling of being rested. This result needs further discussion.

Women had a worse sleep at home than men but there was no significant difference in sleep quality in hospital. Hoch et al. (1987) did find that women had more slow wave sleep (stages 3 and 4 ), which means a deeper sleep and less difficulties with sleep maintenance. Women, however, complained more about their sleep but tended to be more accurate in reporting sleep loss. It is most likely that a difference should be made between sleep quality and complaining about sleep. Physiologically women have a better sleep but it is also known that they complain most frequently about sleep.

Another explanation offered by Ruler \& Lack (1988) is that the gender differences are exaggerated by the use of general connotative questions. The question "do you have difficulty in getting to sleep at night" showed significantly more women than men reporting "difficulty", while the question "how long did it take you to fall asleep last night" did not reveal gender differences. The SSOS contains not only connotative questions but also relatively neutral questions and therefore shows no significant differences between the genders in hospital. In addition sieep in hospital covered a more specific period, while sleep at home concerned a more general period.

In the light of the high correlation of the 5-point scale with the SSOS, it could be favorable to use the former. However, a change in sleep quality will be 
detected sooner with the SSOS than with the 5-point scale. The SSOS has greater discriminative power. In addition the 5-point scale, used as a criterion in: this study, has not been tested for validity. However, using an unvalidated tool as a criterion is not unusual in validation studies (Carmines \& Zeller, 1981).

The shorter a scale, the easier it is to apply, especially in large populations. Reducing a scale, however, should not jeopardize its reliability. Several items of the SSOS are less applicable to the hospital situation. Items 5 (Mostly I toss and turn all night) and 12 (Often I get up in the middle of the night) are not formulated correctly for specific patient groups such as orthopedic patients who cannot get up because they are in traction. Item 8 (It often takes longer than half an hour to fall asleep) may be left out because in a hospital most of the people are already in bed and it is difficult for them to determine when they intended to go to sleep and how long it took them to fall asleep. They can only say that they had difficulties falling asleep. Sleep latency is investigated in another item too. Items 3 (I feel that I sleep poorly most of the time) and 11 (I feel that I mostly sleep well) could be left out because these are specific items about the sleep quality. They should not be in a scale in which the items are summed. They are in fact a one-item scale of the construct being measured, namely sleep quality. Item 1 (I often feel tired and exhausted after awakening in the morning) tends to be more applicable for depressive people. And finally because of the low item-total correlation compared with the other items item 4 (Often I don't sleep a wink) can be left out, it does not discriminate enough.

The consequences for the reliability and validity are minimal. The Cronbach's alphas of a shortened version vary between .83 and .88 (Table 3 Appendix A). The correlations shown in Tables 2.8 and 2.9 will decrease with .03 at most for the specific and the general Subjective Sleep Quality Scale (Tables 4 and 5 Appendix A). Again construct validity is only partly supported (Tables 6 and 7 Appendix A). Although it may be concluded that a shortened version of the SSOS is reliable and valid to use in everyday nursing practice, further research is however still needed to substantiate these results. 



\section{Part II}

Quality of sleep in hospital settings and its determinants 



\section{$3.1 \quad$ Introduction}

It is important to determine the causes of sleep problems since they constitute the factors upon which nursing interventions are based. Establishing the etiology of sleep pattern disturbance is necessary before effective nursing interventions can be implemented (Gordon, 1987).

In this chapter a review of the literature is presented on the variables influencing sleep in hospital settings. It is based on a previous publication on sleep problems in hospital patients (Cox, Senten, \& Halfens, 1988).

Numerous articles on sleep in hospitals have been published but they are often limited to a review of the literature on the causes of sleep problems and the nursing implications (Berlin, 1984, Davignon \& Bruno, 1982, Lerner, 1982, Regestein \& Barbiasz, 1980, Ross, Hare, \& McPherson, 1986, Schirmer, 1983, Thomas, 1987). Only a small number of the publications have concerned research reports, the majority of which are descriptive (Clapin-French, 1986, Ladwig, 1979, Seidl \& Walter, 1984, Snyder-Halpern \& Verran, 1987, Verran \& Snyder-Halpern, 1988). In many cases the research design was not clearly presented (Carrascal, Allona, Oroz, \& Beorlegui, 1982, Leuenberger, Voegeli, \& Wingeier, 1983, Murphy, Bentley, Ellis, \& Dudley, 1977, Stead, 1985).

Several studies concerned validation studies of the accepted nursing diagnosis of the North American Nursing Diagnosis Association (NANDA) "Sleep Pattern Disturbance". The diagnosis was validated by means of reviewing nursing reports (Johnson, 1989), by patients' interviews (Beyerman, 1987, Rossi, Fitzmaurice, Glynn, \& Connors, 1987), by patients' and nurses' interviews (Reimer, 1987) or nurses' recall of patients with sleep pattern disturbances (Metzger \& Hiltunen, 1987) and one study used in addition literature, interviews, and physical examinations (Lo \& Kim, 1986).

Most of the studies conducted on sleep problems in care settings used subjective reports, interviews or questionnaires to obtain information on sleep disturbances. Information was obtained from patient and non-patient groups as well as care givers. The results of studies conducted on sleep problems in hospital settings are consequently difficult to compare due to variability in instruments, populations and research designs used. Empirical correlations between etiological factors and quality or quantity of sleep or sleep pattern changes, are rarely presented, with the exception of one study by Closs (1988b). 


\subsection{Sleep quality and quantity in the hospital}

Most people admitted to a hospital experience disturbances in sleep. Sleep quality as well as sleep quantity deteriorate compared to home (Reimer, 1987, Verran \& Snyder-Halpern, 1988). Patients, however, expect to suffer poorer sleep in hospital, and nurses agree with this (Thomas, 1987), because of pain, stress and environmental disturbances (Murphy et al., 1977, Prokop, 1982, Seidl \& Walter, 1984).

The following sleep problems were validated as critical defining characteristics of the nursing diagnosis "Sleep pattern disturbance": Difficulty in falling asleep (sleep latency), interrupted sleep (frequent awakenings), awaking earlier or later than desired and not feeling rested. Lo \& Kim (1986) also identified certain critical defining characteristics such as malaise, tiredness, and restiessness among others. Problems with falling asleep and interrupted sleep were those mentioned most frequently by patients (Beyerman, 1987, Reimer, 1987, Rossi et al., 1987) and nurses (Metzger \& Hiltunen, 1987). These results were supported by Ladwig (1979) and Clapin-French (1986). Johnson (1989), on the other hand, found interrupted sleep and not feeling rested as the two problems most frequently cited in the nursing notes.

Figures mentioned in the literature about the extent of these sleep disturbances vary due to differences in populations and methods used. Research on sleeping problems was conducted in different care settings such as intensive care units (Hilton, 1976, Johnson, 1989) and long-term care facilities (Clapin-French, 1986, Pacini \& Fitzpatrick, 1982), while the majority of studies were performed on medical or surgical wards of general hospitals (Beyerman, 1987, Carrascal et al., 1982, Closs, 1988b, Ladwig, 1979, Leuenberger et al., 1983, Reimer, 1987, Rossi et al., 1987, Stead, 1985, Verran \& Snyder-Halpern, 1988) with study populations aged 20 years or older. For measuring quality and quantity of sleep, some researchers used standardized instruments such as the Verran-Snyder-Halpern Sleep Scale (Snyder-Halpern \& Verran, 1987), the Sleep Pattern Questionnaire (Baekeland \& Hoy, 1971), the St. Mary's Hospital Sleep Questionnaire (Ellis et al., 1981), and the Sleep Chart (Floyd, 1984, Lewis \& Masterton, 1957). In Carrascal et al.'s (1982) and Leuenberger et al.'s (1983) studies it was not clear what questions were asked and which instruments were used.

Beyerman (1987), Clapin-French (1986), Closs (1988b), Hilton (1976), Ladwig (1979), Reimer (1987) and Snyder-Halpern (1985) developed their own questionnaires and interviews. Beyerman (1987) developed open-ended questions based on the critical defining characteristics accepted by the NANDA. Reimer (1987) did use some questions from the St. Mary's Sleep Questionnaire. Only in one nursing study (Hilton, 1976) were polygraphic recordings used to measure sleep in hospitalized patients. In most studies patients and nurses were interviewed or filled out a questionnaire. Despite the differences in study designs and instruments used, all studies report that there is a change in sleep quality and quantity in the hospital compared to home.

Closs (1988b) interviewed 200 patients, male and female, aged between 50 and 65 , on eight surgical wards, about their sleep pattern in hospital compared with home. One objective was to discover which factors were perceived as important 
in disrupting sleep. The quality of sleep in hospital compared with home was estimated on a 5-point scale (far worse-far better). Sixty-one per cent of the patients felt that their sleep in the hospital had worsened. Significant changes in sleep pattern were reported. Bedtime (home 23.29h - hosp $22.42 \mathrm{~h}$ ) and waking time (home 6.45h - hosp 6.00h) were almost an hour earlier, sleep latency was longer (home 23.6 mins. - hosp 48.7 mins.), duration of sleep was shorter (home 6.54h - hosp 5.37h), and night time awakenings were more frequent (home 1.4 . hosp 2.3). No significant difference was found between the reported time spent napping at home and in hospital.

Ninety-one per cent of the patients in Rossi et al.'s study (1987) and $32 \%$ in Beyerman's study (1987) experienced disturbances in sleep. Leuenberger et al. (1983) and Carrascal et al. (1982) found that between 30 and $40 \%$ of the patients had a poor sleep in hospital compared to eight per cent at home. The total amount of sleep is also affected by hospitalization (Hilton, 1976, Leuenberger et al., 1983, Stead, 1985). According to Reimer (1987), sleep was more spread over the day and in Hilton's (1976) study only 50 to $60 \%$ of the sleep took place at night. This change in sleep time has consequences for the quality of sleep: in the morning more REM sleep takes place, and in the afternoon more SWS (Slow Wave Sleep) (Horne, 1989). Despite the fact that the total sleep time was decreased in hospital, the majority of the patients were satisfied with the amount of sleep they got (Leuenberger et al., 1983).

In her study Clapin-French (1986) reported large changes in total sleep time. Some people in her study reacted to the stress of institutionalization by either gaining or losing hours of sleep. Verran \& Snyder-Halpern (1988) had comparable results in that some patients actually reported undisturbed adequate sleep while hospitalized. Awakening time in the hospital was found by Beyerman (1987), Leuenberger et al. (1983), Reimer (1987), Rossi et al. (1987), and Stead (1985) to be significantly earlier than at home. Clapin-French (1986) found no change in awakening time but did find an earlier bedtime, probably due to an older population in her study. However, the earlier awakening time was not always experienced as a sleep problem, except for patients under 30 years of age (Stead, 1985). According to Leuenberger et al. (1983), it seems that patients quickly adapt to hospital routines, although these are different from their own.

Although nurses knew the extent of sleep problems in hospital settings, none of the nurses in Beyerman's study (1987) made the diagnosis related to sleep pattern disturbance in their care plans. In Closs' study (1988b) nurses' recordings of patients' sleep also tended to be very brief, and in many cases no mention of patients' sleep was made. For patients who felt they had not slept well, no difference in recordings were evident. It is possible that nurses do not consider it important or they do not believe they can affect a change in the problem. According to McGonigal (1986) nurses are not attuned to the need for sleep in patients and therefore it remains neglected in the planning of nursing and medical care. 


\subsection{Etiology of sleep problems}

As seen in the previous chapter sleep quality and quantity change upon admission to a hospital. Hospitals have different routines and schedules from those of patients. Although these changes in daily routines may lead to an alteration in sleep pattern, they are, however, not the only causes of a decrease in sleep quality and quantity when hospitalized. In contrast to sleep quality, no validated instruments exist addressing the etiologies of sleep problems. Researchers in the area of sleep have developed their own strategies.

Some studies did use nursing theories as a conceptual framework such as Roy's Adaptation Model (Beyerman, 1987) or Roger's Science of Unitary Man (Floyd, 1984). Beyerman (1987) also used the classifications of etiological factors such as the related factors of the nursing diagnosis "Sleep Pattern Disturbance" approved by the NANDA (McLane, 1987). The related factors for this nursing diagnosis are divided into internal factors including illness, and psychological stress and external factors such as environmental changes and social cues (Beyerman, 1987).

In presenting and discussing the literature the etiological factors are grouped into environmental variables, disease-related variables and personal characteristics, a classification used by Verran and Snyder-Halpern (1988). The results of Closs' study (1988b) will, however, be presented and discussed first.

Closs (1988b) calculated correlations between the changes in sleep pattern as mentioned in the previous section and some independent variables. The independent variables concerned: Day of the week, age, gender, whether or not patients lived alone, ward design, whether or not it was a waiting night, number of days since admission and since surgery, drug used, type of mattress and whether patients were able to conduct their usual pre-sleep routines. Women reported longer night time sleep in hospital than men and those who lived alone compared their sleep more favorably with sleep at home than those who lived with others. Patients on small wards (1-4 beds) reported longer sleep times and fewer nighttime awakenings than patients on Nightingale wards (20-24 beds). A shorter sleep latency, longer sleep durations and a later time of morning awakening was reported by patients who recieved a hypnotic the previous night. The type of mattress correlated with sleep duration and morning waking time. The remaining independent variables did not correlate with the change in sleep pattern compared with home. Living alone, ward design and type of mattress predicted whether patients slept either the same, better or worse in hospital than at home.

The ability to go through the same pre-sleep routines had no effects on reported sleep. Closs (1988b) argues that there are so many stressful stimuli in hospital whose effects can not be ameliorated by familiar practices.

Noise and pain were the most frequently mentioned causes of night-time awakening in the hospital. Noises were typically caused by nurses and nursing care of other patients. Environmental temperature and an uncomfortable bed were also frequently mentioned as causes of night time awakening. Only $40 \%$ of the patients woke up naturally in Closs' study (1988b).

Again no correlations were estimated on quality of sleep perceived by patients compared with that at home. 


\subsubsection{Environmental variables}

External stimuli constituted $70 \%$ of the causes mentioned by the patients as sleep disturbers (Beyerman, 1987). Of the environmental factors disturbing sleep, noise was the most thoroughly documented factor. This included noise from equipment, roommates and nurses, disruptions for therapeutic or assessment procedures and personal care of both the patients themselves and their roommates. Other factors such as light and temperature received less attention.

Noise levels in hospitals often exceed the recommended level of $35 \mathrm{~dB}(\mathrm{~A})$ for hospitals, which occurs not only in intensive care units but also on general wards (Hilton, 1985, Ogilvie, 1980, Seidlitz, 1981, Turner, King, \& Craddock, 1975, Woods \& Falk, 1974). Noise at $50 \mathrm{~dB}(\mathrm{~A})$ seriously affects sleep and iscapable of enhancing pain perception (Seidlitz, 1981). Patients disturbed in their sleep return to a less deep (shallower) sleep stage and continue their sleep cycle or are awakened (Woods \& Falk, 1974). Whether the patient is aroused by noise or not depends on the perceived noise level, the meaning of the noise within the person's perceptual frame of reference, the age of the person, the stage of sleep involved and effects of anesthesia (Carrascal et al., 1982, Hilton, 1985, Woods \& Falk, 1974). In addition environmental disturbances that do not produce overt awakenings, and are not noticed by the person, can be sufficient to cause documented EEG arousals and stage transitions (Brewer, 1985), which may be an indication of a change in sleep quality.

In Hilton's (1985) study on intensive care units and general care units, patients remained fairly satisfied when the noise level did not exceed $60 \mathrm{~dB}(\mathrm{~A})$. Noise above $60 \mathrm{~dB}(\mathrm{~A})$ interferred with sleep, as reported by the patients. Another study conducted by Hilton (1976), with a small sample of patients on a respira. tory unit and using polysomnographic measurements, demonstrated that noise created by staff members, assessment and therapeutic procedures and environmental noise, were the most influential sleep disturbers. Patients identified these disturbances too, when interviewed, and added to the list factors such as the uncomfortable position, tension, pain, bright light, and fear or anxiety. In addition some patients questioned the necessity of some of these disturbances. A large proportion of the most frequent noise is caused by nurses doing their rounds (Leuenberger et al., 1983) and performing therapeutic and diagnostic measures (Beyerman, 1987), and is not caused by machinery (Ogilvie, 1980), even in acute care areas (Hilton, 1976, Woods \& Falk, 1974), and are more or less within nurse's control (Beyerman, 1987).

What kind of noise is most disturbing to sleep is not clear (Baker, 1984). In one study, Snyder-Halpern (1985) used noise recorded in a CCU, to test the effect on psychological comfort of young healthy adults during sleep, in a laboratory setting. The results showed that mechanical noise was the most disturbing, and patient and staff noise categories were the least disturbing. Self-report was used to estimate the sleep and the evaluation of noise annoyance. In a later study Verran and Snyder-Halpern (1988) showed that major factors disturbing sleep were concern over the well-being of hospital roommates and the nondirect care activities of nurses. 
The fixed environmental conditions such as light and temperature were experienced as less disturbing than disturbances caused by other people like roommates and nurses (Ladwig, 1979). These environmental variables were only occasionally mentioned by patients in the different studies (Beyerman, 1987, Hilton, 1976, Ladwig, 1979, Seidl \& Walter, 1984). In ICU, continuous lighting may disturb patient's circadian rhythm not only in sleep but also the associated biological functions such as body temperature (Baker, 1984). Temperature in hospitals is in general higher than patients are used to at home (Leuenberger et al., 1983). Sleeping at temperatures higher than $24^{\circ} \mathrm{C}$ according to Schmidt-Kessen \& Kendel (1973) causes less efficient sleep. Too much or too little fresh air may also have a negative influence on sleep efficiency (Webster \& Thompson, 1986).

Light, temperature, noise and quality of bed were cited as disturbing sleep with sufficient frequency to be clinically important. However, pain and position in bed were the most frequently mentioned and were reported to be the most important sleep disturbers in hospitals in Reimer's (1987) study. Nurses were less aware of patients' concerns about this positional discomfort, the equipment attached and personal worries (Reimer, 1987).

Pacini and Fitzpatrick (1982) reported that the environment alone did not significantly contribute to the alterations of sleep pattern. Rather, the combination of health status, state of mind, and state of fatigue were found to influence the sleep pattern. These results are in contradiction to other studies which showed that environmental variables are the major factors influencing sleep. This study used, however, an older population in comparison with other studies. These results, however, are in accordance with Ladwig (1979) who concluded that physical-technical stimuli were of minor importance in disturbing sleep when compared to internal conditions such as fear of medical investigations and expectations of an uncertain future.

None of the above mentioned studies, however, addressed the relationship between sleep quality and environmental sleep disturbances. It is clear that environmental variables influence sleep in hospitals. Yet it seems that these environmental variables, mostly noise, are not always expressed by patients as disturbing their sleep. This contrasts with results of polysomnographic measurements indicating sleep disturbance. The source of noise apparently makes a difference with respect to the extent of affecting sleep.

\subsubsection{Personal characteristics}

Sleep changes with age, not only in quantity but also in quality. Elderly people awake more frequently at night, endure longer sleep latencies, and suffer a decrease in sleep time, resulting in a reduced sleep efficiency (Dement et al., 1982). The sleep cycle changes too, stages III and IV of the NREM sleep, the so-called deep sleep, decrease by $50 \%$ or more (Anch et al., 1988), explaining the frequent awakenings. The total amount of REM sleep decreases too, although the same number of episodes occur as in younger adults.

Elderly people have a tendency toward desynchronization of some circadian rhythms (Colling, 1983). Tune's $(1968,1969)$ studies showed that with increa- 
sing age the times of falling asleep and awakening were earlier. This phaseadvancing may displace the phase of other rhythms synchronized with sleep such as body temperature (Dement et al., 1982). On the other hand, it has been speculated that this phase-advancing might be based on altered circadian rhythms, such as reduction in period, or amplitude, and of core body temperature rhythm (Reynolds III, Kupfer, Hoch, \& Sewitch, 1985). The biphasic sleep changes to a polyphasic sleep, and hence the elderly sleep more during the day, which has consequences for the sleep at night (Miles \& Dement, 1980) and associated biological rhythms (Dement et al., 1982). It is not clear, however, whether the elderly nap because of the disrupted sleep at night, hence to increase the total amount of sleep (Johns, 1975, Tune, 1968), or nap because the social cues or "Zeitgebers" are diminished as organizers of the day (Herbert, 1978). Various reports suggest that neither the amount of sleep per 24 hours nor the need for sleep decreases with age (Dement et al., 1982). Verran and Snyder-Halpern (1988) reported a lack of association between sleep characteristics and age in hospitalized subjects. All patients regardless of age showed evidence of disturbed sleep. In addition elderly people do have more multiple medical diagnoses which can alter their sleep (Colling, 1983, Dement et al., 1982) and with advancing age it is more likely that sleep problems become multifactorial in origin (Morgan, Healy, \& Healy, 1989).

Women report more sleeping problems than men (Carrascal et al., 1982, Johnson, 1985, Kales \& Kales, 1970, McGhie \& Russel, 1962). They complain more about problems in falling asleep and frequent awakenings (Kales \& Kales, 1970, Miles \& Dement, 1980). However, the changes in sleep because of aging occur 10 years later in women than in men (Hayter, 1980, Prokup, 1982).

Hospitalization plays a large role in producing anxiety. Patients may worry, for instance, about their illness, test results and surgery, and the family at home. The close proximity of other people may lead to unease or embarrassment, adding to the patient's anxiety (Webster \& Thompson, 1986).

Several studies showed that anxiety and sleep disturbances are related (Haynes, Follingstad, \& McGowan, 1974, Karacan, Thornby, \& Williams, 1983, Webster \& Thompson, 1986). Poor sleepers were found to be more anxious (Haynes et al., 1974, Johns, 1971, Johns, Bruce, \& Masterton, 1974), and anxious people have more problems falling asleep and have a disturbed sleep KKales, 1969. McGhie \& Russel, 1962).

Personality tests indicated a higher probability of symptomatic complaints among poor sleepers than good sleepers (Monroe, 1967). Several psychological studies showed that depressiveness also influences sleep (Kales, Caldwell, Preston, Healy, \& Kales, 1976, Kales, Caldwell, Soldatos, Bixler, \& Kales, 1983, McGhie, 1966, Reynolds III, Coble, Black, Holzer, Caudl, \& Kupfer, 1980). Depressive people have difficulties falling asleep, have frequent awakenings and complain of waking up early in the morning. Long sleepers are worriers and are chronically somewhat depressed and anxious. It has been suggested that the increased sleep need may be a response to anxiety (Hartmann, Baekeland, \& Zwilling, 1972, Hartmann, 1973).

Several studies on sleep in hospital settings report on changes in daily routines and circadian rhythms (Closs, 1988b, Felton, 1987, Milne, 1982, Schirmer, 
1983). Changes in daily routines such as eating times, more or less exercise, contribute to an altered sleep pattern (Farr, Keene, Samson, \& Michael, 1984, Floyd, 1984, Schirmer, 1983). Rogers (1970) stated that hospitalization causes a desynchronization of individual rhythmic patterns which can reduce the therapeutic effectiveness of hospitalization. Taub and Berger's (1976) study supported the hypothesis that acute disruption of the 24-hr sleep-wakefulness cycle produces degradations in human performance. The ability to tolerate changes seems to decrease with increasing age (Dement et al., 1982, Kales, Wilson, Kales, Jacobson, Paulson, Kollar, \& Walter, 1967, Prokop, 1982). Morning people have more problems in adapting to changing rhythms than evening people (Floyd, 1984). Temperature rises more steeply in morning people than evening people (Horne \& Ostberg, 1976). Time of awakening is in the ascending part of the temperature curve which is shorter for morning people, resulting in a less flexible awakening time. In Floyd's (1984) study the hospital routine did not match with either circadian type. For the morning people there was a phase delay and for the evening people a phase advance.

It is obvious that only a few personal characteristics have been studied as factors related to sleep problems in hospitals such as anxiety, daily routines and circadian rhythms.

\subsubsection{Disease-related variables}

Sleep is associated with a fall in blood pressure, heart rate, respiratory rate, and temperature. In REM-sleep, iriegularities in several body functions such as heart rate, blood piessure and bieathing are common, as seen in Chapter 1 on physiological changes during sleep. These changes in body functions influence or lead to exacerbations of some illnesses during the night, possibly leading to sleep disturbances (Dement et al., 1982, Kales \& Kales, 1970, Kales \& Kales, 1974, Williams, Karacan, \& Hursch, 1974).

Breathing difficulties and nocturnal angina become worse during sleep and heart attacks often take place during REM-sleep (Kales \& Kales, 1970. Karacan, Green, Taylor, William, Elliot, Thronby, \& Sales, 1973). Gastric secretion is increased during RE.M-sleep and patients who have peptic ulcers have more pain during that stage (Hayter, 1980).

Pain is frequently mentioned in studies as a cause of sleeping problems (Berlin, 1984, Clapin-F-rench, 1986, Reimer, 1987, Murphy et al., 1977). At night patients are more aware of pain because of lack of distraction. Because of the pain patients become more tense and excited, which leads to difficulties in sleeping. Tension and tiredness increase the pain experience, leading to a vicious circle (McCaffery, 1979). It is therefore important for the patient to relax. before sleep. Pain medications are in most cases sufficient to induce sleep. Unfortunately, pain relief is frequently not sufficiently implemented (Berlin, 1984, Marks \& Sachar, 1973).

Sleep medications, offered to induce sleep, do not improve the quality of sleep (Johnson, 1985, Perry \& Albert, 1984, Seidl \& Walter, 1984); indeed they can even lead to sleep problems (Anch et al., 1988, Berlin, 1984, De Berk, 1988). Besides sleep medications, other medications administered, such as bronchodi- 
lators (McNeil, Padrick, \& Wellmann, 1986), antihypertensives and diuretics (Hayter, 1980, Schirmer, 1983) may alter the sleep pattern.

Bedrest, which is often the case with prolonged hospitalization, changes the circadian rhythms in patients. Prolonged bedrest changes the amplitude and the phases of circadian rhythms of body temperature and heart rate (Dement et al., 1982). It may further disrupt the internal biological rhythms that regulate sleep initiation and maintenance (Miles \& Dement, 1980).

\section{$3.4 \quad$ Conclusions}

It is evident from this literature review that sleep is a very complex phenomenon. Sleep pattern changes in hospital: Bedtime and waking time are earlier, sleep latency is longer, sleep duration is shorther and more awakenings occur, and sleep quality deteriorates. In the studies reported in this literature review the use of sleep medications was not used as an indication of sleep problems.

Factors influencing sleep are very diverse and complex and can not be considered separately. Environmental variables, personal characteristics, and diseaserelated variables are all related to sleep. Studies on sleep in hospital settings, however, are often limited to the environmental variables. Other variables are most often studied in laboratory settings, and their results can often be applied to the hospital setting. Furthermore it is not clear which are the factors, external or internal, most related to sleep. 



\subsection{Introduction}

To describe the extent and kind of sleep problems in the hospital setting and their possible related variables, data from two studies are used: from Study II, a descriptive correlational study, which was an inventarization of the existing sleep problems and possible causes of these sleep problems in three general hospitals, and the pretest data from Study III, an intervention study. Because it is a cross-sectional design, it is not appropriate to speak of causes but rather of related variables.

Three different hospitals, indicated by the letters A, B and C, participated in the first study, one of which (A) also participated in the second study.

in this chapter the research methods from both studies are presented and discussed. Study III is not discussed to the fullest extent because only the data of the pretest are used for the analysis to support the findings of Study II.

The following problem statement was formulated in Study II "What is the extent of sleep problems in a general hospital?" leading to three research questions.

1) What kind of sleep problems exist in a general hospital?

2) What is the extent of these sleep problems?

3) What are the factors related to sleep and which are often cited by patients?

The following problem statement was formulated in Study III.

Does using the nursing process by nurses lead to an improvement of sleep quality and quantity and a decrease in use of sleep medication on hospital wards?

The results of this intervention study will be addressed in Chapter 9, Part III. The research method chosen for Study II is explorative, which is more appropriate regarding the results of the literature review on sleep in hospital settings. Theoretical frameworks are rarely developed and used within this area and offer as a result, few opportunities for hypotheses formulating and testing. An explorative design often gives an un-systematic impression because of the considerable number of variables included in the study. On the other hand this kind of study may lead to the onset of a conceptual model on sleep in hospital settings. 


\subsection{Research design}

\subsubsection{Methods}

\section{Study II}

On surgical and non-surgical wards of three general hospitals an inventarization of sleep problems, sleep quality and quantity, and possible related factors was conducted by means of patient interviews.

Women staying on these wards were approached for an interview. Since the literature review suggested that women had the most complaints about sleep, they were therefore chosen to be the study population. The interview took place on two occasions with one day in between to relieve the patient as much as possible. All the interviews were done by the investigator and took about half an hour each time.

\section{Study III}

A quasi-experimental design was used to test the effect of using a problemsolving process, in this case the nursing process, on the quality of sleep in a general hospital. Six wards of a general hospital, two surgical and four medical, participated in this study. Three wards, one surgical and two medical, formed the experimental group and the others the control group. The pretest took place during a period of six weeks in both groups. During the following 12 weeks the nursing process was implemented on the three experimental wards.

In order to facilitate the use of the nursing process two extra forms, a patient history form and a nursing care plan, were added to the nursing records. More information about the methods used in Study III is available in Chapter 9.

\subsubsection{Population}

\section{Study II}

All women between 30 and 70 years of age, staying on the 9 surgical and 11 medical wards, who were not seriously ill, who could speak and read Dutch, and who spent at least two nights in the hospital and had to stay at least another two nights were approached to participate in this study.

One hundred and forty-one patients were interviewed in three hospitals, 69 patients on medical wards and 72 patients on surgical wards, with a mean age of 52 ( $s d=11.6)$ years. Twenty-nine patients (mean age 57 years) refused to participate in this study, 13 medical and 16 surgical patients. Refusal to participate was mainly attributed to the length of the questionnaire. The non-response group is older than the study population.

\section{Study III}

All Dutch-speaking patients, with no serious condition, aged thirty years or older, who spent at least two nights on that ward were interviewed. Each patient was interviewed only once, meaning that during the second and subsequent weeks only the newly admitted patients were interviewed. 
Two hundred and forty-one patients were included in the pretest and posttest. Only a few patients refused to answer the questionnaire. It is not known, however, how many nor what kind of patients refused to participate in this study. This was due to the fact that the investigator only received the names of the patients willing to participate.

In the total experiment 253 men and 229 women participated. In the pretest, the part of the study essential for this chapter, 130 men and 111 women participated, mean age 57 ( $s d=14$ ) and 63 (sd $=15$ ) respectively.

Neither the number nor the age of men and women differed significantly between the pretest and posttest. For more information on the population of Study III the reader is referred to Chapter 7 .

\subsubsection{Variables and instruments}

\section{Study II}

The variables investigated in this study were not only based on the results of the literature study but also included those which one would commonly expect to be related to sleep.

The dependent variables in Study II were sleep quality, sleep quantity, and sleep medications prescribed and used. The independent variables can be categorized as demographic, environmental, personal characteristics and disease-related. The independent and dependent variables are presented in Tables 4.1 and 4.2. Sleep quality was measured with the Subjective Sleep Quality Scale (SSOS) in general $(a=.92)$ and on two specific nights $(a=.88$ and $a=.90$ respectively) and with a 5-point scale. The 5-point scale ranged from "very poor" to "very good". Because the 5-point scale correlated significantly with the SSOS, as reported in Chapter 2, it was decided to leave it out from the following chapters. Sleep quantity was estimated by the patient using an open-ended question. The SSQS was used to obtain information about sleep quality at home and in hospital. The SSQS consists of 15 statements about sleep on which the patients can agree or disagree, creating a range from 0 (very poor sleep quality) to 15 (very good sleep quality). The SSOS has two versions, which were elaborated in Chapter 2, a general sleep quality scale and a specific one. Sleep quality and quantity were measured on two occasions. During the first intervievv the general SSOS and the question on sleep quantity at home during the previous two months were asked as well as the specific SSQS for the night prior to the interview. During the second interview the general SSOS was used to estimate sleep quality in the hospital till then. The sleep quality and quantity of the night prior to the second interview was measured by the specific SSOS and an open-ended question on sleep quantity. The second night was two nights after the first night which was measured. Information about sleep medications prescribed and administered, was collected from the Kardex.

The demographic variables, such as age, education, marital status, were estimated with open-ended questions. The environmental variables such as noise, light, fresh air, and temperature were compared to home, with answering possibilities more than, equal to or less than at home. 
Table 4.1 The dependent variables and their operationalizations in Studies II and III

\begin{tabular}{|c|c|c|c|}
\hline & operationalization & theoretical range & interview \\
\hline \multicolumn{4}{|l|}{ STUDY ॥ } \\
\hline Sleep quality at home & $\begin{array}{l}\text { * general SSOS } \\
\text { 5-point scale } \\
\text { * sleep problems }\end{array}$ & $\begin{array}{l}0-15 \\
\text { very poor } \\
\text { to very good }\end{array}$ & $\begin{array}{l}1 \\
1 \\
1\end{array}$ \\
\hline Sleep quantity at home & * in hours & & 1 \\
\hline Sleep quality in hospital & $\begin{array}{l}\text { * general SSaS } \\
\text { - s-point scale } \\
\text { - sleep problems }\end{array}$ & $\begin{array}{l}0-15 \\
\text { very poor } \\
\text { to very good }\end{array}$ & $\begin{array}{l}2 \\
1 \\
1\end{array}$ \\
\hline $\begin{array}{l}\text { Sleep quality specific } \\
\text { night in hospital }\end{array}$ & $\begin{array}{l}\text { * specific SSOS } \\
\text { *-point scale } \\
\text { * sleep problems }\end{array}$ & $\begin{array}{l}0-15 \\
\text { very poor to } \\
\text { very good }\end{array}$ & $\begin{array}{l}1,2 \\
2 \\
2\end{array}$ \\
\hline $\begin{array}{l}\text { Sleep quantity specific } \\
\text { night in hospital }\end{array}$ & * in hours & & 2 \\
\hline Sleep medications & $\begin{array}{l}\text { - prescribed } \\
\text { * administered } \\
\text { received as reported } \\
\text { by patients, } 4 \text {-point scale }\end{array}$ & $\begin{array}{l}\text { never to every } \\
\text { night }\end{array}$ & $\begin{array}{l}2 \\
2 \\
2\end{array}$ \\
\hline \multicolumn{4}{|l|}{ STUDY III } \\
\hline Sleep quality at home & * general SSOS & $0-15$ & \\
\hline Sleep quality in hospital & * general SSOS & $0-15$ & \\
\hline Sleep quality specific night: & $\begin{array}{l}\text { * sleep latency (minutes) } \\
\text { - arousals (number) }\end{array}$ & & \\
\hline Sleep quantity specific night & - in hours & & \\
\hline Sleep medications & $\begin{array}{l}\text { * prescribed } \\
\text { - administered previous nigh }\end{array}$ & $t(s)$ & \\
\hline
\end{tabular}

The personal characteristics which were measured included:

1) Trait anxiety: The Dutch version of Spielberger's trait anxiety inventory $(a=.91)^{\prime}$ (Van der Ploeg, Defares, \& Spielberger, 1980) was used.

2) Morningness/eveningness: A Dutch version of Horne and Ostberg's SelfAssessment Questionnaire to Determine Morningness-Eveningness

'Cronbach's alphas concern the current study 
(SAQDME) was used. The instrument was validated by Kerkhof (1984) $(a=$ .75) and is considerably shorter than Horne and Ostberg's (1976), consisting of seven items instead of nineteen.

3) Satisfaction: A modified version of the satisfaction list developed and validated by Visser $(1984 a)(\alpha=.97)$ was used.

4) Coping style: A 26-item version of the Utrecht Coping Questionnaire (Schreurs, Tellegen, \& Van de Willige, 1984) was used. Factor analysis delineated five coping styles, namely active coping $(\alpha=.80)$, palliative coping $(a=.72)$, showing emotions $(a=.72)$, waiting and avoiding $(a=.65)$ and depressive reactions $(\alpha=.79)$.

5) Sleep quality and the use of sleep medications during previous admissions: These were assessed with a 5-and 4-point scale respectively.

6) Sleeping habits: Assessed using open-ended questions.

The disease-related variables which were measured included:

1) The clinical diagnosis; Medical or surgical;

2) The seriousness of the diagnosis as perceived by the patient using a 4-point scale;

3) The length of hospital stay;

4) Pain: A Visual Analogue Scale was used;

5) Well-being on the day of the first interview and the day before the second interview was measured using a Visual Analogue Scale;

6) State anxiety: The Dutch version of Spielberger's State Anxiety Inventory $(a=.91)$ (Van der Ploeg et al., 1980) was used;

7) The medication used by the patient the day before the second interview was collected by the investigator from the Kardex.

A wide variety of drugs influence the sleep-wake cycle although not every drug is offered with the intention to induce sleep. Sleep affecting drugs can be grouped into three categories: 1) sedative hypnotics (sleeping pills) 2) CNS stimulants and 3) drugs used for other purposes that have secondary effects on sleep (Anch et al., 1988). In both studies, Studies II and III, only those sedative hypnotics which are registered (Farmacotherapeutisch Kompas, 1989) as sleeping pills (hypnotics) are reported.

Most of the information was collected during the first interview with the patients except for those variables concerning the night and the morning prior to the second interview and trait anxiety and satisfaction, which were collected during the second interview. Information dealing with the environmental variables and the personal characteristics were gathered twice, once related to the hospital situation and once for the situation at home. The changes happening to the patient because of the hospital stay are emphasized in this study.

\section{Study III}

During the pretest and posttest, sleep quality and quantity were measured, using short structured questionnaires. Sleep quality in the hospital prior to the interview and at home during the past two months was measured by the general Subjective Sleep Quality Scale. Information about sleep quality at home was gathered in the hospital. 
Table 4.2 The independent variables and their operationalizations of Study II.

\begin{tabular}{|c|c|c|}
\hline & operationalization & interview \\
\hline \multicolumn{3}{|c|}{ DEMOGRAPHIC VARIABL.ES } \\
\hline Age & - years & 1 \\
\hline Marital status & $\begin{array}{l}\text { - married } \\
\text { - living alone } \\
\text { - living with parents }\end{array}$ & 1 \\
\hline Children & - yes/no number & 1 \\
\hline Education & $\begin{array}{l}\text { * elementary school } \\
\text { - technical high school } \\
\text { * technical/vocational high school } \\
\text { * vocational regular } \\
\text { * professional/university }\end{array}$ & 1 \\
\hline Profession & $\begin{array}{l}\text { * none } \\
\text { - unskilled labor } \\
\text { * skilled labor } \\
\text { * clerical } \\
\text { * managerial or administrative } \\
\text { emplovees/owners of small businesses } \\
\text { " upper-middle class and professionals }\end{array}$ & 1 \\
\hline
\end{tabular}

\section{ENVIRONMENTAL VARIABLES}

Noise

Fresh air

Temperature

Light

Roommates

Bed
* compared to home

* disturbing to sleep

* compared to home

* disturbing to sleep

- compared to home

* disturbing to sleep

* compared to home

* disturbing sleep

- number

- too many

- disturbing to sleep

- lack of privacy

- quality of the bed

- compared to home less/equal/more 1

never to always $\quad 1$

less/equal/more $\quad 1$ no/yes 1

lower/equal/higher 1 never to always 1

less/equal/more 1 never to allways 1

1

no/yes 1

no/yes 1

no/little/much $\quad 1$

too hard/too high/ 1 too small better/equal/worse 1 
Table 4.2 Continued

PERSONAL CHARACTERISTICS

\begin{tabular}{|c|c|c|}
\hline Trait anxiety & * STAI & $20-80$ \\
\hline Morningness/eveningness & - Kerkhof & $7-31$ \\
\hline Satisfaction & * Visser & $1-10$ \\
\hline Coping & \multicolumn{2}{|c|}{ * Utrecht Coping Questionnaire } \\
\hline Previous admissions & $\begin{array}{l}\text { * sleep quality (5-point scale) } \\
\text { * sleep medications } \\
\text { (4-point scale) }\end{array}$ & $\begin{array}{l}\text { very poor to } \\
\text { very good } \\
\text { never to } \\
\text { every night }\end{array}$ \\
\hline Sleeping habits & $\begin{array}{l}\text { * alone in bed } \\
\text { - warm meal in evening } \\
\text { - eating before bed } \\
\text { drinking before bed } \\
\text { activity level }\end{array}$ & $\begin{array}{l}\text { yes/no } \\
\text { yes/no } \\
\text { no/yes } \\
\text { no/yes } \\
\text { relaxing/ } \\
\text { activities/ both }\end{array}$ \\
\hline & $\begin{array}{l}\text { * bedtime } \\
\text { * waking time }\end{array}$ & \\
\hline & $\begin{array}{l}\text { * awakened too early } \\
\text { * napping, frequency duration ( }\end{array}$ & $\begin{array}{c}\text { no/yes } \\
\text { ninutes) }\end{array}$ \\
\hline
\end{tabular}

DISEASE-RELATED VARIABLES

Clinical diagnosis

* medical/surgical

- seriousness (4-point scale)

not serious

to very serious

Length of stay

- number of days

Pain

Well-being

Position in bed

State anxiety

Worry about discharge

Medications night 2

Previous admissions
* VAS

* VAS

* bedrest

* change in pos.

* impaired pos.

* stal

* 3-point scale

* pain medications

- tranquilizer

- sleep medication

* number
$0-10$

0-10

1

1,2

no/yes $\quad 1$

no/yes 1

no/yes 1

$20-80 \quad 1$

never to always $\quad 1$

no/yes 2

no/yes 2

no/yes 2 (1)

(1) 
Both correlated significantly with the SSOS as presented in Chapter 2. Demographic variables such as age, gender, education, marital status were also collected as well as the date of admission.

Table 4.3 Open-ended questions to estimate sleep quality and quantity on the night prior to the interview in Study III.

At what time did you go to bed last night?

At what time did you fall asleep last night?

At what time did you wake up this morning?

How many times did you awake last night?

How many hours did you sleep last night?

\subsubsection{Procedure}

\section{Study II}

The names of the patients who met the criteria were provided by the head nurse except for one hospital where the names were collected on the admission ward. Women were approached by the investigator only when the nursing staff thought they were capable of being interviewed. The interview was explained to the patients and their consent to participation was obtained. All the patient interviews took place in the patient rooms.

Patients were interviewed anytime after the second night of hospitalization. The duration of hospital stay before the first interview varied between 2 and 84 days (mean 9.5, median 7).

\section{Study III}

The head nurse informed the patients and asked if they wanted to participate. During the pretest and the posttest once a week the newly admitted patients were asked to participate and received a questionnaire. The questionnaires were completed by the patients in the presence of the investigator. Some patients needed some help with filling out the questionnaire.

\subsubsection{Analysis}

Bivariate analyses and multivariate analyses are performed. In performing multivariate analyses conceptually related variables were grouped together. Regression analysis was carried out to find the factors explaining the variance in the dependent variables.

The relationships between the independent variables and the dependent variables were measured in two ways. Firstly, an estimation was made of the extent to which the independent variables disturb sleep as perceived by the patients. Secondly, empirically, in which the independent variables were correlated with the dependent variables. The results of these different analyses are compared.

A difference score between sleep quality at home and sleep quality in hospital in general was calculated. The difference score signifies the change in sleep quality in hospital compared to the home situation. The correlations between 
the difference score and the independent variables are also calculated. For Chapter 6 (Determinants of sleep) it was decided to omit sleep quantity from the analyses because it was strongly correlated with the quality of sleep (see Table 2.91. 



\section{An inventory of sleep problems in hospitals}

\section{$5.1 \quad$ Introduction}

The aim of this chapter is to discuss the quality and quantity of sleep at home as well as in the hospital. The discussion is preceded by a description of the sleep pattern in the hospital compared with home. The questions raised relate to whether patients experience the change in sleep pattern as a sleep problem and what the consequences of these changes are on their quality of sleep.

The research questions addressed in this chapter are:

1) What kind of sleep problems exist in a general hospital?

2) What is the extent of these sleep problems?

As mentioned in the previous chapter, sleep quality and quantity can be measured with several different instruments such as the SSOS and open-ended questions.

The patient history forms used in Study III also provided information on the sleep patterns at home. These forms are, however, only available in the posttest: A comparable population to the population used in this chapter, the pretest population. These data are only used to get an impression of normal sleep patterns. For more information on the method of Study III the reader is referred to Chapter 9 of Part III.

\subsection{Changes in sleep pattern}

Bedtime in hospital was significantly earlier than at home in Study If $(\mathrm{t}=2.29$, $\mathrm{p} \leq .05) ; 62 \%$ of the patients intended to sleep before $11.15 \mathrm{p} . \mathrm{m}$ (Table 5.1 ). In Study III 73\% of the patients intended to sleep before 11.15 p.m. (Table 5.1 ) but only $39 \%$ fell asleep before that time. At home only $56 \%$ of the patients in Study II went to bed before 11.15 p.m., comparable to the $50 \%$ at home in Study III in the posttest (patient history forms). In Study III sleep latency, the time it takes to fall asleep, ranged from falling asleep immediately to six and a half hours later. The mean sleep latency was 50 minutes (median 30 minutes). Half of the patients in the posttest of Study III needed less than 15 minutes to fall asleep at home.

In Study II, 90\% (127) of the population were awake before 7.15 a.m., on the morning of the second interview, either because they woke up spontaneously or were awakened (Table 5.2). In Study III this percentage was lower but still $73 \%$ of those who had slept were awake before 7.15 a.m. (Table 5.2). Sixty per cent of the population in Study II wakes up at home before $7.15 \mathrm{a} . \mathrm{m}$. $(t=11.75, p \leq .001)$ and from the posttest population of Study III only $27 \%$ 
were awake before 7.15 a.m. at home.

Table 5.1 Bedtime at home and in hospital on the night prior to the interview in Study II ( $n=141)$ and Study III $(n=241)$.

\begin{tabular}{lccccc}
\hline & \multicolumn{2}{c}{ STUDY $\|$} & & \multicolumn{2}{c}{ STUDY \|\|} \\
\cline { 2 - 4 } & $\begin{array}{c}\text { At home } \\
\%\end{array}$ & $\begin{array}{c}\text { In hospital } \\
\%\end{array}$ & $\begin{array}{c}\text { At home } \\
\%\end{array}$ & $\begin{array}{c}\text { In hospital } \\
\%\end{array}$ \\
\hline Before 9.15 p.m. & 1 & 3 & 1 & 5 \\
$9.15-9.44$ p.m. & 1 & 1 & 2 & 4 \\
$9.45-10.14$ p.m. & 5 & 7 & 4 & 10 \\
$10.15-10.44$ p.m. & 19 & 19 & 13 & 25 \\
$10.45-11.14$ p.m. & 30 & 32 & 30 & 29 \\
$11.15-11.44$ p.m. & 22 & 11 & 17 & 10 \\
$11.45-00.14$ a.m. & 7 & 14 & 22 & 10 \\
00.15 a.m or later & 16 & 9 & 12 & 5 \\
didn't sleep & - & 4 &.- & 1 \\
didn't know & -- & -- & - & 2 \\
\hline
\end{tabular}

Table 5.2

Awakening time at home and in the hospital according to the patient on the morning of the interview in Studies II $(n=141)$ and III $(n=241)$.

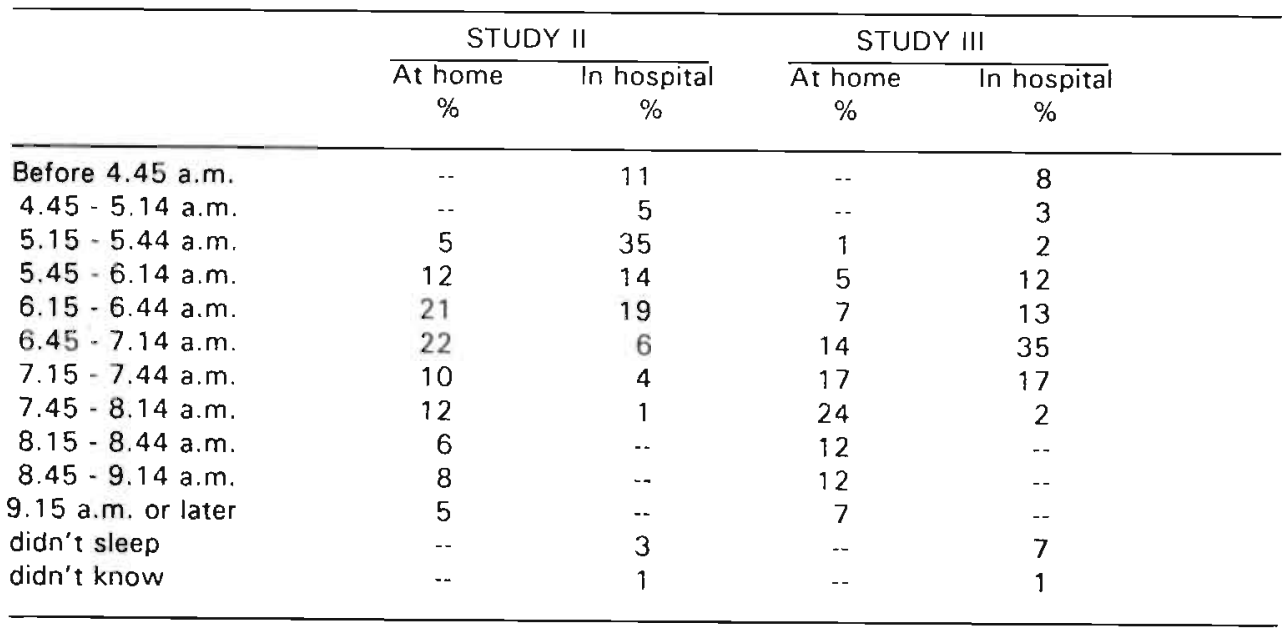

Eighty-six $(61 \%)$ patients woke up spontaneously, of whom 49 (57\%) before 6.00 a.m. One-fifth of the patients in Study III remembered being awake for more than five times the previous night (mean 2.6, sd 2.0, median 2.0). In hospital people are more in bed during the day; therefore they nap or rest more than they are used to at home. In Study II patients took more $(t=-3.21, d f=$ $123, p \leq .01)$ and longer naps $(t=-3.66, d f=114, p \leq .001)$ in the hospital than at home (Table 5.3). 
Table 5.3 The frequency and duration of naps at home and in the hospital for the population in Study II $(n=141)$.

\begin{tabular}{lcc}
\hline & At home & Hospital in general \\
Frequency & $\%$ & $\%$ \\
\hline never & 48 & 33 \\
sometimes & 26 & 8 \\
mostly & 11 & 29 \\
always & 15 & $\%$ \\
\hline Duration & $\%$ & 5 \\
& & 18 \\
less than 15 minutes & 7 & 42 \\
30 to 30 minutes & 28 & 10 \\
1 to 2 hours & 37 & 22 \\
more than 2 hours & 21 & 3 \\
didn't know & 7 & $n=41$ \\
na napping & -- & \\
\end{tabular}

Comparing the sleep pattern in hospital with that to home it becomes clear that there is a change in sleep pattern. How do patients experience these changes in the sleeping pattern and what are the consequences of these changes for their quality of sleep?

\subsection{The extent of sleep problems}

Almost 60 per cent (83) of the patients in Study II indicated experiencing one or more sleeping problems during their hospital stay and 45 per cent (64) at night 2. This contrasts with $38 \%$ (53) indicating problems at home (Table 5.4).

Table 5.4 Sleep problems experienced by patients at home and in the hospital in Study II ( $N=141)$.

\begin{tabular}{lccc}
\hline & $\begin{array}{c}\text { At home } \\
\%\end{array}$ & $\begin{array}{c}\text { Hospital in general } \\
\%\end{array}$ & $\begin{array}{c}\text { Hospital night2 } \\
\%\end{array}$ \\
\hline Problems falling asleep & 21 & 28 & 12 \\
Frequent awakenings & 20 & 38 & 34 \\
Awakening early & 6 & 6 & 7 \\
Not sleeping at all & 4 & 6 & 5 \\
Having a light sleep & 3 & 6 & 2 \\
Having a restless sleep & 2 & 2 & 2 \\
No problems & 62 & 41 & 55 \\
\hline
\end{tabular}

The sleep problems mentioned most frequently were "problems falling asleep" and "frequent awakenings", although the frequent awakenings in the hospital 
setting clearly dominate (Table 5.4). Remarkably nobody mentioned "being awakened too early", although the awakening time in the hospital is considerably earlier than at home.

Thirty-three per cent (46) of the patients in Study II said they had poor or even very poor sleep in the hospital in general and 43 patients $(30 \%)$ on night 2 , estimated by means of the 5-point scale.

Table 5.5 Mean scores on the SSaS in Study II and Study III (pretest) at home and in hospital.

\begin{tabular}{|c|c|c|}
\hline & $\begin{array}{c}\text { Study II } \\
(n=141) \\
\text { Mean (sd) }\end{array}$ & $\begin{array}{c}\text { Study IIf } \\
(n=241) \\
\text { Mean (sd) }\end{array}$ \\
\hline At home & $9.2 \quad(5.0)$ & $10.7 \quad(4.4)$ \\
\hline Hospital in general & $7.9(5.1)^{* *}$ & $(4.9)^{* * *}$ \\
\hline Night 1 & $8.4 \quad(4.5)$ & $\cdots$ \\
\hline Night 2 & $8.9 \quad(4.8)$ & ... \\
\hline
\end{tabular}

$* * p \leq .01 * * p \leq .001$

Sleep quality measured by means of the SSQS in the two studies ranged from 9.2 to 10.7 at home and from 7.6 to 7.9 in hospital. The mean scores on the SSOS are cited in Table 5.5.

The sleep quality in hospital in general was significantly worse than at home, for Study II ( $t=3.03, p \leq .01$ ) as well as for Study III ( $t=9.93, p \leq .001)$. There was no significant difference between the sleep quality at home and sleep on the two specific nights in Study II. No significant differences in sleep quality were evident for the patients of the three hospitals as measured by the SSOS (Table 5.6).

Table 5.6 Sleep quality at home and in hospital in Study II per hospital as measured by Ssas.

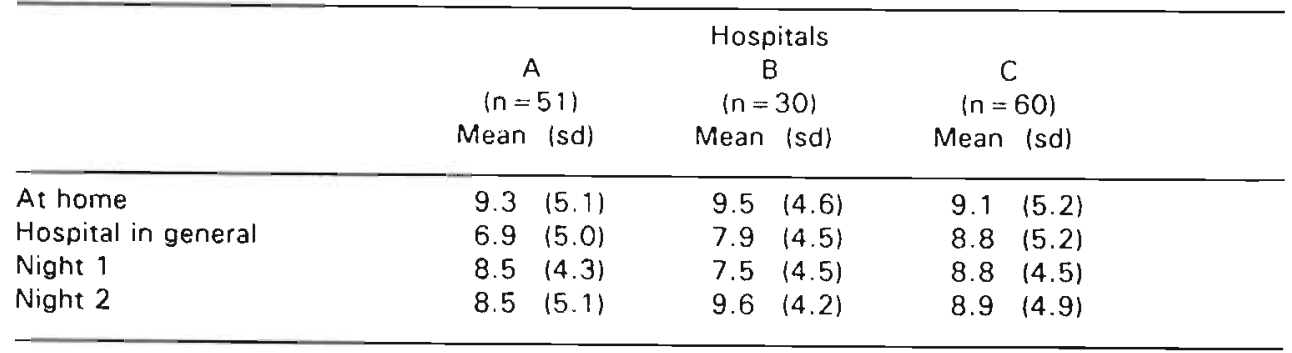

In Study II the total sleep time in hospital was less than six hours (mean 5.8, sd 1.9, median 6.2), significantly less than the total sleep time at home which was more than seven hours (mean 7.2, sd 1.7, median 7.5) $(t=2.87, p \leq .01)$. There was no difference in total sleep time at home and in the hospital between the three hospitals in this study.

More than half of the population (52\%) in Study III said they had slept less than 
six hours and six patients even said they did not sleep at all (mean 5.4 hours, sd 2.2, median 6 hours).

The majority of the population (58\%) of Study II reported sleeping better at home than in the hospital, which seems very logical. However, $32 \%$ stated that it did not make any difference. Despite the fact that sleep quality and quantity decreased significantly during hospitalization, 12 patients did mention sleeping better in the hospital than at home. Possibly these are patients who feel safer in the hospital.

\subsection{Conclusions and discussion}

Both the literature and the results of the two studies make clear that the quality and quantity of sleep in hospital are decreased when compared to the home situation. When people are hospitalized, a change in sleep pattern occurs; the awakening time and bedtime are significantly earlier than at home. These results find support in the literature. Sleep latency is considerably longer than a normal sleep latency of 10 to 15 minutes for adults (Closs, 1988b, Mendelson, 1989) and the awakenings at night were more frequent than in a normal situation. Closs (1988b) and Reimer (1987) did find that patients awakened once or twice a night at home. "Difficulty falling asleep" and "frequent awakenings" were also the most frequently reported sleep problems experienced by the patients in the hospital which is supported by the literature. These two problems are validated as critical defining characteristics of the nursing diagnosis Sleep Pattern Disturbance. The earlier awakening time was not experienced as a sleeping problem. Patients also spent more time asleep during the day. The consequences of these naps for the sleep duration at night depends on the time they take place, as became clear from the literature. Morning naps for the most part consist of REM sleep which is not subtracted from the nocturnal sleep time; however, afternoon naps consisting of SWS reduce the amount of SWS at night (Horne, 1989).

Sleep latency and arousals are significantly correlated with sleep quality, as reported in Chapter 2. Whether the other changes in sleep pattern, such as awakening time and bedtime, are related to sleep quality will be presented in Chapter 6. 


\subsection{Introduction}

Etiological factors identified in the diagnosis of sleep pattern disturbance are the focus of nursing interventions. In this chapter these etiological factors are explored. Most of the data used in this chapter are provided by Study II. Data are presented on the factors related to the dependent variables, sleep quality and the amount of sleep medication prescribed and used in the hospital, with the object of answering the following research question, "What are the factors related to sleep and which factors are often cited by patients" for sleep problems in hospitals.

A difference score is calculated for the change in sleep quality compared to home to control for the effect of sleep at home. The independent variables are mostly presented as a change in hospital compared to home. This is, however, preceded by a description of factors patients experience as disturbing to their sleep and as the causes of their awakenings at night and in the morning.

For all the independent variables the correlations with sleep medication prescribed and used are estimated and only significant correlations are presented. More information about the extent of use of sleep medication in hospital is presented in Chapter 8 of Part III.

\subsection{Factors patients experience as disturbing their sleep}

In this section results are presented and analyzed based on what patients experienced as causes of poor sleep and waking up at night. A difference is made between factors related to a specific night and sleep in general in hospital.

Thirty-three per cent (46) of the patients in Study II, as reported in the previous chapter, said they had poor to very poor sleep in hospital in general and $30 \%$ (43) on night 2 .

Causes frequently mentioned were pain, worrying and the position in bed for the sleep in general and pain and the presence of roommates for the specific night (Table 6.1). Causes for poor sleep differed according to whether it concerned a specific night or in general. Environmental variables like roommates, nursing care of roommates and nurses were mentioned more frequently for a specific night than in general (Table 6.1). These variables can be considered as sources of noise during the night. The frequency of awakenings and their causes were further elaborated in the interviews.

A specific night

When the patients were asked specifically if they were awakened by the environmental variables, noise, light or temperature, a considerable percentage of 
the patients $(34 \%)$ said they were awakened by noise on night 1 , the night before the first interview. The noise was primarily caused by roommates, nurses or nursing care of the roommates (Table 6.2).

Table 6.1 Causes for poor sleep mentioned by the patient in Study II $(n=141)^{*}$.

\begin{tabular}{lcc}
\hline & In hospital in general & In hospital at night \\
\hline Pain & 20 & 19 \\
Worrying & 18 & 8 \\
Position & 14 & 4 \\
Roommates & 9 & 4 \\
Not tired & 9 & - \\
Had to go to the bathroom & 5 & 3 \\
Strange environment & 4 & - \\
Nursing care of roommates & 2 & - \\
Illiness & 3 & - \\
Nurses & -- & 3 \\
Age & -- & 1 \\
Didn't know & 16 & 3 \\
& & (missing 13) \\
\hline
\end{tabular}

* more than one answer possible

Table 6.2 Sources of noise in the hospital as causes for patients' awakenings the night prior to the first interview and in general in hospital, as reported by patients in Study II $(n=141)^{*}$.

\begin{tabular}{lcc}
\hline & Specific night & In general \\
\hline Roommates & 25 & 71 \\
Nurses & 14 & 74 \\
Nursing care of roommates & 11 & 18 \\
Machines/instruments & 2 & 7 \\
Noises from outside & 1 & 6 \\
Calling light & 1 & 9 \\
Didn't know & 1 & 1 \\
\hline
\end{tabular}

- more than one answer possible

Another 17 (12\%) patients were awakened by the temperature of the room, which was mostly too high, and only four patients were awakened by lights being on in their room. During the second interview patients were asked whether they were awakened by roommates or nurses the night or morning prior to the second interview. Again it became clear that many patients were awakened by nurses or nursing care activities at night or in the morning.

Ten patients were awakened at night and 55 in the morning by nurses for nursing care routines such as temperature, blood pressure and pulse rate measurements or for administration of medication. Twenty-three patients experienced these morning awakenings by nurses as too early. At night 47 patients and in the morning another 33 patients were awakened by their roommates or because of nursing care activities of roommates (Table 6.3). 
Table 6.3 Awakenings by nurses and roommates the night and morning prior to the second interview $(n=141)$.

n

\begin{tabular}{|c|c|}
\hline $\begin{array}{l}\text { NIGHT } 2 \\
\text { nurses }\end{array}$ & $10(7 \%)$ \\
\hline roommates & $34(24 \%)$ \\
\hline nursing care of roommates & $35(25 \%)$ \\
\hline $\begin{array}{l}\text { MORNING } \\
\text { nurses }\end{array}$ & $55(39 \%)$ \\
\hline roommates & $22(16 \%)$ \\
\hline nursing care of roommates & $31(22 \%)$ \\
\hline
\end{tabular}

some overlap appeared between being awakened by roommates or nursing care of roommates

Eighty-six $(61 \%)$ patients were not woken up intentionally in the morning: of these 27 were already awake before 5.30 a.m. Again many patients (36) experienced it as too early.

Table 6.4 Causes for the final awakening the morning of the second interview $(n=86$ ).

n

\begin{tabular}{lr}
\hline Spontaneously & 52 \\
Noises from roommates & 10 \\
Noises from nurses & 7 \\
Pain & 5 \\
Lights were turned on & 2 \\
Had to go to the bathroom & 2 \\
Hunger & 1 \\
Didn't know & 2
\end{tabular}

(missing $=5$ )

For 17 patients the causes for their finally waking up were noise from nurses or roommates and $52(64 \%)$ woke up spontaneously (Table 6.4). It seems that a considerable number of patients were already awake before the activities on the wards were resumed. The noise from the nurses and the roommates was primarily caused by the nursing care of these patients.

Patients who were awakened by environmental variables such as noise, light and temperature did not differ in sleep quality from those who were not. The sleep quality of night 2, however, did differ significantly between the patients who were awakened that night by nurses, roommates or the nursing care of roommates, and those who were not $\left(x^{2}=13.4, p \leq .01\right)$. 


\section{In general}

Of the 129 patients not having a room of their own, 29 patients would have preferred to have one of their own or at least with fewer patients. The reasons they mentioned most frequently were the lack of privacy and the restlessness of the environment.

Of the 87 patients who experienced the roommates as disturbing to their sleep, almost half (41) mentioned being awakened almost every night by other patients.

It is remarkable that although many patients were awakened during the night or in the morning by noise, mostly caused by nurses or roommates, the majority of patients did not experience these environmental changes as disturbing their sleep when interviewed (Table 6.5). However, empirically, the level of noise at night had a negative and significant correlation with quality of sleep in hospital.

Table 6.5 Sleep disturbances in general caused by environmental changes for patients sleeping poorly ( $S S Q S<8$ ) and patients sleeping well ( $S S Q S \geq 8$ ), as reported by the patients $(n=141)$.

\begin{tabular}{|c|c|c|c|c|c|c|c|c|}
\hline & \multicolumn{2}{|c|}{$\begin{array}{l}\text { More } \\
\text { noise }\end{array}$} & $\begin{array}{c}\text { M } \\
\text { lig } \\
\text { Sleep } \\
\text { poor }\end{array}$ & $\begin{array}{l}\text { hre } \\
\text { ht } \\
\text { goality } \\
\text { good }\end{array}$ & \multicolumn{2}{|c|}{$\begin{array}{c}\text { Higher } \\
\text { temperture }\end{array}$} & $\begin{array}{c}\text { Le } \\
\text { fres } \\
\begin{array}{c}\text { Sleep } \\
\text { poor }\end{array}\end{array}$ & $\begin{array}{l}\text { ss } \\
\frac{\text { h air }}{\text { quality }} \\
\text { good }\end{array}$ \\
\hline \multicolumn{9}{|l|}{ Disturbing the sleep } \\
\hline never $\mid$ no $\mid$ & 23 & 25 & 28 & 22 & 17 & 18 & 17 & 29 \\
\hline sometimes & 7 & 10 & 2 & 4 & 6 & 5 & & \\
\hline most of the time & 11 & 4 & 3 & 0 & 6 & 2 & & \\
\hline always (yes) & 10 & 4 & 8 & 1 & 4 & 5 & 24 & 12 \\
\hline Total & 51 & 43 & 41 & 27 & 33 & 30 & 41 & 41 \\
\hline
\end{tabular}

A lower temperature and more fresh air were rarely experienced as disturbing sleep; therefore they are not included in Table 6.5. Patients having a good sleep, a score of eight (median) or higher on the SSQS, experienced the little fresh air as significantly $\left(x^{2}=.12, p \leq .01\right)$ less disturbing for their sleep than poor sleepers, those who scored seven or lower on the SSQS. For the other environmental variables no difference in the frequency of disturbing sleep between good and poor sleepers was found.

Noise heard at night was mostly caused by nurses or roommates (Table 6.2). Only a few patients mentioned noise produced by machines. Thirty-seven (26\%) patients had some light on at night, mostly a floor light. However, only 22 patients thought this was necessary.

Noise from roommates or nurses is mentioned more frequently as the cause of awakenings during a hospital stay than noise from machinery or other environmental factors. This is in agreement with results found in the literature. The literature also mentions that nursing care is the most important factor affecting the sleep of hospitalized patients (Carrascal et al., 1982) and fixed environmen- 
tal factors as light and temperature are mentioned as less disturbing than noise produced by people (Ladwig, 1979).

In the following sections the relationship between the independent and the dependent variables was estimated empirically.

\subsection{Demographic variables}

Information on several demographic variables was collected. It concerned the variables age, marital status, having children, education and profession. Information on these variables is presented in Table 6.6.

Of these variables, only age correlated significantly with the quality of sleep in the hospital in general $(r=.18, p \leq .01)$ and on night $1(r=.14, p \leq .05)$. The older the patients were, the better their sleep was in the hospital.

Table 6.6 Demographic variables: descriptive statistics $(n=141)$.

\begin{tabular}{|c|c|c|c|}
\hline & Mean (sd) & Empirical range & $n(\%)$ \\
\hline Age & $52.0(11.6\}$ & $29-70$ & \\
\hline \multicolumn{4}{|c|}{ Marital status } \\
\hline & & & $105(74 \%)$ \\
\hline & & & $35(25 \%)$ \\
\hline $\mathbf{\square}$ & & & $1(1 \%)$ \\
\hline Child & & & $115(82 \%)$ \\
\hline Child & & & $63(44 \%)$ \\
\hline \multicolumn{4}{|c|}{ Education } \\
\hline$\square$ & & & $37(27 \%)$ \\
\hline 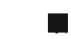 & & & $47(34 \%)$ \\
\hline & chool & & $50(36 \%)$ \\
\hline$\square$ & & & $4(3 \%)$ \\
\hline & & & $-\cdot$ \\
\hline \multicolumn{4}{|c|}{ Profession } \\
\hline & & & $34(24 \%)$ \\
\hline & & & $45(32 \%)$ \\
\hline & & & $18(13 \%)$ \\
\hline & & & $16(11 \%)$ \\
\hline 무 & I businesses & & $26(19 \%)$ \\
\hline & fessionals & & $1(1 \%)$ \\
\hline
\end{tabular}

Although there was no significant increase in sleep medication prescription or administration as reported in the nursing notes, older people reported using significantly more sleep medication $(r=.13, p \leq .05)$. Older patients, however, experienced less change in sleep quality compared to home than younger patients $\langle r=-.21, p \leq .01\rangle$. 
All other demographic variables did not correlate significantly with the quality of sleep or the sleep medication prescribed and administered.

\subsection{Environmental variables}

Hospitalization is certainly a change in environment compared to home. Sleeping in a strange bed and sharing the room with one or more patients are some of the factors possibly contributing to these differences. Patients were asked about the quality of the bed they used (Table 6.7), whether they had problems sharing the room with others, and if they experienced this as a lack of privacy. Sixty-six per cent of the population considered their bed at home better than in the hospital. Sixteen per cent (23) of the patients felt the bed was too small. in this study $72 \%$ of the patients had to share the room with at least two or more patients (Table 6.8).

Table 6.7 The quality of the bed $(n=141)$.

n $\quad(\%)$

\begin{tabular}{cc}
\hline Bed at home better & $93(66 \%)$ \\
no difference & $39(28 \%)$ \\
too hard & $12(9 \%)$ \\
too small & $23(16 \%)$ \\
too high & $7(5 \%)$
\end{tabular}

Thirty $(21 \%)$ patients had problems sharing the room with others and would have preferred to have a room of their own. Of these patients 14 experienced it as a lack of privacy. In total $28(20 \%)$ patients reported a lack of privacy.

Table 6.8 Roommates $(n=141)$.

\begin{tabular}{|c|c|}
\hline Number of roommates: & $\begin{array}{rr}0 & 9 \% \\
1 & 20 \% \\
2 & 26 \% \\
3 & 10 \% \\
4 & 14 \% \\
5 & 22 \%\end{array}$ \\
\hline
\end{tabular}

Environmental variables such as noise, light, temperature and fresh air are less controllable by patients in the hospital compared to home. During the first interview patients were asked about these environmental variables during their hospital stay. The change in environment was estimated because the literature showed that a change of normal sleep environment can disrupt the sleep pattern. In addition patients who were used to sleeping in a noisy environment would not experience the ward as too noisy. This also applies to the other environmental variables. The majority of the patients reported more noise, more 
or equal light, a higher or equal temperature and less fresh air in the hospital when compared with the home situation (Table 6.9).

Table 6.9 Environmental changes in the hospital in general compared with home as reported by the patients $(n=141$ ).

\begin{tabular}{lrrrr}
\hline & Noise & Light & Temperature & Fresh air \\
\hline Less/lower & 5 & 7 & 9 & 87 \\
Equal & 36 & 62 & 62 & 45 \\
More/higher & 100 & 72 & 70 & 7 \\
\hline Total & 141 & 141 & 141 & 139 \\
\hline
\end{tabular}

Table 6.10 shows the correlations between sleep quality in general and during a specific night with the environmental variables mentioned so far.

No difference in sleep quality could be found for the three variables concerning the quality of the bed separately and when summed ("quality of bed"). Since the two variables "quality of bed" and "bed compared to home" correlated significantly $(r=.26, p \leq .001)$, it was decided to include only the latter in the further analyses.

Table 6.10 Pearson correlation coefficients between environmental variables and quality of sleep $(n=141)$.

\begin{tabular}{llll}
\hline & \multicolumn{3}{c}{ Sleep quality } \\
\cline { 2 - 4 } & $\begin{array}{c}\text { Specific } \\
\text { night }\end{array}$ & In general & $\begin{array}{c}\text { Change in } \\
\text { sleep quality }\end{array}$ \\
\hline Noise & -.10 & $-.19^{* *}$ & $.15^{*}$ \\
Light & -.08 & $-.20^{* *}$ & $.15^{*}$ \\
Temperature & -.02 & -.09 & .10 \\
Fresh air & $-.17^{*}$ & -.11 & .05 \\
The bed compared to home & -.12 & $-.13^{*}$ & $.23^{* *}$ \\
Number of roommates & -.05 & .06 & .00 \\
Too many roommates & $-.18^{* *}$ & $-.11^{* *}$ & $.17^{* *}$ \\
Lack of privacy & $-.14^{*}$ & $-.21^{* *}$ & .08 \\
\hline
\end{tabular}

$* p \leq .05 * p \leq .01$

All environmental variables, except temperature and the number of roommates, correlated significantly with sleep quality either during a specific night or in general. As one would expect, more noise, more or equal light, less fresh air, a worse bed than at home and experiencing lack of privacy were related to a poor quality of sleep. The difference in sleep quality correlated in the same direction with the environmental variables as the other two dependent variables, sleep quality at a specific night and in general in hospital. The greater the change in the environment, the larger the difference is in sleep quality between home and the hospital. The variable "lack of privacy" did correlate significantly with sleep quality at a specific night and in general in hospital but not with the change in 
sleep quality. Probably patients experiencing a lack of privacy, sleep poorly at home.

The number of roommates did not correlate significantly with the quality of sleep however it did correlate $(r=.17, p \leq .05)$ with the amount of sleep medication received, as reported by the patient. The more patients in one room, the more sleep medication they thought they received. There was, however, no significant correlation with the amount of sleep medication prescribed and administered as reported in the nursing notes. This difference between the patients' reports and the nursing notes may be explained in two ways: either the patients label more medications which they receive in the evening as sleep medication or the nurses do not record all sleep medication given. The sleep medication prescribed and administered, as reported by the nurses and the patients, did not correlate significantly with either of the other environmental variables.

\subsection{Personal characteristics}

Personal characteristics included the following variables: trait anxiety, morningness/eveningness, coping, satisfaction and sleeping habits such as eating before going to bed, and sleeping alone in bed, sleep quality and the use of sleep medication during previous admissions.

The Utrecht Coping Questionnaire (UCL) was used to assess coping style. Factor analysis of this 26-item questionnaire resulted in five factors (Appendix B) with sufficient reliability. The item composition of the five factors is presented in Table 6.11. For conceptual clarity four items were placed in other factors namely "Showing one's anger with those responsible for the problem", "Trying to avoid difficult situations as much as possible". "Telling oneself that other people also have problems" and "Realising every cloud has a silver lining". Descriptive statistics for the personal characteristics are presented in Table 6. 12.

Factor analysis of the satisfaction list extracted one factor explaining $70 \%$ of the variance and indicating a unidimensional scale (Appendix C). Therefore a mean score was estimated for satisfaction, leaving out three items of which two were not often answered by the patients because they thought they did not apply. It concerned the items "Support with potential personal problems" and "Opportunity to discuss personal problems". The third item "The introduction to the ward" was omitted also because of many missing values. 
Table 6.11 Five coping styles.

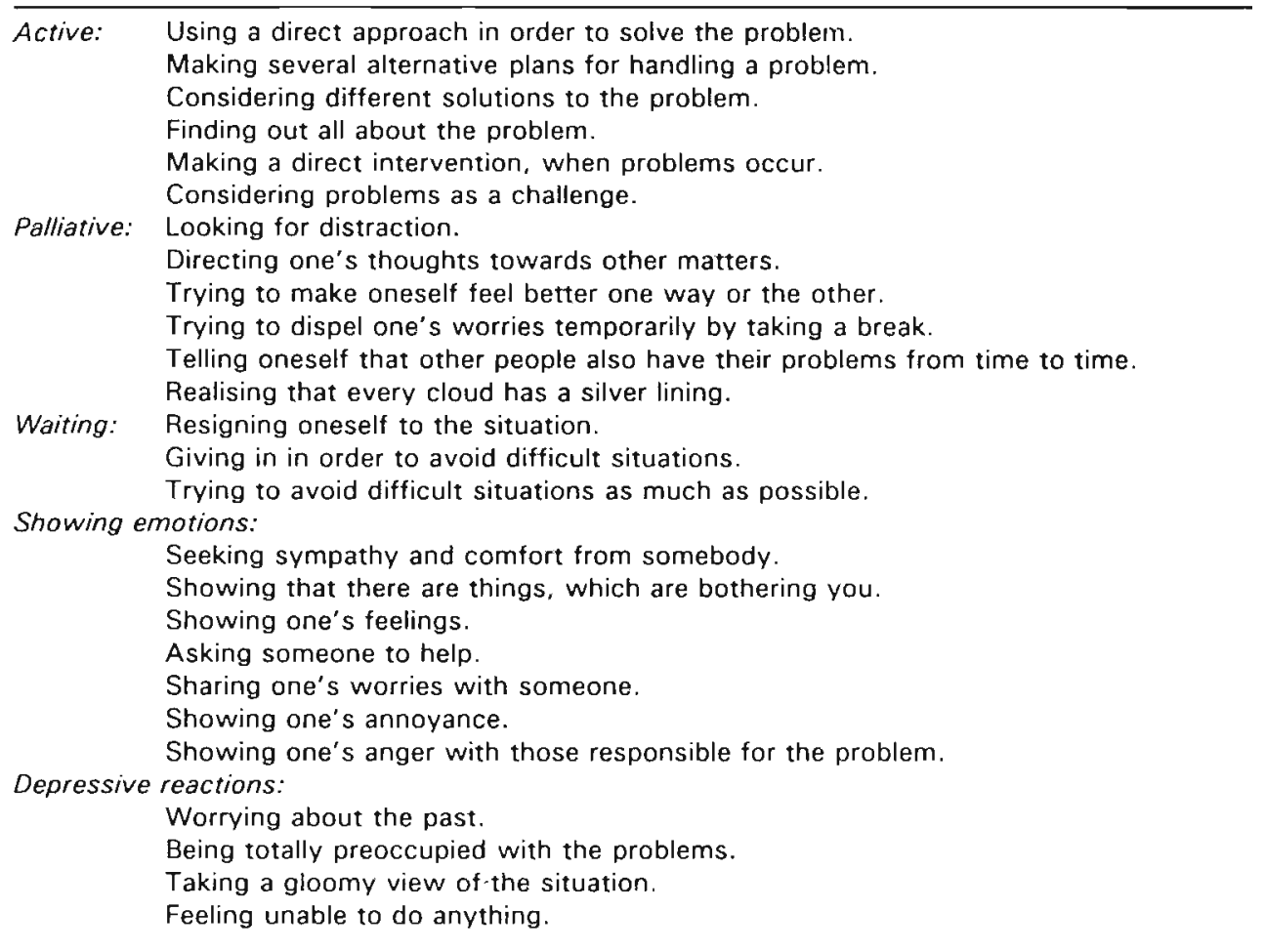

Figures on bedtime, waking time, frequency and duration of napping at home and in hospital have been omitted because these were presented earlier in Chapter 5 (Tables 5.1, 5.2 and 5.3). However, the changes in these habits in hospital are entered as independent variables in the analyses.

Pearson correlation coefficients between the personal characteristics and sleep quality were computed and are presented in Table 6.13.

Except for morningness/eveningness, the coping styles "palliative coping" and "showing emotions", and change in bedtime, all variables correlated significantly with quality of sleep, either in general or for a specific night.

Patients who are less satisfied with their hospital stay had a poorer quality of sleep. The more anxious people are, the worse their sleep quality is. The more people cope actively with their problems, the worse their quality of sleep in the hospital. In hospital the people may not have the means to change the situation to improve their sleep. People with depressive reactions to problems also had a poor quality of sleep. 
Table 6.12 Personal characteristics: Descriptive statistics $(n=141)$.

\begin{tabular}{|c|c|c|c|}
\hline & Mean (sd) & Empirical range & n $(\%)$ \\
\hline Trait anxiety & $39.6(11.3)$ & $20-72$ & \\
\hline Morningness/eveningness & $21.4 \quad(4.8)$ & $7-30$ & \\
\hline $\begin{array}{l}\square \text { evening types }(<15) \\
\square \text { morning types }(>21)\end{array}$ & & & $\begin{array}{l}13(10 \%) \\
70(56 \%)\end{array}$ \\
\hline Satisfaction & $7.6(1.2)$ & $3.5-10$ & $70(56 \%)$ \\
\hline \multicolumn{4}{|l|}{ Coping: } \\
\hline active & $15.5 \quad(3.7)$ & $6-24$ & \\
\hline palliative & $15.0 \quad(3.4)$ & $6 \cdot 24$ & \\
\hline waiting & $6.2(2.2)$ & $3-12$ & \\
\hline showing emotions & $15.3 \quad 3.9\}$ & $7-28$ & \\
\hline depressive reactions & $8.3\{3.1\}$ & $4-15$ & \\
\hline \multicolumn{4}{|l|}{ Sleeping habits': } \\
\hline alone in bed & & & $64(45 \%)$ \\
\hline warm meal in the evening & & & $99(70 \%)$ \\
\hline \multicolumn{3}{|l|}{ activity level in the evening } & $94(67 \%)$ \\
\hline$\square$ relaxing & & & $105(75 \%)$ \\
\hline$\square$ activities & & & $15(11 \%)$ \\
\hline$\square$ relaxing and activities & & & $20(14 \%)$ \\
\hline awakened too early & & & $61(43 \%)$ \\
\hline \multicolumn{4}{|l|}{$\begin{array}{l}\text { Previous admissions: } \\
\text { Q sleep quality }\end{array}$} \\
\hline$\square$ very poor & & & $13(9 \%)$ \\
\hline$\square$ poor & & & $39(28 \%)$ \\
\hline$\square$ moderate & & & $17(12 \%)$ \\
\hline$\square$ good & & & $41(29 \%)$ \\
\hline$\square$ very good & & & $7(5 \%)$ \\
\hline$\square$ do not know & & & $11(8 \%)$ \\
\hline \multicolumn{4}{|l|}{ sleep medications } \\
\hline$\square$ never & & & $68(48 \%)$ \\
\hline sometimes & & & $19(14 \%)$ \\
\hline$\square$ mostly & & & $10(7 \%)$ \\
\hline$\square$ always & & & $22(16 \%)$ \\
\hline$\square$ do not know & & & $9(6 \%)$ \\
\hline
\end{tabular}

"at home except the variable "awakened too early"

As one would expect, a change in sleeping habits was related to a poor quality of sleep in the hospital. Hospitals have their own routines which are not always the same as those of patients. The warm meal in the hospital is served at noon, the last meal is around $5 \mathrm{p} . \mathrm{m}$. and doing the things you are used to doing at home in the evening is not always possible in the hospital. Patients who were used to sleeping alone in bed had a better sleep quality in the hospital than those who were not used to sleeping alone in bed. Patients who were used to having their warm meal in the evening and who were used to eating something before going to bed had a worse sleep than those who had their warm meal 
around noon and were not used to eating something in the evening before going to bed. All these variables correlated in the same direction with sleep quality; that is, the more these variables differed from home, the worse the quality of sleep was. Finally patients who slept poorly during previous admissions and used sleep medication were shown to sleep poorly during subsequent admissions.

Table 6.13 Pearson correlation coefficients between personal characteristics and sleep quality $(n=141)$.

\begin{tabular}{|c|c|c|c|}
\hline & & eep quality & \\
\hline & $\begin{array}{c}\text { Specific } \\
\text { night }\end{array}$ & $\begin{array}{r}\text { In general } \\
\text { sle }\end{array}$ & $\begin{array}{l}\text { ange in } \\
\text { quality }\end{array}$ \\
\hline Trait anxiety ${ }^{+}$ & $-.20^{* *}$ & $-.32 * *$ & -.08 \\
\hline Morningness/eveningness & -.02 & -.03 & .09 \\
\hline Satisfaction ${ }^{\dagger}$ & $.24^{*}$ & .09 & -.10 \\
\hline Coping: & & & \\
\hline active & -.07 & $-.20^{* *}$ & .10 \\
\hline palliative & -.00 & -.14 & .02 \\
\hline waiting &. .06 & $-.16^{*}$ & .08 \\
\hline a showing emotions & -.11 & -.12 & .09 \\
\hline depressive reactions & $-.20 * *$ & $-.22 * *$ & -.11 \\
\hline Sleep habits: & & & \\
\hline bedtime ${ }^{1, *}$ & .06 & -.11 & .09 \\
\hline waking time $\mathrm{w}^{\mathrm{t}, \mathrm{s}}$ & $-.22 \cdots$ & .00 & .01 \\
\hline frequency of napping" &. .04 & .07 & $-.17^{*}$ \\
\hline duration of napping ${ }^{\circ}$ & -.05 & $.16^{*}$ & $-.20^{*}$ \\
\hline alone in bed at home & -.07 & $-.15^{*}$ & $-.14^{*}$ \\
\hline warm meal & -.10 & $-.21^{* *}$ & $.15^{*}$ \\
\hline a eating before going to bed & -.03 & $-.18^{* *}$ & $.15^{*}$ \\
\hline activity level in evening & -.12 & $-.15^{*}$ & .09 \\
\hline awakened too early ${ }^{\dagger}$ & $-.36 * * *$ & $-.24 * *$ & $.24 * *$ \\
\hline Sleep quality previous admissions & -.13 & $-.35 * *$ & -.00 \\
\hline Sleep medication previous admissions & -.11 & $-.20^{* *}$ & $-.19^{*}$ \\
\hline
\end{tabular}

$* p \leq .05 * p \leq .01 * * p \leq .001$

measured during the second interview

change in bedtime and waking time compared to home (bedtime at home - bedtime night 2 and waking time at home - waking time night 2)

change in frequency and duration of napping compared to home

The change in sleep quality correlated only with variables belonging to the sleeping habits and the variable on the use of sleep medications during previous admissions. The variables which correlated significantly with sleep quality on a specific night or in general in hospital and not with the difference score of sleep quality were variables which probably influence the sleep quality at home too.

In contrast to sleep quality, the use of sleep medication did correlate significantIy with the morningness/eveningness score $(r=.18, p \leq .01)$. Morning people received significantly more sleep medication than evening people and had more sleep medication prescribed $(r=.14, p \leq .05)$. The dependent variables on sleep medication either prescribed, administered or received, as reported by the pa- 
tients, correlated with fewer independent variables than sleep quality. Patients who did use sleep medication during previous admissions had more sleep medication prescribed $(r=.31, p \leq .01)$ and administered $(r=.37, p \leq .001)$ than those who did not receive sleep medication during previous admissions. All other personal factors did not correlate significantly with sleep medication, neither prescribed nor administered.

\subsection{Disease-related variables}

The following variables were categorized as disease-related: clinical diagnosis, surgical or medical, length of stay, pain, well-being estimated on two occasions, seriousness of the diagnosis as reported by the patient, state anxiety, worrying about the situation at home after discharge, previous admissions, the medication used at night 2, and the consequences of the diagnosis for the position in bed. Descriptive statistics of these variables are presented in Table 6.14.

Table 6.14 Disease-related variables: Descriptive statistics $(n=141)$.

\begin{tabular}{|c|c|c|c|}
\hline & Mean (sd) & Empirical range & $\mathrm{n}(\%)$ \\
\hline \multicolumn{4}{|l|}{ Clinical diagnosis: } \\
\hline$\square$ medical & & & $76(54 \%)$ \\
\hline a surgical & & & $65(46 \%)$ \\
\hline Length of stay & $21.3(15.3)$ & $5-98$ & \\
\hline Pain & $3.1(2.8)$ & $0-10$ & \\
\hline Well-being (interview 1) & $6.2(2.2)$ & $0-10$ & \\
\hline Well-being (interview 2) & $6.1(2.4)$ & $0-10$ & \\
\hline Seriousness of the diagnosis & $3.1(1.5)$ & $1-4$ & \\
\hline State anxiety & $40.8(11.0)$ & $20-72$ & \\
\hline \multicolumn{4}{|c|}{ Worrying about home after discharge: } \\
\hline$\square$ no & & & $79(56 \%)$ \\
\hline$\square$ sometimes & & & $34(24 \%)$ \\
\hline$\square$ often & & & $28(20 \%)$ \\
\hline Previous admissions & & & $132(94 \%)$ \\
\hline Pain medication & & & $27(19 \%)$ \\
\hline Tranquilizers & & & $17(12 \%)$ \\
\hline Sleep medication & & & $33(23 \%)$ \\
\hline Bedrest & & & $39(28 \%)$ \\
\hline Impaired position in bed & & & $64(45 \%)$ \\
\hline Different position & & & $53(38 \%)$ \\
\hline
\end{tabular}


The majority of the variables correlated significantly with quality of sleep. Exceptions were clinical diagnosis, length of stay, number of pıevious admissions, bedrest and medication used (Table 6.15), which were also the most objective of the disease-related variables estimated. All other variables had a clear subjective element. All the variables correlated in the same direction with quality of sleep. The more pain, anxiety, and worry and the worse the patient feels, the poorer is the quality of sleep. The more serious the diagnosis as was perceived by the patient, the worse the quality of sleep. A change in position or an impaired position was related to a poor quality of sleep.

The variables which correlated with the quality of sleep on a specific night or in general in hospital but not with the change in sleep quality compared to home are probably more personal characteristics than disease-related variables and therefore also influence the sleep quality at home. The number of previous admissions correlated significantly with the change in sleep quality: the fewer the admissions, the greater the difference in quality of sleep in hospital compared to home. In other words, the more acquainted a patient is with hospital routines the better he/she sleeps; or it may be that the medical diagnosis is that serious resulting in more admissions and a poor sleep quality at home too.

Table 6.15 Pearson correlation coefficients between disease-related variables and sleep quality ( $\mathrm{n}=141)$.

\begin{tabular}{|c|c|c|c|}
\hline \multirow[b]{3}{*}{ Worrying about home after discharge } & \multicolumn{3}{|c|}{ Sleep quality } \\
\hline & \multirow{2}{*}{$\begin{array}{c}\begin{array}{c}\text { Specific } \\
\text { night }\end{array} \\
-.05\end{array}$} & \multicolumn{2}{|c|}{$\begin{array}{c}\text { In general Change in } \\
\text { sleep quality }\end{array}$} \\
\hline & & $-.22 * *$ & -.02 \\
\hline State anxiety & $-.28 *$ & $-.35 *$ & .01 \\
\hline Pain $^{\dagger}$ & $-.24 * *$ & $-.42^{* *}$ & .09 \\
\hline Well-being (interview 1) & $.30 * *$ & $.32 * *$ & $-.22 *$ \\
\hline Well-being (interview 2) & $.38^{* * *}$ & $.31 * *$ & $-.17^{*}$ \\
\hline Seriousness of the diagnosis & -.00 & $-.20^{* *}$ & -.02 \\
\hline Length of stay & .02 & -.04 & .08 \\
\hline Clinical diagnosis & -.05 & .01 & .06 \\
\hline Number of previous admissions & .00 & $\cdot, 12$ & $-.18^{* *}$ \\
\hline Pain medication $^{\dagger} \quad .09$ & .01 & -.00 & \\
\hline Tranquilizers ${ }^{\natural}$ & .01 & .02 & .04 \\
\hline Sleep medication ${ }^{\dagger}$ & .05 & .03 & -.10 \\
\hline Bedrest & -.07 & -.03 & .11 \\
\hline Impaired position in bed & $-.14^{*}$ & -.02 & $.22 *$ \\
\hline Different position & $-.26 * *$ & -.11 & $.30 \cdots$ \\
\hline
\end{tabular}

$* p \leq .05 * p \leq .01 * * p \leq .001$

'measured during the second interview 
Sleep medication prescriptions were only significantly correlated with pain $(r=.16, p \leq .05)$ and the variable "worrying about home after discharge" $(r=.13, p \leq .05)$. In addition, patients who received sleep medication on night 2 also received significantly more pain medication $(r=.15, p \leq .05)$ than those who did not receive any on that night. However, the amount of sleep medication received, as reported by the patient, did correlate with other variables, namely pain $(r=.28, p \leq .01)$, bedrest $(r=.13, p \leq .05)$, impaired position $(r=.13$ $p \leq .05)$, and the number of previous admissions $(r=.13, p \leq .05)$. Surgical patients received more sleep medication on night $2(r=.16, p \leq .05)$ and reported receiving more sleep medication during their hospital stay $(r=.18, p \leq .01)$ than medical patients.

The remaining disease-related variables did not correlate with sleep medication, either prescribed or used.

\subsection{Regression analysis}

To find out which of the variables analyzed in this chapter were the most important in predicting the quality of sleep in the hospital, a regression analysis was performed. Twenty-eight variables correlated with sleep quality in general or on a specific night. They included one demographic variable, six environmental variables, 13 personal characteristics and eight disease-related variables. In order to reduce the number of variables a factor analysis was performed for the personal and disease-related variables, and some of the environmental variables were grouped together to form a new variable.

The variables noise, light and fresh air were dichotomized (no change/change compared with homel and summed creating a new variable called "environmental changes" $(\alpha=.33)$. Although the internal consistency appears to be very low, the new variable is used in the analysis because its components all correlated in the same direction with quality of sleep in the hospital. The newly constructed variable is only used in the analysis for the correlation with the quality of sleep in the hospital. Temperature was not used in this construct because it did not correlate significantly with either of the dependent variables on sleep quality.

The variables "too many patients in the room" and "lack of privacy" correlated significantly $(r=.32, p \leq .001)$ and therefore one variable was created out of these two variables called "privacy", based on the median. Patients with scores on both variables below the median scored 1 on the new variable, and both above the median scored 3 . The other two possibilities received score 2 on the new variable "privacy".

The personal characteristics and the disease-related variables which were significantly correlated with the quality of sleep, with the exception of sleeping habits, the position in bed, sleep quality and use of sleep medication during previous admissions, were factor analyzed together because there were obvious subjective elements within the disease-related variables when compared to personal variables. It was decided to include the palliative coping style because it correlated significantly with sleep quantity $(r=.25, p \leq .01)$. Factor analysis of 
these variables revealed three factors as shown in Table 6.16.

Table 6.16 Factor loadings after varimax rotation with three factors.

\begin{tabular}{llll}
\hline & fac1 & fac2 & fac3 \\
\hline Coping (depressive) & .78 & & \\
Trait anxiety & .71 & -.30 & \\
Coping (waiting) & .59 & & \\
State anxiety & .56 & -.55 & \\
Worrying about home after discharge & .48 & & \\
Seriousness of the diagnosis & .43 & -.34 & \\
Well-being (interview 2) & & .79 & \\
Well-being (interview 1) & -.24 & .72 & -.40 \\
Satisfaction & .24 & .55 & .84 \\
Coping (palliative) & & & .82 \\
Coping (active) & & & .39 \\
Pain & .35 & -.25 & \\
\hline
\end{tabular}

These three factors were labeled as worry, well-being and coping and showed sufficient reliability (Table 6.17). Pain was added to factor 1 for conceptual reasons and besides the factor loadings did not differ significantly between the two factors.

Table 6.17 Factors with their reliability coefficients.

factor 1: worry (depressive, trait anxiety, waiting, state anxiety, worrying about home, seriousness diagnosis, pain) $a=.70$

factor 2: well-being (well-being interview 1, well-being interview 2, satisfaction) $a \ldots .67$

factor 3: $\quad$ cope (active, palliativel $\sigma=.68$

The variables on sleeping habits and position were also factor analyzed but produced no results. Two separate variables were formed for the sleeping habits and the position in bed. The variables on sleeping habits (warm meal, eating before going to bed, activity level in the evening), which all correlated significantly with sleep quality in the hospital, were dichotomized (no change/change compared with home) and summed $(\alpha=.01)$. Again, only the correlation with sleep quality in the hospital was computed.

The variables frequency and duration of napping have been omitted because the meaning of napping is not clear. Do patients nap because of the change in daily rhythm in hospital, which has consequences for the sleep at night, or because of the sleep loss at night? 
Table 6.18 Pearson correlation coefficients between standardized factors and sleep quality ( $n=141$ ).

\begin{tabular}{lccc}
\hline & \multicolumn{3}{c}{ Sleep quality } \\
\cline { 2 - 4 } & $\begin{array}{c}\text { Specific } \\
\text { night }\end{array}$ & \multicolumn{2}{c}{$\begin{array}{c}\text { In general Change in } \\
\text { sleep quality }\end{array}$} \\
\hline Age & $.14^{*}$ & $.18^{*}$ & $-.21^{* *}$ \\
Environmental changes & $-26^{* *}$ & $-.29^{* *}$ & $-.16^{*}$ \\
Bed & -.12 & $-.13^{*}$ & $.23^{* *}$ \\
Privacy & $-.20^{* *}$ & $-.22^{* *}$ & $.17^{*}$ \\
Worry & $-.27^{* *}$ & $-.41^{* *}$ & -.05 \\
Coping & -.04 & $-.20^{* *}$ & .07 \\
Well-being & $.36^{* * *}$ & $.36^{* * *}$ & $-.22^{* *}$ \\
Sleep quality previous admissions & .13 & $.35^{* * *}$ & .00 \\
Sleep medication previous admissions & -.11 & $-.20^{* *}$ & $-.19^{* *}$ \\
Sleeping habits & -.06 & $-.23^{* *}$ & $.24^{* *}$ \\
Position in bed & $-.21^{* *}$ & $-.07^{*}$ & $.27^{* *}$ \\
Being awakened too early' & $-.36^{* * *}$ & $-.24^{* *}$ & $.24^{* *}$ \\
Alone in bed & -.08 & $-.15^{*}$ & $.14^{*}$ \\
\hline
\end{tabular}

*p $p .05 * p \leq .01 * * * p \leq .001$

+ determined during the second interview

The two variables on the position in bed were standardized and also summed $(r=.82, p \leq .001)$. The variables "being awakened too early" and "sleeping alone in bed" were kept separately in the regression analysis.

In summary, 13 factors remained for the regression analysis. Table 6.18 shows the correlation coefficients between the standardized independent variables and the dependent variables. It was decided to omit satisfaction from the well-being scale because of the large number of missing values. The factor "being awakened too early" was not included in the regression analysis for the specific night because it applied to night 2 .

Stepwise regression analyses were performed with sleep quality in general in hospital, on a specific night (night 1) and the change in sleep quality compared to home, as the dependent variables and the independent variables as presented in Table 6.18. Sleep quality at home was significantly correlated with sleep quality in the hospital in general $(r=.44, p \leq .001)$ and with sleep quality at a specific night $(r=.23, p \leq .01)$. Therefore it was included in the regression analysis. The figures of the regression analysis are presented in Table 6.19.

One would expect the variable "use of sleep medication" to act as a moderator between the dependent and independent variables because it is offered with the intention to improve sleep. However, it is not possible to correct for the influence of sleep medication because there was no clear policy in offering sleep medication. Patients who sleep poorly do not necessarily receive sleep medication and in addition patients using sleep medication had even a worse sleep than patients who did not. This seems to be supported by the analysis of variance in which no interaction effect could be estimated between the use of sleep medication and other dependent variables (Table 1 Appendix D). 
Table 6.19 Stepwise regression analysis with sleep quality in hospital and the change in sleep quality as dependent variables $(n=141)$.

\begin{tabular}{lcccc}
\hline & \multicolumn{4}{c}{ Sleep quality in general } \\
\cline { 2 - 5 } & entered at step & $\mathrm{R}^{2}$ & $\mathrm{~B}^{\dagger}$ & $\mathrm{sr}^{+}$ \\
\hline Sleep quality at home & 1 & .19 & .37 & .36 \\
Well-being & 2 & .28 & .27 & .32 \\
Sleeping habits & 3 & .34 & -.21 & -.21 \\
Environmental changes & 4 & .37 & -.19 & -.23 \\
\hline
\end{tabular}

\begin{tabular}{|c|c|c|c|c|}
\hline & \multicolumn{4}{|c|}{ Sleep quality at night 1} \\
\hline & entered at step & $\overline{\mathrm{R}^{2}}$ & $B^{\dagger}$ & $s r^{+}$ \\
\hline Worry & 1 & .07 & -- & -. \\
\hline Environmental changes & 2 & .12 & -.23 & -.23 \\
\hline Position in bed & 3 & .17 & -.28 & -.27 \\
\hline Well-being & 4 & .20 & .23 & .22 \\
\hline Worry (removed) & 5 & .18 & -- & .- \\
\hline \multirow[t]{3}{*}{ Sleep quality at home } & 6 & .23 & .22 & .21 \\
\hline & \multicolumn{4}{|c|}{ Change in sleep quality } \\
\hline & entered at step & $\mathrm{R}^{2}$ & $B^{1}$ & $\mathrm{sr}^{+}$ \\
\hline Position in bed & 1 & .07 & .29 & .29 \\
\hline Sleeping habits & 2 & .14 & .19 & .19 \\
\hline Well-being & 3 & 20 & -.28 & -.27 \\
\hline Sleep medication during & & & & \\
\hline previous admissions & 4 & .24 & -.24 & -.23 \\
\hline Environmental changes & 5 & .27 & .17 & .16 \\
\hline
\end{tabular}

\footnotetext{
at the final step
}

From the literature it appeared that morning people had more problems than evening people in coping with phase shifts, which is the case in hospitals. Because morningness/eveningness did not correlate with sleep quality, it may act as a moderator between the independent and dependent variables. However, again no interaction effect could be established in an analysis of variance between morningness/eveningness and the other independent variables (Table 2 Appendix D). Estimating the correlations between the independent variables and dependent variables for the morning people and evening people separately showed some differences in these correlation coefficients. However, these differences were not significant.

Six of the 13 variables (including sleep quality at home) entered in the regression equation were found to explain the variance in the dependent variables. The six are "sleep quality at home" (not for the latter regression analysis), "wellbeing", "sleeping habits", "environmental changes", "position in bed", and "sleep medication during previous admissions".

Variables which did not enter the regression analysis, in contrast to what could be expected, such as worry, privacy, sleep quality previous admissions, correlated with certain predictors as shown in Table 6.20. Table 3 in Appendix D 
shows the correlation coefficients between all the independent variables used in the regression analysis.

Table 6.20 Pearson correlation coefficients between independent variables and predictors $(n=141)$.

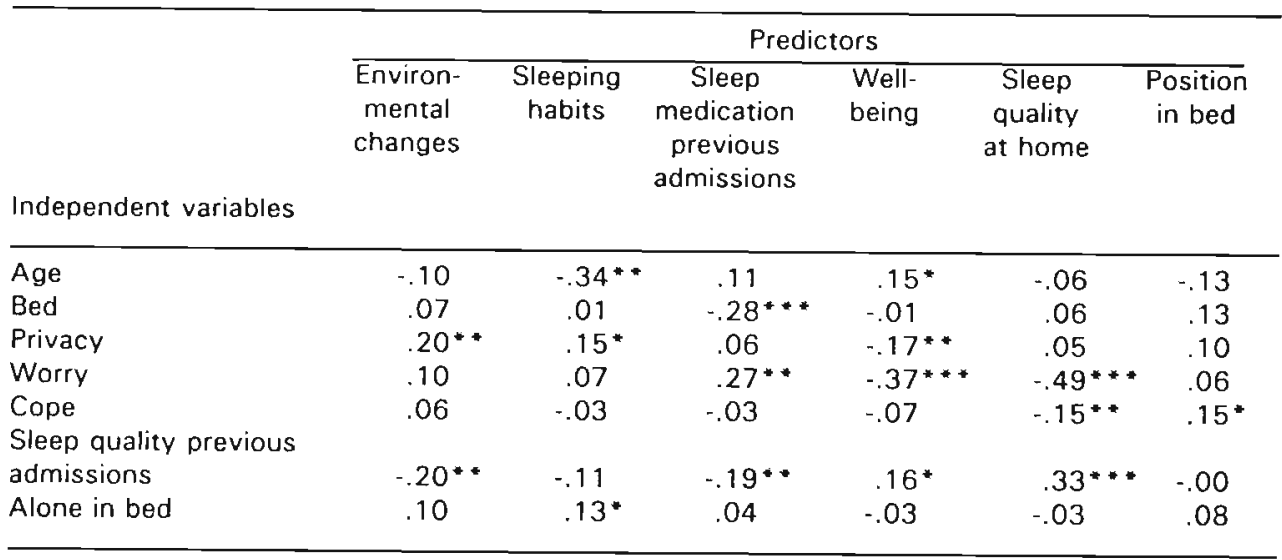

$* p \leq .05 * p \leq .01 * * p \leq .001$

In Figure 6.1 the correlations between the independent variables, the predictors and the dependent variables are presented in a model. Worry correlated significantly with sleep quality at home $(r=-.49, p \leq .001)$, sleep quality and the use of sleep medication during previous admissions, and well-being as shown in Figure 6.1. The latter two variables did enter the regression analysis. These results support the assumption that the variables within the construct worry are more personal characteristics than disease-related variables. The constructs well-being and worrying did not, however, correlate significantly with the "change" variables.

It is emphasized that the independent variables and predictors are coded as follows: The higher the code, the greater the change of that variable in the hospital setting compared to home.

Patients who are used to coping actively with their problems or to doing something about the feelings these problems provoke, experience more changes during hospital admissions, have a worse sleep at home, and have a worse sleep during previous admissions.

Patients experiencing privacy problems in hospital also experience more changes in sleep habits and environment and feel worse in hospital.

Previous sleep problems in hospital or use of sleep medication correlated significantly with the "change" variables and well-being. Larger changes in sleep habits and environment were experienced when patients sleep well at home, and the better they sleep at home, the better they felt in hospital. 
Independent

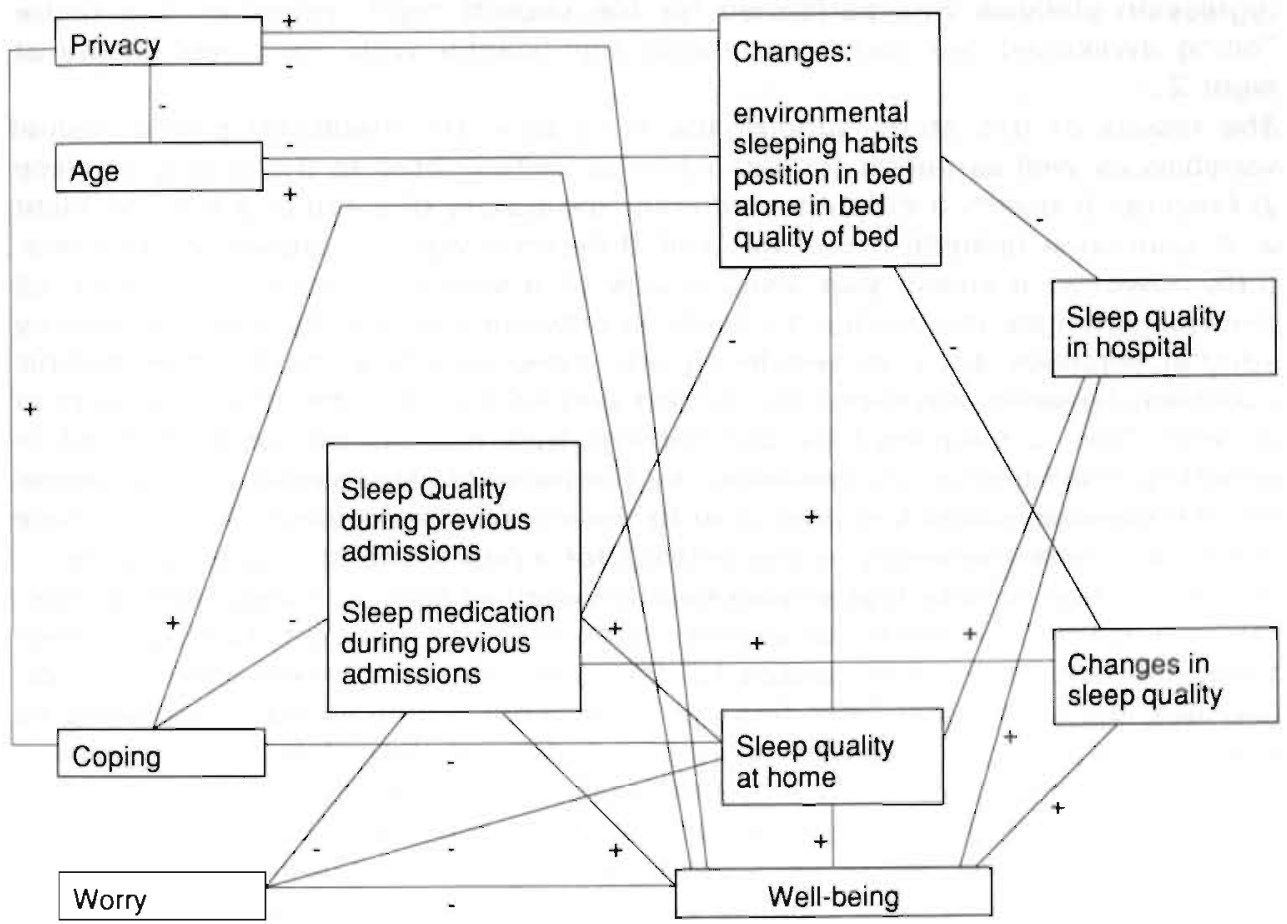

Figure 6.1 Model depicting the relations between the independent variables, the predictors. and dependent variables.

\subsection{Conclusions and discussion}

Many variables such as age, environmental variables, personal characteristics, and disease-related variables, were found to correlate with sleep quality in the hospital. Sleep medication prescribed or administered, however, did correlate only with a few independent variables. This may be attributed to the lack of policy regarding the administration of sleep medication on hospital wards. The variables which did correlate with sleep medication were morningness/eveningness, sleep medication during previous admissions, pain and worrying about home. Due to this lack of policy it was not possible to correct for the influence of sleep medication on the quality of sleep. In this case the expectation could not be sustained that the use of sleep medication acts as a moderator between the 
independent and dependent variables on sleep quality.

The most important factors explaining the variance in sleep quality in a hospital were found to be sleep quality at home, well-being, environmental changes, changes in normal sleep pattern such as sleeping habits, and position in bed.

Because only a few variables were measured during the second interview no regression analysis was performed for the second night. However, the factor "being awakened too early" correlated significantly with the sleep quality at night 2 .

The results of this study support the findings in the literature: Environmental variables as well as personal characteristics were related to the quality of sleep in hospital. It makes a difference whether the quality of sleep of a specific night or in general in hospital is studied. This difference was not studied in the literature, however. It seems that sleep quality of a specific night can be explained more by changes caused by the hospital environment and its routines than by internal variables such as well-being and sleep quality at home. The internal variables, however, explained the largest part of the variance of sleep quality in general. This is supported by the findings that the causes for poor sleep in general in the hospital, as mentioned by the patients, are related more to personal and disease-related variables than to the environmental variables which were mentioned more frequently as the reasons for a poor sleep at a specific night.

It is interesting to note that environmental variables such as noise, light, temperature and fresh air were not expressed by the patients as disturbing to their sleep and not reported as causes for their poor sleep. Of these environmental changes, only the factor "less fresh air" was experienced as disturbing sleep by significantly more patients who had a poor quality of sleep than those who slept well. The other environmental changes were experienced as disturbing to sleep by almost equal numbers of patients with both good and poor quality of sleep. Empirically, however, these environmental changes (noise, light and fresh air) were found to correlate significantly with sleep quality in general as well as on a specific night.

Awakenings were not always considered as part of the quality of sleep despite the fact that frequent awakenings are the sleeping problems most frequently mentioned. Sleeping problems and sleep quality as reported by the patient are perhaps different concepts. In addition a considerable number of patients are awakened at night and in the morning by noise, primarily caused by nurses, roommates and the nursing care of roommates and less so by fixed environmental conditions. Maybe these awakenings and environmental changes are accepted as a consequence of the hospital environment and not considered as causes of poor sleep. The patients who indicated that they were awakened by environmental variables at night 1 did not differ in sleep quality from those patients who were not. Patients who were awakened at night 2 by a nurse or by roommates had a worse sleep than patients who were not awakened. It may be that the fixed environmental variables are not considered as sleep disturbers, while noise caused by nurses or roommates is. This would support the literature and implies that in further studies the cause of the sleep disturbance should be taken into account in research on determinants of sleep problems in hospital settings. 
In the investigation for variables explaining the change in sleep quality compared to home, personal characteristics such as worry and coping seem to be less important. Probably these variables already had their effect on the quality of sleep at home. The variables in which a change occurred during hospitalization, including sleeping habits and the position in bed, and the factor well-being, explained a significant part of the variance of the change in sleep quality compared to home.

Older people seem to experience fewer changes in personal habits when admitted to a hospital. Age is negatively correlated with changes in sleeping habits $(r=-.34, p \leq .001)$, position in bed $(r=-.13, p \leq .05)$, and being awakened too early $(r=.21, p \leq .01)$. Are older people more flexible in their rhythms and therefore perhaps experience fewer changes in sleep quality than younger people or is the strict institutional regime beneficial in preventing desynchronization of the biological rhythms of the elderly? The hospital routines in this respect may provide some clear cues or Zeitgebers to the elderly, thus influencing their sleep quality. It is also possible that older people do not want to complain about their sleep. Further research is needed to answer this question.

Sleep quality during previous admissions correlated significantly with sleep quality in the hospital now and a poor sleep quality during previous admissions may be an indication for a poor quality of sleep in future hospital admissions. This factor did not enter the regression analysis because it correlated significantly with worry $\langle r=.31, p \leq .001)$ and sleep quality at home $(r=.33$, $p \leq .001)$. The latter factor did enter the regression analysis. Morningness/eveningness was expected to act also as a moderator between the dependent and independent variables, but this could not be confirmed in this study. Although it seemed that morning people reacted differently to the hospital admission than evening people, no significan difference regarding the quality of sleep could be found, probably due to a small sample size or the fact that there were only a few evening types in this study.

Changes in environmental and sleeping habits should be avoided as much as possible. Although personal characteristics seem to be less important in explaining the change in quality of sleep compared to home, they should not be neglected by nurses. These variables are related to the quality of sleep in hospital.

For further research on the quality of sleep it is recommended that a distinction is made between the sleep quality of a specific night, sleep quality in general and the change in sleep quality compared to home and between data collected empirically or expressed subjectively by patients. 

Part III

Nursing decisions regarding sleep problems 



\section{$7 \quad$ Sleep medication in a general hospital}

\subsection{Introduction}

Sleep medications are the interventions most frequently planned for sleep problems in hospitals (Johnson, 1985). Sleep medications are often perceived by nurses as well as by patients to be the most important sleep intervention (Reimer, 1987), despite the fact that other nursing interventions would be more appropriate with respect to the cause of the sleep problems (Harris, 1981, Smith, 1985, Todd, 1982). Interventions such as relaxation therapy, back massage, music therapy, pain medications, comfort measures such as position in bed and a comfortable environment, and promoting sleep rituals, such as a nightcap or a light snack (Davignon \& Bruno, 1982, Hoch \& Reynold III, 1986, Johnson, 1985, Milne, 1982, Thomas, 1987) are among the possibilities. In Closs' study (1988b) the majority of the suggestions made by patients to improve sleep concerned environmental factors such as noise reduction and a more comfortable bed. Hypnotics were only suggested by four per cent of the population.

Research on the effects of alternative sleep interventions in hospital has rarely taken place. Research on relaxation therapy is often limited to chronic sleep problems and rarely on situational or transient insomnia. Literature reviews showed that there is support for the therapeutic use of relaxation techniques (Buckwalter, Hartsock, \& Gaffney, 1985, Hyman, Feldman, Harris, Levin, \& Mallory, 1989, Scandrett \& Uecker, 1985) but there is little documentation on the effects of these interventions in nursing studies (Scandrett \& Uecker, 1985). In hospital settings the effects of relaxation therapy and music therapy as preoperative intervention, are measured on pain or anxiety, factors which inhibit sleep. However, results of these studies are often contradictory which may be due to the weak designs used (Scandrett \& Uecker, 1985).

Because sleep medication is still the sleep intervention most frequently offered and often on the initiative of the nurse, the aim of this chapter is to get an impression of the extent of their use in a general hospital.

Study I was an inventarization of the use of sleep medications in three general hospitals based on the following problem statement.

What is the extent of use of sleep medication in a general hospital?

The following research questions were formulated in order to provide an answer.

1) How often are sleep medications prescribed in a general hospital setting?

2) In which form are sleep medications prescribed (standard, as needed or premedication)?

3) How many patients actually receive sleep medication in a general hospital? 
In Study I a sleep medication is defined as every medication ordered to induce sleep, which means that besides the sedative hypnotics registered as sleeping pills (hypnotics) also the minor tranquilizers are reported.

In addition to Study I, data collected in Studies II and III on sleep medications prescribed and administered are also presented here, thus providing in total data from five different hospitals ( $A$ to $E$ ). The methods of those two studies are presented in Chapters 4 and 9. In contrast to Study I, in Studies II and III sleep medications were limited only to hypnotics.

Study $I$ as it is presented in this chapter was part of a master's thesis. Besides the information on sleep medication, nurse characteristics were studied in relation to the administration of sleep medications (Lendfers, 1988). These results, however, are not presented here.

\subsection{Sleep medications}

Sleep medications or hypnotics induce a state which is comparable with sleep but mostly interfere with the normal sleep cycle (Farmacotherapeutisch Kompas, 1989, Todd, 1982). Hypnotics can be divided into benzodiazepines, barbiturates and others such as chloralhydrate, methaqualon, antihistamine and cyclopyrolone (Mendelson, 1989).

In this section only benzodiazepines will be discussed because these are the most frequently prescribed hypnotics (De Berk, 1988). They were introduced in the beginning of the 1960 s replacing the use of barbiturates. Barbiturates had too many serious side effects and a low therapeutic level. Benzodiazepines not only have a sedating effect but also an anxiolytic, anticonvulsive and a muscle relaxing effect. Depending on the dose, benzodiazepines are used as minor tranquilizers, anxiolytics (low dosage) or hypnotics (high dosage). Minor tranquilizers are also prescribed with the aim of inducing sleep. The following benzodiazepines and derivatives are registered as hypnotics in the Netherlands: Diazepam, flunitrazepam, flurazepam, Ioprazolam, lorazepam, lormetazepam, midazolam, nitrazepam, oxazepam, quazepam, and temazepam. Diazepam, lorazepam, and oxazepam are mostly given as tranquilizers to the patients (Farmacotherapeutisch Kompas, 1989).

Sleep medications decrease the sleep latency and arousals during sleep and increase the sleep time and sleep efficiency (time asleep/time in bed). It is well known, however, that hypnotics do affect the sleep structure and do not lead to a natural sleep. The NREM sleep stages 1,3, 4 and REM sleep are decreased by hypnotics and stage 2 and REM sleep latency, the time the first REM sleep occurs are increased. In addition, benzodiazepines suppress the respiratory drive and increase the heart rate during sleep (Anch et al., 1988, Bruyneel, 1986). According to Mendelson (1989), hypnotics have benefits on nocturnal sleep for only a few weeks, while their effect on daytime function has not been documented.

The onset and duration of action of benzodiazepines depend on the absorption rate and the extent of distribution. The metabolic half-life indicates the rate at which the benzodiazepine is eliminated from the system. Long-acting benzodia- 
zepines have active metabolites with a metabolic half-life longer than 24 hours. They may accumulate with multiple use causing serious problems for the elderly and those with impaired liver functions. Long-acting benzodiazepines may also produce daytime hangover when given as hypnotic (higher dosage). Intermediate-acting and short-acting benzodiazepines have half-lives of 4 to 24 hours. Short-acting benzodiazepines are associated with withdrawal effects such as rebound insomnia, REM rebound, early morning awakenings and the likelihood for dependency development (Berlin, 1984, De Berk, 1988). Rebound is the recurrence of complaints which are usually worse than before starting the use of sleep medication. Rebound can also lead to dependence on the use of sleep medication. A measurable rebound in sleep may occur within a single night (Morgan \& Oswald, 1982). Tolerance though should be distinguished from dependency. Tolerance means that the effect of the drug decreases and ever higher doses are necessary to reach the same effect. Tolerance for the sedating effect of benzodiazepines may develop after using the drug for a week. Tolerance for the anxiolytic effect has not been proven (Zitman, 1988).

The ideal hypnotic would be one that (1) has a rapid onset and a duration of action allowing a full night's sleep without morning drowsiness, (2) induces sleep patterns comparable with natural sleep, (3) does not produce dependence, (4) does not precipitate drug withdrawal symptoms or rebound insomnia when discontinued (Simon, 1983). Unfortunately the ideal hypnotic has not been discovered yet, although recent studies with zopicline, a new hypnotic belonging to the cyclopyrrolone class, suggest that it can represent a useful alternative to existing hypnotics (Musch \& Maillard, 1990). In case of transient insomnia related to situational stress such as a hospitalization, Mendelson (1989) recommends small doses of short-acting benzodiazepines but only for a few nights, because withdrawal symptoms can stimulate the use of hypnotics without medical indication.

\subsection{Sleep medication in hospital}

Figures about the use of sleep medication in care settings vary across the different studies conducted. In addition the results of these studies are difficult to compare because of differences in definition of sleep medication, samples used and the design of the study. Definitions of sleep medication varied from "any medication given that induces sleep" (Clapin-French, 1986), "hypnotics" (Closs, 1988b, James, 1985, Morrison \& Mayfield, 1972, Perry \& Albert, 1984, Salzman, 1981), "hypnotics and minor tranquilizers" (Visser, 1984b), "benzodiazepines" (Johnson, 1985) to no clear definition at all (Bayer \& Pathy, 1985, Carrascal et al., 1982, Ladwig, 1979, Leuenberger et al., 1983).

The percentages of sleep medications prescribed in care settings ranged from $2 \%$ (James, 1985 ) in a nursing home to $96 \%$ on surgical wards (Perry \& Albert, 1984). It should be considered that a large number of these prescriptions are never filled or rarely offered on a nightly basis (Morrison \& Mayfield, 1972). In Morrison and Mayfield's study (1972), 85\% of the general surgical patients 
had a standing sleep medication prescription: However, the average number of nights per month patients received a sleep medication was seven.

The actual use of sleep medication in Perry and Albert's study (1984) decreased significantly on medical wards throughout the hospital stay in contrast with surgical wards where the chance of receiving increased. Visser (1984b) also concluded that the length of stay should be considered when estimating the use of sleep medication.

The rationale for prescribing sleep medication is often lacking (Mayfield \& Morrison, 1973, Morrison \& Mayfield, 1972, Perry \& Albert, 1984, Salzman, 1981), and if administered, no notes on the effectiveness or side effects were made by the physician (Perry \& Albert, 1984). In the nurses' notes no correlation could be found between the quality and quantity of sleep and the administration of sleep medication (Perry \& Albert, 1984). According to Clapin-French (1986), sleep medication is administered without much inquiry into the factors promoting the insomnia.

Most orders for sleep medications were on as-needed basis, the filling of these orders is presumably controlled by the nurses (Morrison \& Mayfield, 1972, Perry \& Albert, 1984). Morrison and Mayfield (1972) did find, however, little agreement among nurses about the meaning of as needed prescriptions. The interpretations nurses gave ranged from "if patients requested it and gave evidence of difficulty in sleeping" to "every patient who didn't refuse it". Patients often do not know what they were offered (Ladwig, 1979) and why a certain medication was given (Leuenberger et al., 1983). Routinely prescribing hypnotics by physicians reinforces a drug orientation among patients (Morrison \& Mayfield, 1972) and may contribute to drug tolerance and dependence (Mayfield \& Morrisson, 1972, Regestein \& Barbiasz, 1980).

Although much more study is needed, several authors have affirmed that a consequence of starting patients on hypnotics is that a certain percentage will continue to use them for prolonged periods (Mendelson 1989, Offerhaus, 1988). Clift (1975) found that patients started on nitrazepam or amobarbital had taken them continuously for two years. Van Merwijk (1990) found that patients in a general hospital who used sleep medications for 5 days or longer used significantly more sleep medications at home for a period of six weeks after discharge, than patients who did not use them in the hospital. Both groups had not used sleep medication at home before hospital admission. However, it is possible that patients who used sleep medication were more seriously ill than those who did not and therefore continue using them at home. No information was available on the patients' medical diagnoses in Van Merwijk's study (1990). These results are in contrast to Hengeveld's findings (1982) that the amount of prescriptions at the moment of discharge did not differ from the amount prescribed on admission. However the actual use of sleep medication was not determined.

Sleep medication prescriptions should be based on a clear rationale. Hence, the factors promoting the sleep problems should be carefully assessed first, a plan made, and the appropriate interventions instituted. 


\subsection{Research design}

This section presents only the methods of Study 1. The methods of Studies II and III are presented elsewhere (Chapter 4 and 9).

\subsubsection{Methods}

Study I used a descriptive design and took place on nine surgical and nine medical wards in three hospitals. It was an inventarization of the use of sleep medication. One night a week and for three weeks the prescriptions and the actual use of sleep medications were counted. Information was offered by the nurse on duty during the night shift.

Criteria used to select the wards were:

* 3 surgical and 3 medical wards in each hospital

* no first-class wards

* no children's wards or maternity wards

No first-class wards were selected because more sleep medication is prescribed for first-class patients (Perry \& Albert, 1984). Children's wards and maternity wards were omitted because less sleep medication is used on these wards. The purpose was to select nine comparable medical wards and nine comparable surgical wards.

\subsubsection{Population}

The study population included all the patients staying on the ward on the night the information was collected.

The nine surgical wards involved seven general surgical wards and two wards with a combination of vascular surgery and urology patients. The selection of nine comparable medical wards was impossible. The selection finally fell on three general medical wards and the rest was a combination of oncology, nephrology or gastroentorology. Data on sleep medication prescriptions and the actual use were available on 1076 patients, 536 medical and 540 surgical patients. No further information is available on those patients.

\subsubsection{Instruments}

A questionnaire was developed and was completed by the nurse on the night shift. The questionnaire included information on the prescriptions of sleep medication, the actual use of sleep medication and the number of patients staying on the ward that night.

Information was asked about three kinds of prescriptions, namely standard prescriptions, as needed prescriptions and pre-medications. For each of these prescriptions information was noted on whether or not they were administered. Sleep medications offered without a prescription were recorded separately. The use of sleep medication at home was also asked for in Study II to compare it with the use in hospital. 


\subsubsection{Procedure}

Each ward participated three times in this study. For three weeks on one night a week information was provided by the nurse on the night shift by filling out the questionnaire. Fifty-four nurses were contacted and asked to fill out the questionnaire. Of the 54 nurses $46(85 \%)$ returned the questionnaire. The reason given for the non-response was lack of time. The non-response was equally divided over the three hospitals and between the medical wards and surgical wards.

\subsubsection{Analysis}

The data were analyzed per hospital as well as per study. One surgical ward of hospital $E$ was omitted from the analysis because every patient on that ward received a standard as needed prescription $(n=77)$.

\subsection{Results}

The three Studies, I, II and III provided information on sleep medications. In Studies II and III only the medications registered as hypnotics are counted in contrast to Study I which included minor tranquilizers as well.

This section will address all three research questions together since they are interrelated.Table 7.1 shows the distribution of the sleep medications prescribed and administered for the three studies.

Table 7.1 Prescription and administration of sleep medication in Study I ( $n=999$ ), Study II $(n=141)$ and Study III $(n=241)$.

\begin{tabular}{|c|c|c|c|c|}
\hline & & $\begin{array}{l}\text { Study I } \\
\%\end{array}$ & $\begin{array}{c}\text { Study II } \\
\%\end{array}$ & $\begin{array}{c}\text { Study III } \\
\%\end{array}$ \\
\hline Standard & $\begin{array}{l}\text { prescription } \\
\text { administered }\end{array}$ & $\begin{array}{l}27.0 \\
26.6\end{array}$ & $\begin{array}{l}18.4 \\
15.6\end{array}$ & $\begin{array}{l}10.5^{* * *} \\
10.5 * \cdots\end{array}$ \\
\hline As needed & $\begin{array}{l}\text { prescription } \\
\text { administered } \\
\text { administered }\end{array}$ & $\begin{array}{r}11.5 \\
2.3 \\
1.5\end{array}$ & $\begin{array}{r}12.8 \\
5.0 \\
-.\end{array}$ & $\begin{array}{l}1.3^{* * *} \\
1.3 \\
\cdots\end{array}$ \\
\hline Pre-medication & $\begin{array}{l}\text { prescription } \\
\text { administered }\end{array}$ & $\begin{array}{l}3.5 \\
3.0\end{array}$ & $\begin{array}{l}\cdots \\
\cdots\end{array}$ & $\begin{array}{l}\cdots \\
\cdots\end{array}$ \\
\hline No prescription & administered & $\begin{array}{r}58.0 \\
1.0\end{array}$ & $\begin{array}{r}68.8 \\
2.8\end{array}$ & $\begin{array}{l}88.3 \\
13.4 \ldots\end{array}$ \\
\hline Total & $\begin{array}{l}\text { prescriptions } \\
\text { administered }\end{array}$ & $\begin{array}{l}42.0^{* *} \\
34.4^{*}\end{array}$ & $\begin{array}{l}31.2 \\
23.411\end{array}$ & $\begin{array}{r}11.8(10.0) \\
.0) 25.1(16.7)\end{array}$ \\
\hline
\end{tabular}

${ }^{*} p \leq .05 * * p \leq .001$ during evening shift during night shift ${ }^{i}$ tranquilizers between brackets 
Between $23 \%$ and $35 \%$ of the patients on surgical and medical wards received sleep medication for a specific night during their hospital stay. The amount of sleep medications prescribed varied even more among the three studies: Between $11 \%$ and $42 \%$ of the patients had some kind of sleep medication prescription. Sleep medication was prescribed most often as a standing order in these three studies. As a consequence the amount of sleep medications administered differed significantly $\left(x^{2}=6.05, p \leq .05\right)$ between the studies as well as the amount of sleep medication prescribed $\left(x^{2}=79.81, p \leq .001\right)$ as shown in Table 7.1. Results showed that in Study III significantly less sleep medication was prescribed as a standing order $\left(x^{2}=32.40, p \leq .001\right)$ and as "as needed" prescriptions $\left(x^{2}=24.94, p \leq .001\right)$ than in the other two studies. Even when the pre-medications in Study I were excluded from the analysis, Study I still had the highest rate of prescriptions $\left(x^{2}=64.05, p \leq .001\right)$ and administrations $\left(x^{2}=7.09, p \leq .05\right)$. This high rate could be explained by including minor tranquilizers in the study. When the use of tranquilizers is included the figures of Studies II and III become more comparable with Study I (Table 7.1). The significant difference in the amount of sleep medication administered between the three studies disappears. Another explanation could be that all the patients on the wards participated in Study I, not just those with minor diagnoses, as in Study II and III.

As shown in Table 7.1, the administration of the prescriptions also varied significantly per study. Not all standard prescriptions are actually offered and patients, especially in Study III $\left(x^{2}=91.25, p \leq .001\right)$, received more often sleep medication without prescription. In Study III, on one or more nights before the interview took place, 46 (19\%) patients received sleep medication without prescription. The number of nights ranged from 1 to 7 (mean 2.4). The mean length of stay before the interview was 12.9 days (median 8 ).

The use of sleep medication in the hospital is considerably higher than at home. Of the population of Study II, $12 \%$ mentioned using sleep medication at home almost every night. In the hospital this figure was $20 \%$, which included all the medications mentioned by the patient as sleep medications. These estimates are difficult to compare with other studies such as De Berk (1988), CBS (1986), De Graaf (1984), and Halfens, Drop, \& Philipsen (1984) because of differences in definitions of sleep medications, samples used and the period of use. The figures in Table 7.1 collected from the Kardex, differed from the information patients had given, probably patients do not always know what kind of medication they receive in the evening.

As mentioned before, the amount of prescribed and administered sleep medication varied significantly between the three studies. This variation is probably due to the different hospitals which participated in the studies. Comparing the data from Study I per hospital Table 7.2 showed a significant difference between the hospitals in the total amount of sleep medication prescribed $\left(x^{2}=25.23\right.$, $p \leq .001)$ and administered $\left(x^{2}=6.43, p \leq .05\right)$, with and without prescriptions. Even excluding the ward with the standard as needed sleep medication prescriptions, hospital E had a significantly higher amount of "as needed" sleep medication prescriptions $\left(x^{2}=26.40, p \leq .001\right)$. However, the actual use of sleep medication with an "as needed" prescription did not differ significantly. 
Table 7.2 Percentages of sleep medication prescribed and administered per hospital in Study I ( $N=999)$.

\begin{tabular}{|c|c|c|c|c|}
\hline & & $\begin{array}{c}A \\
(N=245)\end{array}$ & $\begin{array}{c}D \\
(N=386)\end{array}$ & $\begin{array}{c}E \\
(N=368)\end{array}$ \\
\hline Standard & $\begin{array}{l}\text { prescription } \\
\text { administered }\end{array}$ & $\begin{array}{l}28 \\
27\end{array}$ & $\begin{array}{l}22 \\
22\end{array}$ & $\begin{array}{l}32 * * \\
32 * *\end{array}$ \\
\hline As needed & $\begin{array}{l}\text { prescription } \\
\text { administered } \\
\text { administered }\end{array}$ & $\begin{array}{l}7 \\
2 \\
0\end{array}$ & $\begin{array}{l}8 \\
2 \\
2\end{array}$ & $\begin{array}{l}19^{*+*} \\
3 \\
2\end{array}$ \\
\hline Pre-medication & $\begin{array}{l}\text { prescription } \\
\text { administered }\end{array}$ & $\begin{array}{l}4 \\
3\end{array}$ & $\begin{array}{l}5 \\
5\end{array}$ & $1^{*}$ \\
\hline Total & $\begin{array}{l}\text { prescriptions } \\
\text { administered }\end{array}$ & $\begin{array}{l}38 \\
32\end{array}$ & $\begin{array}{l}35 \\
31\end{array}$ & $\begin{array}{l}53^{* * *} \\
38^{*}\end{array}$ \\
\hline \multicolumn{2}{|c|}{ Administered without prescriptions } & 2 & 1 & 1 \\
\hline
\end{tabular}

* $p \leq .05 * * 0 \leq .01 * * p \leq .001$ during evening shift ${ }^{\square}$ during night shift

Omitting the ward with the standard as needed sleep medication prescriptions did not change the percentages of the administered prescriptions significantly. Although the percentages of patients with an as needed sleep medication prescription was $10 \%$ lower, the number of patients who actually received the sleep medication was only $1 \%$ lower for that hospital when the ward with the standard as needed prescriptions was excluded.

Table 7.3 Percentages of sleep medication prescribed and administered per hospital in Study II $(n=141)$.

\begin{tabular}{|c|c|c|c|c|}
\hline & & $\begin{array}{c}A \\
\{n=51\}\end{array}$ & $\begin{array}{c}B \\
(n=60)\end{array}$ & $\begin{array}{c}C \\
(n=30)\end{array}$ \\
\hline Standard & $\begin{array}{l}\text { prescription } \\
\text { administered }\end{array}$ & $\begin{array}{l}14 \\
14\end{array}$ & $\begin{array}{l}22 \\
15\end{array}$ & $\begin{array}{l}20 \\
20\end{array}$ \\
\hline As needed & $\begin{array}{l}\text { prescription } \\
\text { administered }\end{array}$ & $\begin{array}{l}4^{*} \\
\cdots\end{array}$ & $\begin{array}{l}18 \\
10\end{array}$ & $\frac{17}{3^{*}}$ \\
\hline Total & $\begin{array}{l}\text { prescriptions } \\
\text { administered }\end{array}$ & $\begin{array}{l}18 \\
14\end{array}$ & $\begin{array}{l}40^{*} \\
25\end{array}$ & $\begin{array}{l}37 \\
23\end{array}$ \\
\hline \multicolumn{2}{|c|}{ Administered without prescription } & 2 & 5 & -- \\
\hline
\end{tabular}

$\cdot p \leq .05$

In Study 11 the differences between the hospitals were less obvious (Table 7.3). The amount of as needed sleep medication prescribed $\left(x^{2}=5.72, p \leq .05\right)$ and administered $\left(x^{2}=6.34, p \leq .05\right)$ and the total number of prescriptions 
$\left(x^{2}=7.02, p \leq .05\right)$ differed significantly for the three hospitals. However the total amount of medication administered did not differ significantly per hospital.

Hospital B had significantly more prescriptions than the other two hospitals $\left(x^{2}=7.02, p \leq .05\right)$, but it was the only hospital where not all standard sleep medication prescriptions were actually offered. Hospital A had significantly fewer as needed prescriptions than the other two hospitals $\left(x^{2}=5.72, p \leq .05\right)$.

The number of prescriptions whether standard, as needed or the total amount, varied more between the hospitals in Study I than between those in Study II. However, the administration of sleep medications, including the minor tranquilizers did not differ significantly between the hospitals of the two studies.

\subsection{Conclusions and discussion}

It is obvious that more sleep medications are used in the hospital than at home. Sleep medications are prescribed most frequently as a standing order. Due to ward policies there are differences in the number of prescriptions but the administration of sleep medication differs less between hospitals. One may conclude that it does not make any difference for the administration of sleep medication, in which way sleep medications are prescribed. This contrasts with Mayfield and Morrison's (1973) and Morrison and Mayfield's (1972) findings.

Sleep medication is often provided on the initiative of the nurse although in the literature and based on empiral work it was shown that sleep problmes are rarely diagnosed and the effects of sleep medication rarely evaluated. These reasons, among others, emphasize the role that nurses can play in accurately diagnosing sleeping problems and accordingly in instituting appropriate interventions. In Study III the nursing process was introduced to provide a tool to assess the cause of sleep problems so that the most appropriate intervention can be planned, and which in some cases may be the use of sleep medication (Chapter 9). 


\section{$8 \quad$ Problem-solving in nursing}

\subsection{Introduction}

Although sleep problems are more specific than just having a poor sleep and the determinants of these sleep problems are varied, the interventions implemented are often limited to sleep medication. It was clear from the previous chapter that, in contrast to what was expected, the form in which sleep medications are prescribed does not influence the amount of sleep medication actually offered. The question then arises regarding the processes nurses use to decide if sleep problems exist and when sleep medications or other nursing interventions should be used.

The nursing process is viewed basically by many authors as a problem-solving, systematic approach to care delivery (Bulechek \& McCloskey, 1985, Chinn \& Jacobs, 1987, Yura \& Walsh, 1983). It is generally accepted and used as a framework or organizer of this reasoning process (Stevens, 1984). However, little is understood about the mental processes involved in deriving diagnoses or in making clinical judgements, since few studies have been conducted in this area (Putzier, Padrick, Westfall, \& Tanner, 1985).

In order to shed more light on clinical decision processes that nurses use this chapter reviews the literature on the theoretical underpinnings of the nursing process and its related diagnostic processes.

\subsection{The nursing process}

The nursing process, a concept familiar to all nurses today, is often considered as the core and essence of nursing (Yura \& Walsh, 1988). It is a method of problem identification and problem-solving in nursing. Stanton, Paul, and Reeves (1985) define the nursing process as a deliberate intellectual activity through which the practice of nursing is approached in an orderly and systematic manner. Marriner (1979) defines it as the application of scientific problem-solving to nursing care, and McFarlane and Castledine (1983) define it as a systematic method of decision-making and planning. The widely used definition by Yura and Walsh (1983), describes the nursing process as " a designated series of actions intended to fulfill the purposes of nursing to maintain the client's wellness and, if this state changes, to provide the amount and quality of nursing care the situation demands to direct the client back to wellness, and if wellness cannot be achieved, then to contribute to the client's quality of life, maximizing his resources as long as life is a reality". The systematic way of problem-solving and the cognitive process are elements most definitions have in common.

The idea that nursing is a process rather than a set of separate actions started to emerge in the USA in the 1950s. Until the 1960 s this process had not been 
described in detail. Orlando introduced the concept "nursing process" in her book in 1961 (Orlando, 1961). From that time on, interest in the nursing process grew rapidly, although in the beginning it was primarily seen as a teaching tool (de la Cuesta, 1983).

In 1973 the ANA published the standards of nursing practice which provide a systematic approach to nursing and incorporate as a result the nursing process (Torres, 1986). The first publication on the nursing process, edited by Yura and Walsh who popularized the nursing process, was in 1967 and was based on a Nursing Continuing Education Series. Twenty years later in 1988 the fifth edition was published (Yura \& Walsh, 1988).

Four phases of the nursing process were identified by Yura and Walsh: Assessment, planning, implementation, and evaluation (Yura \& Walsh, 1988). These four phases are the ones most often referred to in the literature. Assessment begins with the nursing history and ends with the nursing diagnosis, planning includes goal-setting and writing the care plan, implementing is the carrying out of the nursing actions, and evaluation is rethinking of the diagnosis and treatment in terms of patient's response. Since 1973 the nursing diagnosis has been listed as a step in the nursing process (Bulechek \& McCloskey, 1985). Because the nursing diagnosis is a critical link in the nursing process, it provides a clear focus for care planning, that is for goal setting and the reflection on nursing interventions (McFarland \& McFarlane, 1989). Incorrect assessment could lead to an incorrect nursing diagnosis which would mean inappropriate planning, implementing and evaluating.

Henderson (1982) cautions that the nursing process (1) concentrates on the independent role of the nurse almost to the exclusion of the dependent and interdependent roles, (2) emphasizes the nurse's process rather than the nurseclient process, and (3) stresses problem-solving aspects of a nurse's work while ignoring subjective or intuitive aspects of nursing and the role of experience, logic, and expert opinion. According to Yura and Walsh (1988), the use of this orderly and definable activity does not preclude the use of intuition in making decisions. They even argue that a healthy dose of intuition assists the problemsolving process.

Several authors argue that the nursing process cannot function without a nursing theory (Aggleton \& Chalmers, 1985a, Stanton et al., 1985, Torres, 1985, 1986). Nursing theory is the content, the knowledge used for practice while the nursing process is the method used to apply the theory (Torres, 1986). Nursing theories provide a rationale for decision-making (Stanton et al., 1985) and improve nursing practice (Torres, 1986). During the assessment stage, knowledge of theories and concepts can be used to cluster the collected data. Nursing actions are however characterized differently by nursing theorists (Stanton et al., 1985). Stanton (1985) presents three different ways of conceptualizing nursing actions: (1) assuming responsibility for the person until he/she is ready to assume responsibility for him- or herself, (2) changing the environment to facilitate heaith, and (3) helping the person toward some goal.

Stevens (1984) states that until the nursing process is linked with the context and form of a nursing theory, it is not different from the medical process. The process alone is not unique to nursing. Aggleton and Chalmers (1985b) state 
that without the use of a nursing model the nursing process might be unwittingly used to plan and deliver care around medical concerns. The choice of a model depends on the appropriateness of the model in understanding the particular patients and their needs (Aggleton \& Chalmers, 1985b).

According to Fräser (1990) no single model will provide all the answers to the problems faced by nurses, because nursing practice provides many different situations, contexts and perceptions for both nurse and patient. A multi-model approach is considered to be the most appropriate.

\subsection{Why a nursing process?}

The nursing process has been claimed to be the most effective way of organizing and delivering nursing care (Richards, 1987b) and it is generally accepted that care given by implementing the nursing process is more effective (Hawthorn, 1984).

Yura and Walsh (1983, p5) state that "through organized and deliberate nursing action, provision of quality of care is more certain and means for evaluating the quality of care are provided". By using the nursing process more problems are identified and treated, and care is more standardized (Bulechek \& McCloskey, 1985). In addition to the benefits it brings for the direct patient care, it is considered as a vehicle for developing inquiry skills and nursing knowledge (Chinn \& Jacobs, 1987).

Little research has, however, been conducted to demonstrate the effectiveness of the nursing process for patient care. Information in general is primarily based on scholarly papers or books. A few studies on the impact of the nursing process on the nursing care delivered could be found. Milter (1985a) did find that using the nursing process had measurable benefits for elderly patients in hospitals when using the dependency, discharge rates and length of stay as indicators. No significant results were found, however, during short hospital stays of less than one month. Vandenbosch et al. (Vandenbosch, Bentley, Jones, \& Blake, 1986), based on interviews with nurses, concluded that the introduction of standardized nursing care plans within a nursing process framework improved the quality of care. Neither Hawthorn (1984), who used the assessment of activities of nurses and patients as a means to examine nursing practice, nor Richards (1987b), who used patient's satisfaction with nursing care as effect size, found significant effects of introducing the nursing process on the nursing care.

The nursing process as a means to evaluate the quality of care as reflected in patient records, or assessed by observations and interviews, has received more attention in research (Cardellino, 1986, Cottrell, Cox, Kelsey, Ritchie, Rumph, \& Shannahan, 1986, Curtis \& Simpson, 1985, Lillisand \& Korff, 1983, Schmele, 1985) and seems to be a viable approach for purposes of quality studies (Schmele, 1985). This means of assessing the quality of care is based, however, on the assumption that the effectiveness of the nursing process reflects the quality of nursing care given. 
The question whether implementing the nursing process only leads to improved documentation remains unanswered (Haussmann \& Hegyvary, 1976). Although the nursing process is a designated series of actions to fulfill the purpose of nursing (Yura \& Walsh, 1983), little research has been found to confirm this.

\subsection{The diagnostic process}

The importance of clinical judgement in nursing is well recognized. Although decisions have to be made in every phase of the nursing process, studies on decision-making in nursing are often limited to the diagnostic process or diagnostic reasoning during the first phase of the nursing process. Because the nursing diagnosis is the critical link in the nursing process, it is important that the diagnoses formulated are clear and valid. However the diagnostic process involved is still not well known (Craft, 1991a).

Conceptual disorder is obvious when one reviews the literature with regard to labeling the reasoning processes such as "problem-solving", "diagnostic reasoning", "decision analysis", "clinical judgements" and "medical decision making" (McGuire, 1985).

The diagnostic process in nursing is mostly described as a hypotheses testing process with the following steps or including these steps: Data collection, data interpretation, data clustering and data naming (Craft, 1991b, Gordon, 1987). Within this process critical reasoning is an important cognitive skill (Craft, 1991b, Gordon, 1987).

In the mid-1960s the cognitive aspects of the nurses' tasks were studied for the first time by Hammond and others (Hammond, Kelly, Schneider, \& Vancini, 1966a, 1966b, Hammond, Kelly, Castellan, Schneider, \& Vancini, 1966c). In a series of experimental studies, the researchers studied the process of clinical inferences performed by nurses. They concluded that the cognitive tasks encountered by nurses were complex with respect to the number of cues involved, the number of responses to the tasks and the relation between cues and actions. Because of this complexity and the uncertainty of the tasks the inferences had to be made intuitively. No single cue nor cluster of cues were found to be related to inferences made by the nurses (Hammond et al., 1966a). The nurses did not discriminate between the usefulness of various cues and were only moderately certain about the appropriateness of their decisions (Hammond et al., 1966b). Despite the complexity of the tasks, no systematic and efficient information-seeking strategies were found to be used by nurses (Hammond et al., 1966c). Hammond et al. (1967), concluded that nurses appeared to be cautious in revising their judgements.

Hammond's view (1966) that by obtaining greater theoretical knowledge and developing instrumentation the uncertainty and need for intuitive reasoning was expected to be reduced supports Benner and Tanner's (1987) assumption that intuitive knowledge in nursing is not considered as legitimate knowledge. This is in contrast to Benner's (1982, 1984) results demonstrating that intuitive reasoning can lead to rapid recognition of a patient's nursing diagnosis. The experience level of the nurse affects the reasoning process in the opposite way 
as demonstrated by Benner (1982, 1984). In her studies (1982, 1984) she used the Dreyfus Model of Skill Acquisition which posits that in the acquisition and development of a skill one passes through five levels of proficiency (novice, advanced beginner, competent, proficient, expert). Novices operate from a set of rules, such as the nursing process, while expert nurses have an intuitive grasp of the situation using past concrete experiences and are no longer using rules or formulas to guide their practice (Benner, 1982, 1984, Benner \& Tanner, 1987. Woolley, 1990). Hence it is difficult for the expert nurse to describe the assessment data that lead to a rapid recognition of a nursing diagnosis and thus make the study of intuition in diagnostic reasoning difficult (Radwin, 1990).

The complexity of the task is also a major determinant of decision-making behavior (Corcoran, 1986). An opportunistic approach was used by experts in more complex cases while a systematic approach was used in least complex cases. Novices used the opportunistic approach in all cases, because all cases were complex to them. No relationship was found between the approaches used and quality of plan developed.

Several studies on the diagnostic reasoning process in nursing compared the diagnostic reasoning process used by nursing students and nurses (Itano, 1989, Tanner, Padrick, Westfall, \& Putzier, 1987, Westfall, Tanner, Putzier, \& Padrick, 1986). Tanner et al. (1987) concluded that with increased levels of knowledge and experience the data acquisition was more systematic and the diagnoses were more accurate. Tanner et al.'s (1987) and Westfall et al.'s (1986) studies showed that nurses as well as nursing students did activate diagnostic hypotheses early in the nurse-patient encounter; however, the nurses in Westfall's et al. study (1986) activated more complex inferences than the student group. These findings, although not in accordance with the theory, were similar to those reported in the literature. However, this lack of difference between "novices" and "experts" raised methodological and theoretical questions (Westfall et al., 1986). In accordance with Westfall et al. (1986), Itano (1989) did find that registered nurses used more cues in their diagnostic reasoning process than nursing students and scored higher on a judgement process rating scale.

The introduction of a structural definition of nursing diagnosis, containing three elements, which are the health problem (P), the etiological or related factors $(E)$, and the defining characteristics or signs and symptoms (S) may improve the accuracy of the nursing diagnostic statement. This PES format, originated by Gordon, is the most widely publicized structural definition (Craft, 1991a). The critical defining characteristics are the major criteria for diagnostic judgement; they permit the discriminations among diagnoses. Critical defining characteristics are "found nearly always when the diagnosis is present and are absent when the diagnosis is absent" (Gordon, 1987). Accurate diagnostic reasoning is dependent on the ability of the nurses to associate defining characteristics with a specific nursing diagnosis (Capuano, Hitchings, \& Johnson, 1990, Carpenito, 1991). Validation of these defining characteristics, stimulated and coordinated by the NANDA, may further improve the accuracy of diagnostic statements.

Critical defining characteristics for the nursing diagnosis "sleep pattern disturbance" are for example "verbal complaints of difficulty in falling asleep", "awa- 
kening earlier or later than desired", "interrupted sleep", "verbal complaints of not feeling rested", "daytime sleepiness" (McFarland \& McFarlane, 1989).

Whether these defining characteristics are needed in the diagnostic statement is still a subject of discussion (Craft, 1991a). The diagnosis may be limited to the problem (P) and the related factors (E) linked by "related to". An example of a nursing diagnosis on sleep problems is "sleep pattern disturbance related to increased environmental stimuli".

\subsection{Nursing process and nursing care plans}

Despite the widespread use of the nursing process and the positive effects assigned to it on the quality of nursing care, implementation and application are still problematic. The emphasis in nursing is more on doing and less on planning. The implementation was the step in the nursing process showing the least deficiencies in the care plans in Lampe and Hitchock's study (1987), while the evaluation phase was the most neglected.

Stevens (1984) stresses the importance that the format of the nursing care plan be adjusted to the nursing process in order for the latter to function. Adjusting the documentation to the nursing process improves the use of the nursing process (Lampe \& Hitchock, 1987, Mulhearn, 1989).

An example of a nursing diagnosis with interventions as it could be reported in a nursing care plan is presented in Table 8.1.

Table 8.1 An example of a nursing diagnosis with interventions.

\begin{tabular}{lll}
\hline Nursing diagnosis & Goal & Interventions \\
\hline sleep pattern disturbance related to: & will experience 6 hours of & $*$ plan daily exercises \\
- possible insufficient & uninterrupted sleep & $*$ assist in pre-sleep \\
stimulation during day & and awaken feeling & rituals \\
- possible psychopathologic & refreshed & relaxation \\
impact of depression & & exercises \\
evidenced by & will need only one & \\
- frequent napping during & nap in early after- & \\
the day & noon within one week & \\
- sleepless at night & & \\
\hline
\end{tabular}

adapted from Yura and Walsh (1983)

Besides an unsuitable format of the nursing care plan additional causes for the malfunctioning of the nursing process are diverse (Shea, 1986): Among them are personal characteristics of the users, such as insufficient education (Roeder, 1980 ) leading to their perceiving the nursing process as irrelevant (Miller, 1985b, Young \& Lucas, 1984), and the anxiety that nurses experience in writing nursing care plans and reflecting their knowledge (Young \& Lucas, 1984); institutional factors such as workload or lack of time (Price, 1980), and lack of clarity as to who is responsible for writing the care plans (Roeder, 1980) which may 
be related to the fragmented methods of assignment (Price, 1980). Milne (1985) concluded that institutional variables exert more control over the use of the nursing process than personal characteristics.

Despite the fact that sleep pattern disturbance is a nursing diagnosis accepted by the North American Nursing Diagnosis Association (Carroll-Johnson, 1989), little research has been conducted on the use of this diagnosis or the nursing process in nursing practice. In Beyermann's (1987) study, none of the nurses made the diagnosis in the nursing care plan although $80 \%$ of the patients mentioned having sleep pattern disturbances in the hospital when the defining characteristics were used as cues in the interviews.

\subsection{Conclusions}

Although diagnostic reasoning and clinical decision-making are receiving increasing attention in the literature, more research is still needed to shed light on the problems experienced. Studies on clinical decision-making in nursing are often limited to the assessment phase of the nursing process. Decisions on interventions and evaluation received less attention.

It is to be hoped that in stimulating the use of the nursing process, which is the aim of the intervention study (Study III), including an adjusted nursing care plan, the care administered to patients will improve, leading among other things, to a better sleep quality. According to Benner and Tanner (1987), the use of a systematic problem-solving method, such as the nursing process, can be applied to relatively structured problems. Because sleep is a very common problem among hospital patients and known to all nurses, it is expected to be less problematic to solve sleep pattern disturbances within a nursing process framework. 



\section{The management of sleep: An intervention study}

\section{$9.1 \quad$ Introduction}

As appeared in Study II, the causes or related factors of sleep are diverse and interrelated. Changes in environmental factors and in sleeping habits are related to the quality of sleep in hospital, as shown in Chapter 6. Appropriate nursing care aims to reduce these changes which can be done with rather simple nursing interventions such as a glass of warm milk or an extra pillow in bed. In addition sleep problems are often related to other nursing diagnoses, such as anxiety or pain, which means that interventions suited for these nursing diagnoses may reduce the sleep problems.

Sleep medication is, however, the intervention most frequently used in case of sleep problems regardless of the cause, as became evident from the literature review and the results of Study I presented in Chapter 7.

By implementing the nursing process it is expected that patients' sleep problems would receive more attention resulting in a better identification of the cause or causes of these sleep problems so that appropriate interventions would be instituted.

The problem investigated in Study III was formulated in the following way:

Does using the nursing process by nurses lead to an improvement of sleep quality and quantity and a decrease in the use of sleep medication on hospital wards?

For this purpose three research questions were formulated.

1) Does the use of the nursing process with sleep problems lead to an improvement in the quality of patients' sleep in a general hospital?

2) Does using the nursing process with sleep problems lead to an improvement in the patients' sleep quantity in a general hospital?

3) Does using the nursing process with sleep problems lead to a decrease in consumption of sleep medication?

\subsection{Research design}

The research method of Study III presented in this section has already been partly presented and discussed in Chapter 4. 


\subsubsection{Methods}

A quasi-experimental design was used to test the effect of the nursing process on the quality of sleep in a general hospital. Six wards, two surgical and four medical of a general hospital participated in this study: Three wards, two medical and one surgical, in the experimental group and the other three in the control group. The intervention in this quasi-experimental study was the implementation of the nursing process. Three extra forms, a care plan with examples on nursing diagnoses, goals and interventions on sleep, a patient history form and a blank nursing care plan, were added to the nursing records to facilitate this systematic way of working. Once a week for 12 weeks the investigator and two co-investigators visited the experimental wards to explain the nursing process and to discuss the problems the nurses experienced with the nursing process and the additional care plans. The nursing process was explained to them as follows: To choose an appropriate intervention for any nursing problem the problem should be clear, the kind of problem as well as the possible cause of the problem. When the intervention is implemented it should be evaluated whether it was effective or not and consequently decisions are made for further actions. This process was illustrated by examples from the literature and examples from the additional care plans on sleep. During the pretest and posttest the dependent variables, sleep quality, sleep quantity, and sleep medication prescribed and administered, were determined. In addition to this output evaluation, throughput evaluation was conducted by testing whether nurses would resort to using other nursing interventions than sleep medication because of the implementation of the nursing process. Nurses from the experimental group as well as the control group completed a questionnaire to this effect in the pretest and posttest. In this study no input evaluation has been performed.

The research design is depicted in the following scheme.

Scheme 1 The research design.

\begin{tabular}{llll}
\hline & $\mathrm{t}_{1}$ & $\mathrm{t}_{2}$ & $\mathrm{t}_{3}$ \\
EXPERIMENTAL WARDS & 0 & $\mathrm{x}$ & 0 \\
CONTROL WARDS & $(\mathrm{n}=119)$ & & $(\mathrm{n}=120)$ \\
& 0 & 0 \\
$(\mathrm{n}=122)$ & & $(\mathrm{n}=121)$
\end{tabular}

$0:$ observation $=$ sleep quality and quantity and the use of sleep medication, throughput evaluation

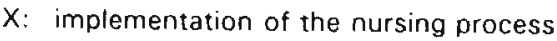

$t_{1}=$ pretest

$t_{2}=$ implementation of the nursing process

$t_{3}=$ the posttest 


\subsubsection{Population}

The head nurses of the six wards selected all Dutch-speaking patients aged thirty years or older, who were not seriously ill, and who spent at least two nights on that ward. The head nurse sought the patients' consent for participation in the study.

Two hundred and forty-one patients were included both in the pretest and posttest. Only a few patients refused to answer the questionnaire. It is, however, not known what kind of patients nor how many exactly refused to participate. This was due to the fact that the investigator only received the names of the patients willing to participate.

Based on the admission rates per month, about 210 patients were admitted on the experimental wards and 240 on the control wards during the pretest as well as the posttest. In the total experiment 253 men and 229 women participated as shown in Table 9.1. The population of the pretest and postest and experimental and control group did not differ significantly on age, gender and speciality. However, they did differ on length of stay prior to the interview $(F=5.24$, $d f=2, S S=2,109, p \leq .01$ ). The experimental group had a significantly shorter stay than the control group in the pretest $(t=1.95, d f=1, p \leq .05)$ as well as the posttest $(t=2.80, d f=1, p \leq .01)$ which is controlled for in the further analyses. This difference in length of stay was not expected. The aim was to select two comparable groups of patients. The year prior to this study the mean length of stay for wards participating in this study did not differ significantly.

Table 9.1 Description of the population in the experimental group ( $n=239$ ) and control group $(n=243)$.

$\begin{array}{cccc}\text { Gender } & \text { Age } & \text { Length of stay } \\ M & F & \text { (mean) } & \text { (mean) } \\ \% & \% & & \end{array}$

EXPERIMENTAL WARDS

\begin{tabular}{|c|c|c|c|c|}
\hline Pretest & 52 & 48 & 59 & 10.6 \\
\hline Posttest & 45 & 55 & 60 & 10.1 \\
\hline
\end{tabular}

CONTROL WARDS

Pretest

$56 \quad 44$

59

14.4

Posttest

5743

60

14.8

The four groups (pretest/posttest and control/experimental) of nurses who completed the questionnaire for the throughput evaluation did not differ significantly on gender, education, and years of experience (Table 1 Appendix E). 


\subsubsection{Instruments}

Short structured questionnaires were used to measure sleep quality and quantity during the pretest and posttest. Sleep quality in the hospital prior to the tests and at home during the past two months was measured by the general Subjective Sleep Quality Scale. Information on the sleep quality at home was gathered in the hospital. Sleep quantity and quality of the night prior to the interview was measured by open-ended questions asking about sleep latency, number of arousals, and total sleep time (see Table 4.3).

Information was also gathered of all the patients interviewed about the medication prescribed and used. This information was collected from the Kardex. It concerned information about the medication prescribed and the medication used the night prior to the interview with and without a prescription. The use of sleep medication without prescription was recorded for the duration of admission up to the interview. Demographic variables such as age, gender, education, marital status were also collected as well as the date of admission.

A new questionnaire, divided into three parts, was developed and used to estimate the throughput factor of this intervention study. One part of the questionnaire consisted of ten cases presenting sleep problems for which the nurses could select nursing interventions from a list of 15 interventions, as they would actually do and as they would prefer to do (Table 3 Appendix E). Three cases used in this questionnaire are shown in Table 9.2. The same list of interventions was presented on which the nurses could indicate on a 5-point scale inever to llearly always) how often they choose these interventions with sleep problems (Table 2 Appendix E). In addition eight statements on sleep problems were offered with which the nurses could agree or disagree (Table 4 Appendix E).

Table 9.2 Cases used for the throughput evaluation, three examples.

- Ms. M.J. $(55$ years of age) reported this morning that she felt tired all morning.

* Mr. H.H. (25 vears of age) will have surgery on his knee tomorrow; at midnight he is still awake and states that he wants to get some sleep.

* This morning the physician of Ms. N.B. 157 years of agel ordered sleep medication be stopped. Since her admission, two weeks ago she received it every night. At $11.45 \mathrm{p} . \mathrm{m}$. she calls and requests a sleeping pill.

This questionnaire was based on a literature review on nursing interventions on sleep, and evaluated and changed by members of the department of nursing science. It has not been validated so far. The questionnaire, with exception of the 10 cases, is presented in Appendix $E$ with descriptive statistics.

\subsubsection{Procedure}

The pretest took place over a period of six weeks in both the control and experi mental group. During the following 12 weeks the intervention was implemented 
on the three experimental wards. For the first six weeks $\left(t_{2}\right)$ the nurses were given enough time to get acquainted with using the additional forms. During the last six weeks $\left(t_{3}\right)$ the posttest took place on the control and the experimental wards.

During the first week of the study in the pretest as well as the posttest, all patients who met the selection criteria were potential respondents; however, during the following weeks only the newly admitted patients were interviewed. The questionnaires were completed by the patients in the presence of the investigator. Some patients needed some help in doing this.

At the start of the pretest and at the end of the posttest the nurses of both the experimental and the control wards filled out the questionnaire for the throughput evaluation.

\subsubsection{Analysis}

Sleep quality, quantity and the use of sleep medications were compared between the pretest and posttest for the control group and the experimental group.

A factorial analysis of (co)variance was used to analyze the independent and interactive effects of the factors pretest/posttest, and experimental/control group on the dependent variables, to test whether the means of the separate groups have come from the same sampling distributions of means (Tabachnick \& Fidell, 1989). Age, gender, length of stay, and speciality are potential covariates. Every dependent variable in the design was tested for homogeneity of regression with MANOVA on the covariates age, gender, length of stay and speciality. The results of this test are presented and discussed in the results section.

\section{$9.3 \quad$ Results}

Whether the intervention, stimulating the use of the nursing process, had the expected effect is the subject of this section. Sleep quality, sleep quantity and the use of sleep medication are the dependent variables.

From the analyses of variance of the covariates age, gender, length of stay and speciality it appeared that length of stay was the only covariate which differed significantly for the four groups (pretest/posttest and control/experimental) of patients. Next, all the dependent variables were tested for homogeneity of regression on the covariates with MANOVA. Only for the dependent variable sleep latency did the covariate length of stay interact with the two factors, pretest and posttest and control and experimental group $(\mathrm{F}=4.08, \mathrm{df}=1$, $\mathrm{SS}=17,438, p \leq .051$. 


\subsubsection{Sleep quality and quantity}

In Tables 9.3 to 9.9 the scores on the dependent variables and the results of the factorial analyses of variance are presented per dependent variable. The variable length of stay is included in the factorial analysis of variance as a covariate for all the dependent variables, except for sleep latency, because the mean scores for the four cells of the design differed significantly. However, for sleep latency, it is included as a factor because it interacted with the other two factors. For this reason length of stay is dichotomized based on the median score (median $=8$ ).

Sleep quality as measured by the SSOS (Table 9.3), and number of arousals (Table 9.4) improved in both the experimental group and the control group: however, these improvements were not significant $(F=.49, \mathrm{df}=2, \mathrm{SS}=22.59$, $p>.05, F=.68, d f=2, S S=13.45, p>.051$.

Table 9.3 Mean scores on the SSOS for the pretest $(n=241)$ and posttest $(n=241)$.

\begin{tabular}{lcccc}
\hline & $\mathrm{t}_{1}$ & $\mathrm{t}_{3}$ & \\
& Mean & (sd) & Mean & (sd) \\
\hline EXPERIMENTAL WARDS & 7.68 & $(4.87)$ & 8.11 & $(4.54)$ \\
CONTROL WARDS & 7.45 & $(4.90)$ & 8.25 & $(4.54)$ \\
\hline
\end{tabular}

Table 9.4 Mean number of arousals for the pretest $(n=241)$ and posttest $(n=241)$.

\begin{tabular}{lll}
\hline & Mean $^{\mathrm{t}_{1}}(\mathrm{sd})$ & Mean $^{\mathrm{t}_{3}}$ \\
\hline EXPERIMENTAL WARDS & $3.99(3.40)$ & $3.43(3.20)$ \\
CONTROL WARDS & $3.38(2.90)$ & $3.16(3.16)$ \\
\hline
\end{tabular}

No significant difference in sleep latency (Table 9.5), $(F=1.19, d f=3$, SS $=14,946, p>.05)$ and sleep quantity (Table 9.7). $(F=1.31, d f=2$, $S S=12.37, p>.051$ appeared in the experimental group nor in the control group. The pretest/posttest and length of stay interacted with sleep latency $(F=6.93, d f=1, S S=28,985, p \leq .01)$ and a three-way interaction of experimental/control group, pretest/posttest and length of stay $(F=5.62, d f=1$, $S S=23,500, p \leq .01)$. The interaction effect is presented in Table 9.6. No explanation could be found for this interaction effect.

The change in sleep quality compared with home was the only dependent variable which differed significantly for the four groups $(F=4.06, d f=2$, SS $=169.70, p \leq .01)$ (Table 9.8). 
Table 9.5 Mean sleep latency in minutes for the pretest $(n=241)$ and posttest $(n=241)$ and the results of the factorial analysis of variance.

\begin{tabular}{|c|c|c|c|}
\hline & Mean $^{\mathrm{t}_{1}}$ (sd) & \multicolumn{2}{|c|}{$\operatorname{Mean}^{t_{3}}(s d)$} \\
\hline EXPERIMENTAL WARDS & $54.5(72.6)$ & \multicolumn{2}{|c|}{$56.6(66.7)$} \\
\hline CONTROL WARDS & $46.7(59.6)$ & \multicolumn{2}{|c|}{$45.0(64.1)$} \\
\hline Analysis of variance & $\mathrm{F}$ & SS & $d f$ \\
\hline main effects & 1.19 & & \\
\hline experiment/control & 2.86 & & \\
\hline pretest/posttest & .006 & & \\
\hline length of stay & .92 & & \\
\hline $\exp \times$ pre & .004 & & \\
\hline $\exp \times$ length & 1.70 & & \\
\hline pre $\times$ length & $6.93 * *$ & 28,985 & 1 \\
\hline exp $\times$ pre $\times$ length & $5.62 * *$ & 23,500 & 1 \\
\hline
\end{tabular}

$* * 0.01$

Table 9.6 Three way interaction effect on sleep latency in minutes.

\begin{tabular}{lccccc}
\hline & \multicolumn{2}{c}{ Pretest } & & \multicolumn{2}{c}{ Posttest } \\
\cline { 2 - 3 } \cline { 5 - 6 } & $\begin{array}{c}\text { Short stay } \\
\leq 7 \text { days } \\
\text { Mean }\end{array}$ & $\begin{array}{c}\text { Long stay } \\
\geq 8 \text { days } \\
\text { Mean }\end{array}$ & $\begin{array}{c}\text { Short stay } \\
\leq 7 \text { days } \\
\text { Mean }\end{array}$ & $\begin{array}{c}\text { Long stay } \\
28 \text { days } \\
\text { Mean }\end{array}$ \\
\hline EXPERIMENTAL WARDS & 39.8 & 69.3 & 76.7 & 42.0 \\
CONTROL WARDS & 35.8 & 52.4 & 36.7 & 49.7 \\
\hline
\end{tabular}

Table 9.7 Mean sleep quantity in hours for the pretest $(n=241)$ and posttest $(n=241)$.

\begin{tabular}{lcc}
\hline & Mean $^{t_{1}}$ (sd) & Mean $^{t_{3}}$ (sd) \\
\hline EXPERIMENTAL WARDS & $5.09(2.17)$ & $5.48(2.14)$ \\
CONTROL WARDS & $5.61(2.12)$ & $5.16(2.31)$ \\
\hline
\end{tabular}

Patients from the control group showed a larger difference in sleep quality than the experimental group $(F=6.81, \mathrm{df}=1, \mathrm{SS}=142.22, \mathrm{p} \leq .01)$. This may be caused by the fact that people having a poor sleep at home may be less affected in their sleep in hospital than good sleepers. 
Table 9.8 Mean change in sleep quality for the pretest $(n=241)$ and posttest $(n=241)$.

\begin{tabular}{llll}
\hline & \multicolumn{2}{c}{$\mathrm{t}_{1}$} & Mean $^{\mathrm{t}_{3}}(\mathrm{sd})$ \\
\hline EXPERIMENTAL WARDS & $2.31(\mathrm{sd})$ & 2.22 & $(4.58)$ \\
CONTROL WARDS & 3.95 & $(4.90)$ & $2.65 \quad(4.06)$ \\
\hline
\end{tabular}

In the control group more patients $(201)$ were good sleepers at home than in the experimental group (171). However, there was no significant difference in change of sleep quality between the pretest and posttest for good and poor sleepers at home, in both the experimental and the control groups, as shown in Table 9.9, although of the good sleepers in the control group in the posttest, more people tended to maintain their good sleep in hospital than in the pretest $\left(x^{2}=2.91, p=.08\right)$.

With the exception of sleep latency, no interaction effects between the independent factors were found for any of the dependent variables on sleep quality and quantity.

Table 9.9 Good sleepers in the hospital both in the experimental and control group in pretest and posttest divided in good and poor sleepers at home.

\begin{tabular}{llll}
\hline & & \multicolumn{3}{c}{ Good sleep quality in hospital } \\
& & $t_{t_{1}}$ & $t_{3}$ \\
\hline Good sleep quality at home & Control & $55 \%$ & $67 \%$ \\
& Experimental & $61 \%$ & $68 \%$ \\
\hline Poor sleep quality at home & Control & $20 \%$ & $10 \%$ \\
& Experimental & $25 \%$ & $12 \%$ \\
\hline
\end{tabular}

\subsubsection{Nursing interventions on sleep}

The following variables were measured during the pretest and posttest.

Table 9.10 Nursing interventions on sleep.

$t_{1}$ and $t_{3}$

Dependent variables

- sleep medication prescribed

- sleep medication administered
Throughput evaluation

* interventions per case

- interventions in general on sleep

* statements on sleep

The amount of sleep medication prescribed and used in the pretest and posttest for the control and experimental group is presented in Tables 9.11 to 9.13. 
It concerned three sorts of information on sleep medication, the number of prescriptions, the amount of medication used the night prior to the interview without prescription and the use of sleep medication for the duration of the admission up to the interview without prescription. This latter variable is divided by the number of nights since admission up to the interview.

Standard prescriptions as well as as needed prescriptions were all offered the night prior to the interview. All three dependent variables on sleep medication differed significantly for the four groups of the design. The amount of sleep medication prescribed and administered differed mainly between the experimental and control group. The experimental wards had more sleep medication prescribed and administered for a specific night as well as a higher use of sleep medication than the control wards at both moments. The pretest and posttest did not differ significantly for these dependent variables for the total population. On the control wards the amount of sleep medication prescribed increased (Table 9.11) and the amount of sleep medication administered the night prior to the interview decreased (Table 9.12). However, these differences were not significant.

Table 9.11 Sleep medication prescribed for the pretest $(n=241)$ and posttest $(n=241)$ and factorial analysis of variance.

\begin{tabular}{|c|c|c|c|}
\hline & $n^{t_{1}}(\%)$ & $n$ & $(\%)$ \\
\hline EXPERIMENTAL WARDS & $18 \quad(15)$ & 18 & (15) \\
\hline CONTROL WARDS & $10 \quad(8)$ & 13 & $(11)$ \\
\hline Analysis of variance & $\begin{array}{c}F \\
\text { (length of stay as covariate) }\end{array}$ & SS & $d f$ \\
\hline $\begin{array}{l}\text { main effects } \\
\text { experiment/control } \\
\text { pretest/posttest } \\
\text { exp } \times \text { pre }\end{array}$ & $\begin{array}{l}4.35 * \\
8.63^{*} \\
.05 \\
.05\end{array}$ & $\begin{array}{l}.864 \\
.858\end{array}$ & $\begin{array}{l}2 \\
1\end{array}$ \\
\hline
\end{tabular}

$* p \leq .01$

On the experimental wards the mean number of nights sleep medication was offered increased; again this difference appeared to be not significant (Table 9.13). No interaction effects between the independent factors and the dependent variables on sleep medications prescribed and administered were found. 
Table 9.12 Sleep medication administered the night prior to the interview for the pretest $(n=241)$ and posttest $(n=241)$ and factorial analysis of variance.

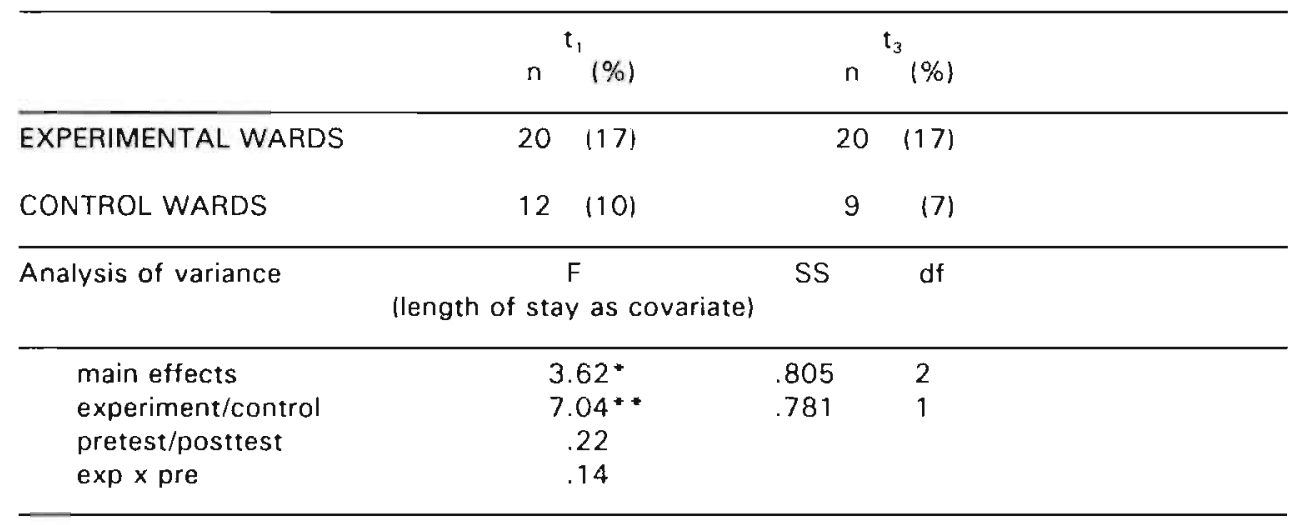

$* p \leq .05 * p \leq .01$

Table 9.13 Mean number of nights sleep medication administered prior to the interview without prescription for the pretest $(n=241)$ and posttest $(n=241)$ and factorial analysis of variance.

\begin{tabular}{|c|c|c|c|}
\hline & Mean $^{t_{1}}(s d)$ & Mean & (sd) \\
\hline EXPERIMENTAL WARDS & $.09 \quad(.18)$ & .12 & $(.20)$ \\
\hline CONTROL WARDS & $.02 \quad(.09)$ & .02 & (.07) \\
\hline Analysis of variance & $\begin{array}{c}F \\
\text { (length of stay as covariate) }\end{array}$ & SS & $d f$ \\
\hline $\begin{array}{l}\text { main effects } \\
\text { experiment/control } \\
\text { pretest/posttest } \\
\text { exp } x \text { pre }\end{array}$ & $\begin{array}{l}16.73^{* *} \\
31.94^{* *} \\
1.53 \\
1.39\end{array}$ & $\begin{array}{l}.763 \\
.728\end{array}$ & $\begin{array}{l}2 \\
1\end{array}$ \\
\hline
\end{tabular}

$* * p \leq 001$

In addition to sleep medication, the output evaluation in this study, other interventions are appropriate in case of sleep problems. For the throughput evaluation nurses were asked what kind of interventions they institute in general on sleep and which they would prefer to do.

The interventions nurses institute in general on sleep and for the cases presented in the questionnaire did not differ between the pretest and posttest, for the experimental and control group. The nurses' opinions about the statements on sleep did not differ neither between the pretest nor the posttest (Table 4 Appen$\operatorname{dix} E$ ).

The significant F-statistics presented in Appendix $E$ in Table 2 are mainly caused by the significant differences between the control group and experimental group in instituting these interventions. It seems that nurses on the experimental 
wards are more likely to administer sleep medication in case of sleep problems which is in accordance with the interventions presented for the 10 cases (Table 3 Appendix E) and in accordance with the results on the dependent variables. Nurses from the experimental wards are less likely to consult physician $\mathrm{F}=$ $12.54, \mathrm{df}=1, \mathrm{SS}=11.10, p \leq .001$ ), less likely to try to discover the cause of the sleep problem $(F=5.09, d f=1, S S=2.88, p \leq .05)$, and are more likely to administer sleep medications $(F=11.92, d f=1, S S=6.10, p \leq .001)$ and pain medication ( $F=8.40, d f=1, S S=5.11, p \leq .01)$ and are less likely to try alternative interventions on sleep such as a glass of warm milk $(F=4.63, d f=1$, $S S=3.11, p \leq .05)$, straighten bed $(F=3.66$, $d f=1, S S=2.67, p \leq .05)$, offer the opportunity to wash face or brush teeth $(F=9.33, d f=1, S S=9.69, p \leq .01)$ or decrease noise as an intervention $(F=8.50, \mathrm{df}=1, \mathrm{SS}=7.64, p \leq .01$ ) or hold a reassuring conversation $(F=23.58$, df $=1, S S=10.45, p \leq .001)$.

\subsection{Conclusions and discussion}

None of the research questions formulated in the introduction can be answered positively. Although the experimental and control group showed small improvements in sleep quality, number of arousals and change in sleep quality, these changes were not significant. These changes may be caused by the extra attention given to sleep during the study on the wards. Another consequence of this extra attention might be that more sleep medication was used during the posttest.

The duration of the intervention and the intensity of the support in using the nursing process may not have been sufficient to have some positive effects on the care provided. The introduction of the adjusted care plans, a requirement for the application of the nursing process, was probably not enough.

Although the study seems to have been succussful in choosing comparable wards for the experimental and control groups some selection bias appeared, which may have consequences for the results of this study. The patients from the experimental wards had a shorter length of stay and had more sleep medication prescribed and administered. It may be that the nurses of the experimental wards have fewer problems with the administration of sleep medication, which seems to be supported by the results of the throughput evaluation, and as a consequence are less open to alternative interventions or to changing their habits than the nurses of the control wards. Or at least it would take a longer period to change their attitudes towards sleep medications. In addition the patients in the control group had a better sleep at home in the pretest as well as the posttest.

Introducing the nursing process did not influence already existing knowledge on sleep because no extra information was given on sleep. Whether the intervention affected the experimental factor, the application of the nursing process, was not tested in an appropriate way. Instead of testing the application of the nursing process in practice, the throughput factor was tested by analyzing the nursing interventions chosen by the nurses in case of sleep problems, in the pretest and posttest. As a result only limited conclusions can be drawn on the 
effect of the intervention. No change in the kind of interventions occurred in the posttest, either on the experimental wards or on the control wards. As appeared from the questionnaire, nurses on the experimental wards are more likely to offer sleep medication than nurses on the control wards.

Another explanation for the absence of improvements in sleep quality and quantity may be caused by the ceiling effect. The quality and quantity of sleep could have been that good that no improvement could be detected despite the fact that the quality of sleep in hospital was significantly worse than at home.

On the other hand, patients who had already sleep problems at home which were often chronic, could not be expected to improve during a relatively short hospital stay. Therefore a future study should consider including in the analysis only those patients with a good sleep at home. Maybe a population with a longer admission would be more appropriate for this kind of study than one with a relatively short stay.

Whether the nurses used the nursing process can be studied by analyzing the nursing care plans and patient history forms used in this study. This analysis is presented in the next chapter. 


\section{The nursing process in practice}

\subsection{Introduction}

The extra forms added to the care plans on the experimental wards in Study III were evaluated on the use of the nursing process. A considerable number of these additional nursing care plans were returned which indicates that the experimental factor was influenced.

The evaluation of the nursing care plans provides additional information on the nursing diagnoses formulated and the interventions planned on sleep, on those experimental wards. The problem to be investigated was formulated in the following way:

Do the nurses of a general hospital accurately assess patients' sleep problems and what diagnoses and interventions do they formulate with respect to sleep problems?

This led to the formulation of six research questions.

1) Do the quality of sleep and the sleep problems as reported in the nursing care plans correspond with the patients' interview reports on sleep?

2) What kind of nursing diagnoses are formulated on sleep problems?

3) What kind of nursing interventions are used with sleep problems in a general hospital?

4) Do the planned interventions lead to an improvement in sleep quality and quantity of the patient according to the nurse?

5) Are the planned nursing interventions related to the nursing diagnosis formulated?

6) Do the planned interventions relate to sleeping habits and rituals at home?

A master's thesis based on these results, is completed by a student who participated in the intervention study (Bongers, 1989).

\subsection{Research design}

\subsubsection{Methods}

A secondary analysis was performed on the nursing forms used during the last six weeks $\left(t_{3}\right)$ of Study III. It concerned two forms, a nursing history form and a nursing care plan. The history form was completed by the nurse together with the patient during the intake about normal total sleep time, existing sleep problems, sleep medication, and sleeping habits and rituals. The nursing care plans on sleep were used during the whole admission period of the patient. These 
nursing care plans have been evaluated on the use of the different steps of the nursing process. For more information on the design of this study the reader is referred to the previous chapter.

\subsubsection{Population}

All patients admitted to the three experimental wards whose nursing history forms and nursing care plans were available in the existing nursing records, were included in this study.

One hundred and eighty-four patient history forms and nursing care plans were returned.

Table 10.1 Description of the sample $(n=184)$.

\begin{tabular}{lccccc}
\hline & $\begin{array}{c}\text { Forms } \\
\text { returned }\end{array}$ & $\begin{array}{c}\text { History forms } \\
\text { filled out }\end{array}$ & $\begin{array}{c}\text { Nursing care plans } \\
\text { filled out }\end{array}$ \\
\hline Medical ward & 26 & $26(100 \%)$ & 3 & $(12 \%)$ \\
Medical ward & 56 & 53 & $(96 \%)$ & 55 & $(98 \%)$ \\
Surgical ward & 102 & 97 & $(94 \%)$ & 82 & $(81 \%)$ \\
\hline & 184 & 176 & $(96 \%)$ & 140 & $(76 \%)$ \\
\hline
\end{tabular}

Ninety-six per cent (176) of the history forms were completed and $76 \%$ (140) of the care plans were used by the nurses (Table 10.1). One medical ward filled out the nursing care plans only a few times.

\subsubsection{Instruments}

The information provided by the history forms and the nursing care plans of the first six weeks of the implementation phase of Study III $\left(t_{2}\right)$ were transcribed and categorized which led to the development of a code book. Five care plans and nursing history forms were coded by two independent raters and showed sufficient intercoder-reliability $(r=.83, r=.88$, respectively). This code book was then used to quantify the diagnoses formulated and interventions planned on the extra forms in the posttest $\left(t_{3}\right)$. The interventions have been evaluated whether they were based on the assessment data and the diagnoses formulated, and for their effect on the sleep quality or quantity, according to the nurse.

\subsubsection{Procedure}

This study used the same procedure as mentioned in Chapter $\mathbf{9}$ for Study III. Data from the last six weeks $\left(t_{3}\right)$ of Study III was used for the present study. In a first meeting with the nursing personnel the purpose of the study was explained to them and how to use the nursing process, facilitated by the extra forms in the nursing records. Once a week during the implementation phase of Study III $\left(t_{2}\right.$ and $\left.t_{3}\right)$ the problems the nurses experienced in using the nursing 
process and the extra forms were discussed with the investigator. The forms of the patients discharged from the hospital were collected and analyzed.

\subsubsection{Analysis}

A content analysis was performed on the forms completed by the nurses during the last six weeks of the implementation phase (posttest) of Study III. By means of the code book developed by the investigator the diagnoses and interventions formulated by the nurses were quantified.

\section{$10.3 \quad$ Results}

\subsubsection{Correspondence between patients' view and nursing care plans}

Approximately 225 patients were admitted to the experimental wards during the posttest of the intervention study. Of these 225 patients, 184 forms were returned, history forms and nursing care plans, with both or one of both forms filled out, which means that for about 40 patients no additional forms were filled out.

One hundred and twenty patients were interviewed about their sleep in hospital and at home, during the posttest. Of these, 76 patients also had a nursing care plan filled out; thus enabling the data files to be matched. A comparison between the nursing notes and the patients' report on sleep was facilitated this way.

Besides this group of patients with care plans and interview reports, there were two other groups of patients, one without care plans and one without interview reports.

Forty-four patients who were interviewed had no additional care plan on sleep. No significant differences could be estimated between the two groups, with and without care plans, on age, gender and duration of admission. However, patients without these care plans had significantly fewer arousals at night $(t=-2.73, d f=107, p \leq .01)$ and had a significantly longer sleep duration $(t=2.06, d f=89, p \leq .05)$ than patients who were interviewed and had a nursing care plan. Absence of sleep problems may be a reason for not using the additional nursing care plan on sleep. No differences in sleep quality and sleep latency were found between the two groups.

The second group, 108 patients (59\%) who had a nursing care plan but were not interviewed had significantly fewer sleep problems reported in the nursing care plans $\left(x^{2}=11.28, \mathrm{df}=1, \mathrm{p} \leq .001\right)$ than the patients who were interviewed. It was, however, expected that patients who were seriously ill and therefore, among other reasons, not selected for an interview would have more sleep problems.

Information on sleep latency, number of awakenings, sleep quantity and quality was used from the patients' interviews. The median score on these variables was used to decide whether there was a sleep problem or not. 
With the exception of sleep quality which related to all the nights during the admission up to the interview, the sleep variables concerned a specific night. The complete nursing care plan had to be coded for the diagnoses on sleep latency, number of awakenings and sleep quantity because it was not known which night the patient interviews referred to. Sleep latency is presented in Table 10.2 as an example as how the nursing care plans and patients' reports are coded.

Table 10.2 Sleep latency: As reported by patients and in the nursing care plans $(n=76)$.

\begin{tabular}{|c|c|c|c|}
\hline \multirow[b]{2}{*}{$\begin{array}{l}\text { Nursing diagnoses reported } \\
\text { in care plans }\end{array}$} & \multicolumn{3}{|c|}{ Sleep latency reported by patients } \\
\hline & $\begin{array}{l}30 \mathrm{~min} \text {. } \\
\text { or more }\end{array}$ & $\begin{array}{c}\text { less } \\
\text { than } \\
30 \mathrm{~min}\end{array}$ & total \\
\hline \multirow{3}{*}{$\begin{array}{l}\text { Related diagnoses } \\
\text { Diagnoses not related } \\
\text { or no diagnoses }\end{array}$} & 16 & 12 & 28 \\
\hline & 27 & 10 & 37 \\
\hline & 43 & 22 & 65 \\
\hline
\end{tabular}

Only 16 of the 43 patients $(37 \%)$ who had difficulties falling asleep (Table $10.2)$ and 19 of the 43 patients $(44 \%)$ with three awakenings or more (Table 10.31, had a diagnosis reported in the care plans which could be related to these problems. Thirty of the 44 patients with a sleep duration of less than 6 hours had some kind of diagnosis reported in their care plans (Table 10.3). This could be any kind of sleeping problem.

Of the 39 patients who scored less than 8 on the SSOS, 29 patients had some kind of nursing diagnosis addressed in the care plan (Table 10.3). However, for 35 patients reporting a sleep quality of more than 8,23 also had a sleep problem reported in the care plans. Remarkably no difference in the number and kind of nursing interventions could be found between those two groups.

These results point at a low correspondence between patients' reports and nursing care plans. For this reason sensititivity, specificity and odds ratio were estimated of the nurses' reports on sleep latency, number of awakenings, sleep quality and sleep duration (Table 10.3).

Sensitivity of the nursing care plans was only for sleep duration and sleep quality higher than 50\%, which was still low, indicating that not every patient reporting a short sleep duration or a poor quality of sleep is detected by the nurse. For sleep latency and awakenings it was even less than would be expected by chance. Specificity of the nurses' score was even worse, none of the percentages exceeded 50. It seems that nurses see more sleep problems than patients report. Odds-ratio was only for sleep quality higher than 1 , which means that the accuracy of diagnosing sleep by nurses was only for sleep quality somewhat better than by chance.

The correspondence between the patients' reports and nursing notes may actually be higher because the patient interviews concerned only a specific night or only a limited period of admission while the care plans concerned the whole 
admission period. Taking into consideration that patients without sleep problems have less nursing care plans than those who have, improves readily the correspondence between patient's reports and nursing care plans.

Table 10.3 Sensitivity, specificity and odds-ratio for four facets of patients" sleep as scored by nurses in their care plans $(n=76)$.

\section{Sensitivity Specificity Odds-ratio}

\begin{tabular}{llll}
\hline Sleep latency & $37 \%$ & $45 \%$ & 0.5 \\
Awakenings & $44 \%$ & $35 \%$ & 0.4 \\
Sleep duration & $68 \%$ & $26 \%$ & 0.8 \\
Sleep quality & $74 \%$ & $35 \%$ & 1.5 \\
\hline
\end{tabular}

Sensitivity = percentage of patients with problems scored correctly, at least $50 \%$ to be of any value

Specificity $=$ percentage of patients without problems scored correctly, at least $50 \%$ to be of any value

Odds-ratio $=$ should be higher than 1.0

It seems that nurses are moderately capable of detecting sleep problems, but they have difficulties in assessing the problems accurately. In the next sections the diagnoses and interventions nurses formulated in the care plans, are presented.

\subsubsection{Nursing diagnoses}

In the 184 nursing care plans returned to the investigator 240 nursing diagnoses were formulated. The PES format (problem-etiology-signs and symptoms) proposed by Gordon (1987) was not used to decide whether the problem reported was a nursing diagnoses or not because none of the problems reported were formulated that way, instead all the statements of problems reported in the care plans were counted. Included in the diagnosis category are the statements of the nurses that the patient had no problems during his or her hospital stay as shown in Table 10.4. Because the etiologies or etiological factors are the links to the nursing intervention to be chosen it was decided yet to code these etiological factors.

The diagnoses as they are reported in the nursing care plans are often lacking clarity. The nursing diagnosis "poor sleep" is not clear because it can mean several things such as frequent awakenings or difficulty falling asleep. The nursing diagnosis "potential sleep problem" ammounted to $30 \%$ of all nursing diagnoses reported and was primarily written when the patient had to undergo surgery or some kind of medical test the following day. Awakenings at night, difficulty falling asleep, awakening early and daytime sleepiness were mentioned as sleep problems in the care plans. They correspond with the descriptions used by several authors as defining characteristics of the NANDA approved nurisng diagnosis "sleep pattern disurbance" (Beyerman, 1987, Johnson, 1989, Reimer. 1987, Rossi et al., 1987). 
Table 10.4 Nursing diagnoses on sleep reported in 184 nursing care plans $(n=240)$.

Number of diagnoses $(\%)$

\begin{tabular}{lrr}
\hline No problems during admission & 27 & $(11 \%)$ \\
Potential sleep problem & 73 & $(30 \%)$ \\
Poor sleep & 66 & $(28 \%)$ \\
Not sleeping at all & 35 & $(15 \%)$ \\
Awakenings at night & 26 & $(11 \%)$ \\
Problems falling asleep & 8 & $(3 \%)$ \\
Awakening early & 4 & $(2 \%)$ \\
Daytime sleepiness & 1 & $(.4 \%)$ \\
\hline
\end{tabular}

The etiology of the sleep problem is not always mentioned in the care plans. As shown in Table 10.5, 227 etiological factors are reported in the care plans related to 149 diagnoses.

Table 10.5 Etiological factors of the nursing diagnoses $(n=227)$.

Number of etiological factors $(\%)$

Etiological factors related to:

Psychological well-being

Physiological well-being/pain

$96 \quad(42 \%)$

Medical treatment

Noise

Activity-exercise pattern

Elimination pattern

Position in bed

Sleep medication

Not known to nurse

Environmental temperature

Nutritional pattern

This means that $30 \%$ of the diagnoses in the care plans were stated without reference to the etiology. The etiological factors most frequently mentioned are related to psychological well-being $(42 \%)$ and physiological well-being $(25 \%)$. The former concerned primarily stress or anxiety before surgery or test, whereas in 35 cases the latter concerned pain. The etiological factor "elimination pattern" included "had to go to the bathroom" (6), constipation (2), and incontinence (2). 


\subsubsection{Nursing interventions}

Three hundred and three interventions were reported in the nursing care plans including the notation that no intervention was chosen deliberately, as shown in Table 10.6. The majority of the interventions reported concerned the administration of medication, premedication (47) and pain medication (41) categorized as other medication, and sleep medication (89). A conversation with the patient was the intervention categorized as "related to psychological well-being".

"Interventions related to nutritional pattern" included among others, "a glass of warm milk" (8), "drink not so close to bedtime" (3), and "an extra snack shortly before bedtime" (2). "Interventions related to noise" were actions such as "moving patient or roommate to another room" (4) or "closing the door at night" (3).

Table 10.6 Nursing interventions on sleep problems reported in 184 nursing care plans $(n=$ 303).

Number of nursing interventions (\%)

Interventions related to:

Other medication

Sleep medication

Psychological well-being

Nutritional pattern

Medical treatment

Noise

Position in bed

Deliberately no intervention

Elimination pattern

Activity-exercise pattern

Environmental temperature

Consulting physician

$\begin{array}{rr}102 & (34 \%) \\ 89 & (29 \%) \\ 24 & (8 \%) \\ 17 & (6 \%) \\ 16 & (5 \%) \\ 16 & (5 \%) \\ 12 & (4 \%) \\ 8 & (3 \%) \\ 6 & (2 \%) \\ 6 & (2 \%) \\ 5 & (2 \%) \\ 2 & (1 \%)\end{array}$

The interventions reported in the care plans were evaluated poorly by the nurses. Fifty-one $(17 \%)$ of the interventions were not evaluated and of another 13 interventions the nurse did not know whether they had been successful or not. Only $51 \%$ (154) of the interventions had been evaluated positively.

Those interventions reported twice for a single diagnosis are only counted once which explains the different total figures, $298(154+80+64)$ instead of 303 interventions. More than one intervention per diagnosis did not increase the chance of being evaluated positively, as can be concluded from Table 10.7. 
Table 10.7 Evaluation of the nursing interventions reported in 184 nursing care plans.

\begin{tabular}{|c|c|c|c|}
\hline & \multicolumn{2}{|c|}{$\begin{array}{c}\text { Number of interventions } \\
\text { evaluated }\end{array}$} & \multirow[t]{2}{*}{$\begin{array}{c}\text { Number of interventions } \\
\text { not evaluated }\end{array}$} \\
\hline & Success & No success & \\
\hline \multicolumn{4}{|l|}{ One intervention per diagnosis } \\
\hline \multicolumn{4}{|l|}{ Interventions related to: } \\
\hline Other medications & 48 & 11 & 21 \\
\hline Sleep medications & 36 & 18 & 18 \\
\hline Noise & 7 & 2 & -- \\
\hline Nutritional pattern & 7 & 1 & -- \\
\hline Psychological well being & -- & 7 & 4 \\
\hline Medical treatment & 6 & 1 & -- \\
\hline Deliberately no intervention & 2 & 3 & 2 \\
\hline Elimination pattern & 2 & 2 & -- \\
\hline Position in bed & -- & 2 & 1 \\
\hline Environmental temperature & 1 & 1 & -- \\
\hline Activity-exercise pattern & 1 & -- & 2 \\
\hline Consulting physician & -- & -- & 1 \\
\hline Two interventions per diagnosis & $13(26)$ & $13(26)$ & $6(12)$ \\
\hline Three interventions per diagnosis & $6(18)$ & $2(6)$ & $1 \quad(3)$ \\
\hline Total number of interventions & $129(154)$ & $63(80)$ & $56(64)$ \\
\hline
\end{tabular}

\subsubsection{Nursing interventions based on nursing diagnoses}

For the following problems "potential sleep problem", "poor sleep" and "not sleeping at all", the majority of the nursing interventions concerned the administration of sleep medication or other medication such as tranquilizers and pain medication. "Frequent awakenings" was the only diagnosis with interventions reported related to the nutritional pattern, environmental noise, talking with the patient and pain medications or tranquilizers.

Almost a quarter of the 295 (303-8 "deliberately no interventions") interventions (68) were reported without a cause in the nursing care plan. Of these 68 interventions a considerable number of interventions (55) were reported without a diagnosis formulated, and as a consequence without etiological factors, and in addition 5 interventions were reported in the care plan for a diagnosis of which the nurse indicated she did not know the cause, and another eight interventions were reported with a diagnosis without a cause mentioned. For 10 diagnoses no interventions were reported in the nursing care plans. As a result 248 interventions were formulated for 230 diagnoses.

The total figures of the etiologies and interventions may differ form previous sections because the intervention reported twice for a single cause was only counted once and a cause reported twice for one diagnosis was also counted once in the analysis. 
Table 10.8 Nursing interventions based on cause of the sleep problem $(n=232$ ).

intervention based on cause

yes no

Etiological factors related to:

Psychological well-being

Physiological well-being

Medical treatment

Activity-exercise pattern

Noise

Elimination pattern

Sleep medication

Position in bed

Environmental temperature

Nutritional pattern

$\begin{array}{rr}7 & 72 \\ 38 & 26 \\ 8 & 18 \\ 2 & 13 \\ 6 & 8 \\ 5 & 7 \\ 1 & 7 \\ 1 & 7 \\ 2 & 1 \\ 3 & -\end{array}$

159

Because a cause was not always formulated for a diagnosis, as indicated earlier, or a diagnosis was not always made, it was expected that when a cause was reported, the intervention was not always related to this cause.

Only a third of the interventions (73) formulated for the diagnoses with etiological factors reported were based on that etiology (Table 10.8). For the etiological factors related to psychological well-being and physiological well-being, one cannot determine whether the interventions were based on the cause of the problem because the interventions which were primarily offered were medication.

Some examples of interventions planned by nurses but not based on the etiology of the nursing diagnosis are presented in Table 10.9.

Table 10.9 Examples of nursing interventions reported in the nursing care plans.

Interventions reported:

reduce noise

sleep medication

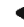

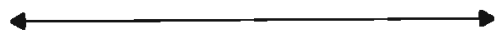

\author{
Etiology related to: \\ rest-activity pattern \\ medical treatment \\ position in bed \\ temperature
}

From the history forms information was gathered about the things people do at home before going to bed and when they have difficulty falling asleep or difficulty going back to sleep. Relaxation, watching television or reading, and eating or drinking something before going to bed were the activities most frequently mentioned. Unfortunately none of these actions were found in the care plans as an intervention to improve sleep except the interventions related to the nutritional pattern such as "a glass of warm milk" or "drink more before going to bed" 
which were reported 17 times. However, these interventions can be done by the patients without knowledge of the nurse.

\subsection{Conclusions and discussion}

When comparing the patients' interviews with nursing care plans, only half of the sleep problems reported by patients find reflection in the nursing care plans. The sensitivity and specificity of the nursing diagnoses on sleep are low. It seems that nurses have less problems detecting sleep problems in general than in diagnosing them accurately and specifically.

Comparable results were found by van der Bruggen (1991) for assessing privacy, Klop (1984), Schulkens (1987), Abu Saad (1990) on nursing diagnoses such as anxiety and pain. Closs (1988b) stated that nurses may have inadequate questioning techniques and assessment skills, instead of asking "did you sleep well last night?" the question asked should be "how did you sleep last night?".

The nursing diagnoses most frequently mentioned were "potential sleep problem" and "poor sleep", accounting for $58 \%$ of the diagnoses reported. Thirty per cent of the diagnoses were reported without an etiological factor, despite the fact that this is the basis for choosing the nursing intervention. The etiological factors mentioned most frequently were psychological well-being and physiological well-being primarily related to the potential sleep problem, because this was recorded when the patient had to go for surgery or some medical test the following day.

The majority of the interventions planned involved the administration of sleep or other medication such as pain medication and tranquilizers. This is not surprising, because the diagnoses were formulated poorly, often without an etiology, and in addition $23 \%$ of the interventions were chosen without reporting the cause of the problem and only a third of the interventions related to a diagnosis with cause and were based on this cause. It is equally no surprise that only half of the interventions were successful. A careful assessment of the sleep problem uncovers the underlying factors leading to an appropriate nursing intervention.

Other interventions as mentioned in Chapter 8 , such as relaxation therapy, back massage or exercises, are not found in the nursing care plans. An explanation for this limitation in interventions could be that the nursing staff did not have enough knowledge about other interventions although some alternatives are quite simple, such as home remedies, and can still be remarkably effective, or nurses consider these interventions as part of their routine nursing care. Information on interventions patients are used to doing at home such as a glass of warm milk, a nightcap, a light snack, watching television or reading, when they have problems with sleeping, was available in the nursing history forms.

Why every patient did not have this additional nursing care plan is not clear. One reason may be that for those patients without sleep problems or only mild sleep problems, no nursing care plan was used on sleep, although this is not plausible because no history form was completed for those patients at admissi- 
on either. At that moment it is not clear whether the patients will develop sleep problems in hospital.

Despite the fact that the diagnoses were formulated poorly, the defining characteristics of the NANDA approved nursing diagnosis were all present. With a more extended training it should be possible to improve the diagnostic skills of the nurses on the wards. Nurses should know what information to assess, how to assess, and what interventions are available and how to perform these interventions.

All together it may be concluded that the nursing process was rarely used which may also explain why the intervention study reported in the previous chapter did not show significant results. 



\section{Part IV}

Conclusions and discussion 



\section{Conclusions and discussion}

\subsection{Introduction}

In this last chapter a summary of the results of the four studies is presented and discussed in section 11.2. In section 11.3 the research methods used in these studies are discussed with regard to the possible constraints on and threats to internal and external validity. Theoretical and practical implications resulting from the four studies are mentioned in sections 11.4 and 11.5 . Finally suggestions for further study are proposed in section 11.6 .

\subsection{Summary of the results}

The results of the four studies are presented with regard to each problem the research investigated.

Reliability and validity of the Subjective Sleep Quality Scale (Chapter 2).

The Subjective Sleep Quality Scale, which was used in Studies II and III to measure sleep quality, showed sufficient internal consistancy, stability, content validity and concurrent validity.

The extent of sleep problems in a general hospital (Chapter 5).

Sleep quality and quantity in hospital decreased significantly compared to home (measured in the hospital) and sleep patterns changed. Awakening time and bedtime were significantly earlier and more time was spent asleep during the day when hospitalized than at home. Sleep problems mentioned most frequently in the hospital were "problems falling asleep (sleep latency)" and "frequent awakenings".

Determinants of sleep in a general hospital (Chapter 6).

Often patients were awakened for routine nursing care activities. Well-being, sleep quality at home, changes in environment, sleeping habits, position in bed, and sleep medication during previous admissions correlated significantly with sleep quality in hospital. If the effects of the environmental variables on sleep had not been asked for specifically, they would not have been mentioned by the patients as causes of a poor sleep. Based on the results of this chapter a theoretical model has been developed which will be presented in section 11.4.

The extent of sleep medication prescribed and administered in a general hospital (Chapter 7).

Significantly more sleep medication is used in the hospital than at home. Sleep medications are most frequently prescribed as a standing order. With the exception of few variables such as morningness/eveningness, pain, worrying about 
the situation at home and clinical diagnosis, none of the independent variables correlated with the amount of sleep medication prescribed or administered. Morning people had more sleep medication prescribed than evening people and surgical patients received more sleep medication at a specific night than medical patients. Lack of rationale for offering these medications probably explains the fact that the independent variables did not correlate with sleep medication. This lack of rationale for prescribing and offering sleep medication is supported by the findings from the literature study.

The amount of sleep medication prescribed as well as administered differed significantly between the studies. The significant differences in administration of sleep medication between the three studies disappeared when the tranquilizers were included. It seems that the form in which sleep medication is prescribed barely makes any difference for the administration of sleep medication.

The implementation of the nursing process (Chapter 9).

Because the determinants of sleep quality were varied the implementation of the nursing process was chosen to improve the quality of sleep and reduce the use of sleep medication. Although some changes in the dependent variables (sleep quality, quantity and sleep medication) occurred none of these changes were significant. In addition some unexpected serious problems occurred in the selection of the control and experimental groups.

Nursing diagnoses and intervention in the care plans (Chapter 10).

Only half of the sleep problems patients report were found in the nursing care plans, indicating a low correspondence between patients' view and nursinn reports. On the other hand nurses report more diagnoses on sleep when compared to sleep problems reported by patients. This needs serious thought because the nurses decide on the interventions instituted, among which the administration of sleep medication. Besides, the nursing diagnoses in the additional care plans were formulated poorly and the interventions were not always related to these diagnoses. "A potential sleep problem" and "poor sleep" were the diagnoses most frequently reported in the care plans. Sleep medication was the intervention most frequently planned in case of sleep problems. A third of the interventions reported were not based on the nursing diagnoses. As a result only $51 \%$ of the interventions were evaluated positively.

In general it may be concluded that the additional nursing care plans on sleep problems, added for this study, did not support the expectation that the nursing process was used properly.

\subsection{Methodological reflections}

The methodological problems are presented and discussed in this section, including the constraints on and threats to internal and external validity. First the Subjective Sleep Quality Scale is commented on followed by the separate problem statements. 


\section{Subjective Sleep Quality Scale.}

Although this instrument gave evidence of sufficient reliability and validity, it does need further construct validation. For the construct validation of the SSOS, age and gender were used to discriminate between groups. It was hypothesized that older patients and women had a worse sleep in the hospital than younger patients and men respectively. Both hypotheses were not supported by the results.

There are several explanations why these hypotheses were not supported. Firstly, older people in a dependent situation are possibly less likely to complain about their hospital stay and in this case about their sleep. Secondly, older people may have more flexible rhythms and as a consequence accommodate better to the hospital situation. And finally, age may not be a good operationalization of aging in a hospital population.

Women on the other hand tend to complain more about their sleep than men: However, physiologically their sleep seems to be better. Possibly the lack of clarity in what determines the quality of sleep is important here.

Although the specific questionnaire and the general questionnaire correlated significantly, the specific sleep quality for both nights was better than the quality of sleep in general in hospital. It seems that the appraisal of the quality of sleep in general in hospital is a summation of the poor facets of sleep of the specific nights.

Several items in the SSOS were less appropriate for the hospital situation. Removing those items had no serious impact on the reliability and validity of the instrument. It is recommended that the SSQS should be further tested before it can be used in nursing practice.

The extent of sleep problems in a general hospital.

In the hospital a decrease in sleep quality and a change in sleep pattern occurred compared to home. However, information bias may have happened because the quality of sleep at home was estimated while the patient was hospitalized. It is possible that sleep at home was reported less favorably than is actually the case which would make the difference between sleep at home and in the hospital less. Similarly, the interviews took place in the patient rooms which may have had consequences for the information provided by the patients, because of lack of privacy. They may express themselves more favorably about their sleep in the hospital than they actually are.

For the change in sleep pattern, this bias may be less serious because expressing a change in pattern may not be perceived as complaining behavior and therefore experienced as less threatening.

In Study II the population comprised only women while in Study III both women and men participated. However, for sleep in hospital it did not make any difference whether it was only women participating or a mixed population. The figures on sleep quality, sleep quantity and sleep pattern in the hospital changed in the same way compared to home in both Studies II and III. Only for sleep quality at home did women in Study II sleep significantly worse than the participants of Study III. This may be explained by the gender differences in responding to less specific questions on sleep. 
For organizational reasons each of the three hospitals in Study II had one specific day of the week for the first interview and two days later the second interviews. For two hospitals the first interview day was Tuesday and for one hospital it was Wednesday. In Study III the days of the week varied, but it is not known whether it makes any difference which day of the week it is for the quality of sleep. No difference in sleep quality was found by Closs (1988b) for day of the week. Sleep quality and quantity at home and in the hospital did not differ significantly between the three hospitals in Study II, although the change in sleep quality in hospital compared to home was not significant for hospital C.

\section{Determinants of sleep in a general hospital.}

It appeared from Study II that the methods used to collect information on the determinants of sleep influence the results. In other studies these influences of the methods are not considered.

Environmental variables were experienced as greater sleep disturbers when measuring sleep on a specific night than when measuring sleep in general in hospital. Environmental variables seem to be forgotten in the first place when reporting sleep disturbers but when it was asked more specifically whether some environmental variables disturbed sleep, it was confirmed more frequently. Empirically, on the other hand, the correlations between environmental variables and sleep quality are supported: They are more important in explaining the variance in specific sleep quality while personal characteristics explain more the variance of the general sleep quality in hospital.

Because the medication appeared not to be prescribed and administered on a rational basis, it was not possible to correct for the influences sleep medication may have on the variables in this study. In fact, sleep medication did not correlate significantly with quality of sleep. So the influence of sleep medication on the results of these studies remains uncertain.

The results of Study II are limited to women and hence are less generalizable. In the third part of this dissertation the emphasis was on nursing interventions. Sleep medication is the intervention most frequently instituted in case of sleep problems.

The extent of sleep medication prescribed and administered in a general hospital.

No distinction was made between hypnotics and other medications offered to induce sleep in Study I which made it difficult to compare the results with Studies $I I$ and III. In addition, in Study I all patients admitted to the wards the night of the study participated while in Studies II and III only the patients interviewed participated with the inclusion criterion that they were not seriously ill. There was a significant difference in the amount of sleep medication prescribed and administered between the three studies although the amount of sleep medication administered varied less. Including the minor tranquilizers in the amount of sleep medication in Studies II and III, the significant differences in administration of sleep medication between the three studies disappeared. 
The implementation of the nursing process.

No significant results appeared from the intervention, the implementation of the nursing process, which was implemented to improve sleep quality, sleep quantity and reduce the use of sleep medication. Neither sleep quality nor sleep quantity improved nor did the use of sleep medication decrease.

This lack of results can mean two things: Firstly, the study was conducted appropriately but the hypotheses are to be rejected, or secondly, the hypotheses are correct but the study showed some methodological problems. The latter explanation seems to be more plausible. Despite this lack of results it may be concluded that a considerable number of nursing forms are filled in and returned to the investigator. This may be an indication that the experimental factor was influenced.

One of the most serious methodological problems, contrary to expectation, is the comparability of the experimental and control groups. The experimental group used more sleep medication, had a shorter stay, and had a worse sleep at home than the control group. It is not clear what caused these differences. This may have had consequences on the results of this study.

Another reason for the lack of results may be that the experimental factor was not well introduced. Possibly the duration of the experiment was too short and the intensity of the support was insufficient to have some effects on the care provided.

It may be that the duration of admission was too short for the intervention to have some effects on the quality of sleep. Patients in long-stay settings would be a more appropriate target population. Theoretically this is possible but empirically this seems less plausible considering the accuracy of the nursing diagnoses.

Another plausible explanation may have to do with the ceiling effect that sleep in hospital settings cannot be further improved considering the seriousness of the patients' situation.

In a hospital setting it is not feasible to prevent diffusion of the intervention. Nurses of the control and experimental wards may have communicated about the study, and as a result the control wards may have implemented the intervention in some way. The control wards may even try as a result to improve their care for sleep problems too. The nursing process may have been used on the control wards. So the differences between the control and experimental wards were less than they were supposed to be. It was not expected that the control group would differ in the application of the nursing process and the use of the nursing care plans in the pretest. However, no nursing care plans were examined on the control wards to validate the above. Again in theory the previous two explanations are possible but empirically they are less plausible.

As mentioned before, there appeared to be a significant difference between the control and experimental groups in prescribing and administering sleep medica" tion. This might have consequences for the effect of this intervention. Nurses on the experimental wards administered significantly more sleep medication than those on the control wards, an indication of more favorable attitudes towards sleep medication. As a consequence nurses on the experimental wards 
may have less reason to change their administration habits. However, to estimate the effect of the intervention on the experimental factor, a pre-and posttest should have been included.

Nursing diagnosis and interventions in the care plans.

Diagnosing the problems accurately is not dependent on the quality of the study. Despite the methodological flaws of the intervention study, nurses are expected to diagnose accurately. It is not plausible that nurses on purpose diagnosed poorly in this study.

Not all patients admitted to the experimental wards had an additional care plan on sleep. The reason for this is not clear. It seems that those patients without care plans have fewer sleeping problems. The diagnoses in the care plans are inaccurate and poorly formulated and the interventions are primarily limited to sleep medication.

For the appraisal of the nursing process in the care plans, only limited information was available to decide whether the intervention instituted by the nurse was the appropriate one. Because only the nursing care plans are studied, that is the outcome of the diagnostic process, the process of this decision-making remains unilluminated. Whether the problem solving-method is used, in other words the nursing process, or the use of the nursing care plans is stimulated remains in the dark. It is also uncertain whether all the interventions reported in the nursing care plans were actually carried out and vice versa.

At last the population of all four studies was limited to surgical and medical patients. This limits the generalizability of the results.

\subsection{Theoretical issues}

Although the function of sleep is still a moot point, sleep deprivation is generally accepted as detrimental for recovery.

Sleep quality is correlated negatively with well-being; however, causality cannot be determined within this research design. It may be a reciprocal relation. A poor sleep may have a negative effect on well-being; on the other hand feeling not well may cause a poor sleep. These two variables may reinforce each other. As a consequence of the absence of a specific theoretical framework in this dissertation, the number of variables were enormous. The advantage of this way of investigating a problem may lead to new insights which would be left unilluminated when a specific theoretical framework is used. On the other hand the process of data-collection occurs less systematically. From the results of these studies hypotheses can be derived leading eventually to a new theory or contribute to existing nursing theories.

Changes in sleeping habits and in environment correlated with a poor quality of sleep in hospital. This is reflected in the fact that in several nursing theories changes in patterns are central concepts such as Rogers' Science of Unitary Man (Rogers, 1970) and Newman's Health as Expanding Consciousness (Newman, 1986). 
The results of this inventarization study can be presented in a conceptual model as shown in Figure 11.1. Personal characteristics, such as coping style and worrying, correlated in two ways with sleep in hospital, on the one hand via sleep quality at home and sleep experienced during previous admissions, and on the other hand via the changes patients experience during their present hospital stay and their well-being.

The more people actively cope with problems and the more they worry, the worse they sleep at home and the worse their sleep was during previous hospital admissions. In addition the more changes they experienced and the worse they felt during the present admission, the worse they slept in hospital.

Patients who felt disturbed in their privacy experienced more changes and felt worse in hospital than patients who did not experience these privacy problems. With increasing age hospital admissions seem to provoke less changes in environment and personal habits. Older patients also seem to experience less disturbances in their privacy. It should be questioned whether maintaining sleep rituals outweigh the seriousness of a situation like a hospital admission. This conceptual model needs to be tested and developed further.

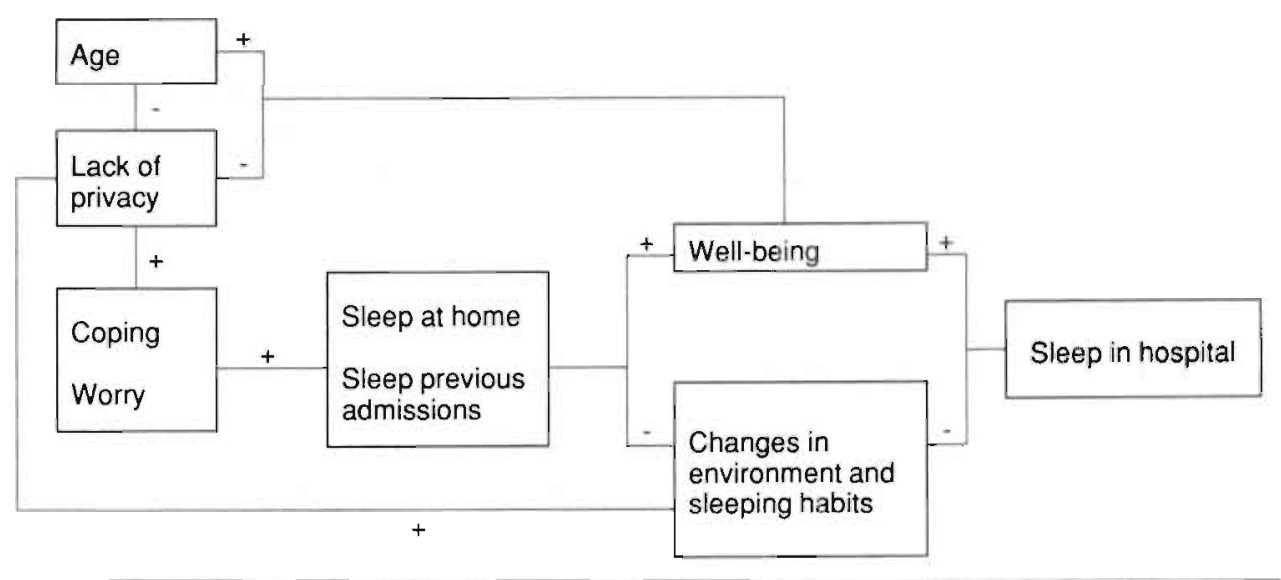

Figure 11.1 The conceptual model

Although the nursing process may be viewed as a barrier for expert nurses in the reasoning process, as Benner $(1982,1984)$ states, it is necessary for the continuity of care that the different steps of the nursing process are reported, so that it is possible for other nurses to continue the care as planned.

Using validated defining characteristics to formulate the nursing diagnosis may enhance the diagnostic accuracy. The nursing diagnosis "sleep pattern disturbance" as currently defined by the NANDA, is not specific enough for application in the Dutch nursing practice. One argues if some of the defining characteristics should not be also included as separate diagnoses. 


\subsection{Practical implications}

Because the determinants of sleep in hospital are diverse, environmental variables, personal characteristics as well as disease-related variables, it is not possible to offer one solution appropriate for all the sleep problems in hospital. An accurate assessment of the variables which influence sleep in hospital would provide a good data base for deciding on an intervention.

Information should be assessed regarding the sleep habits and the sleep environment, such as level of noise and light, and fresh air. Nurses should support the maintenance of these sleep habits as far as possible within a hospital situation. In addition, experiences regarding sleep during previous admissions might be an indication that sleep during future admissions may be problematic too. Nurses should be aware of that and try to prevent sleep problems.

How information is collected influences the accuracy of the information. Asking patients whether they experienced some environmental factors as disturbing their sleep will rarely be confirmed, while asking patients whether they were awakened by these environmental variables will rarely be denied. Noise caused by nurses is experienced as more disturbing than noise from machinery or instruments, which are fixed environmental conditions. Nurses should be aware of the noise they produce at night or early in the morning.

The early waking time in hospital and the routine care activities in the morning should be evaluated whether these are actually necessary. Flexible waking times should be considered, of course within the limitations of the hospital setting.

In the nursing curricula more attention should be paid to alternative interventions on sleep. Currently interventions are limited to sleep medication.

Assessments of sleep problems by nurses appeared to be inaccurate. A more systematic approach to this nursing problem should improve the assessment and as a consequence the interventions instituted. Although it may be concluded that the SSQS was found to be valid and reliable as a research instrument, it is too long to use in everyday nursing practice. A shortened version should be more feasible for application in nursing practice. Research data including our results could be used for the construction of a shortened version of the SSOS. The total sum of the problems experienced by patients correlated significantly with the items concerning these problems. It concerned the sleep problems, "problems falling asleep", "difficulty staying asleep" and "early awakening". Maybe it is sufficient in nursing practice for nurses to ask about these three facets of sleep quality.

However, it may be argued whether sleep in hospital should receive more attention considering the results of this dissertation. A hospital stay often only lasts a few days and after discharge, the patient will sleep again at home. In addition nurses seemed to be unable to assess sleep accurately. Asking "did you sleep well" belongs to the rituals nurses have without instituting actions. On the other hand in this quasi-experiment no seriously ill patients were included with a longer length of stay. With a prolonged admission, however, it becomes more important to spend more time on patients' sleep.

Using the nursing diagnosis "Sleep pattern disturbance" as it is proposed by the NANDA is not feasible within the current situation because nurses are not used 
to working with this general diagnosis. The defining characteristics as they are accepted by the NANDA, such as problems falling asleep or frequent awakenings would be more usable as a nursing problem by themselves. Such a specific nursing diagnosis guides the assessment by describing the client behaviors more accurately and the related variables, offering a better basis for interventions. However, nurses do need more support in using the nursing process and not only regarding the lay-out of the nursing care plans. Sleep problems and appropriate interventions which in some cases will be sleep medication should as a result receive more attention in the nursing curricula.

\subsection{Recommendations for further study}

In future experimental designs on improving the quality of sleep in patients nurses should be convinced that interventions on sleep problems are relatively simple to implement, essential is however to diagnose accurately. It appeared from these studies that several facets of sleep make it difficult to diagnose sleep accurately and as a consequence to institute appropriate interventions. Firstly, the quality of sleep is judged subjectively by the person him- or herself. In addition, it is still not clear what constitutes the quality of sleep, and thirdly, the variables related to sleep quality vary considerably. All three factors hinder the accuracy of the diagnostic process.

What factors determine the quality of sleep certainly need further study. These factors are in fact the defining characteristics nurses should use in their decisions on the presence or otherwise of a sleep problem. The validation of those defining characteristics should include patients' reports and nurses' observations.

At the same time the diagnostic skills of nurses should be further investigated and improved. Whether using these validated defining characteristics enhances the diagnostic process is certainly worth further study.

A more accurate diagnosis should lead to an appropriate intervention. A shortened version of the SSQS could be used as an evaluation instrument to test the effects of the implemented interventions. A shortened version of the SSOS naturally needs to be further validated.

Alternative interventions on sleep deserve more attention in research and in practice than is currently the case. These interventions should be tested on their effects on sleep problems.

A poor sleep quality and the use of sleep medication during previous admissions, and a poor sleep quality at home may be considered as indicators of potential sleep problems. Recognizing these factors early during the admission may prevent the development of sleep problems. 



\section{Summary}

While hospitalized several things change for people especially in their daily routines. Among these changes are the changes in sleep-wake pattern.

Although sleep is in general considered as restorative and belonging to the domain of nursing, underscored by the fact that the NANDA accepted the diagnosis "Sleep pattern disturbance", little nursing research has been performed on these changes. The aim of this dissertation was to explore the sleep problems experienced by hospitalized patients and the nursing interventions provided to prevent sleep problems. Central to this dissertation were the questions "how patients experience sleep in hospital settings" and "what nurses do about the sleep of patients". For that cause four studies were executed with five hospitals participating.

Study I concerned an inventarisation of the amount of sleep medications prescribed and administered on three medical and three surgical wards in three general hospitals, one night a week for three weeks. Data were available on sleep medications of 1076 patients.

In Study II 141 medical and surgical patients, women between 30 and 70 years of age, from three hospitals were interviewed about their sleep in hospital. Sleep quality, sleep quantity, the use of sleep medications and possible related variables were estimated that way.

Based on the results of Study II, in Study III a quasi-experimental design was used to test the effects of the introduction of the nursing process on the quality and quantity of sleep and the use of sleep medications of patients. For this reason extra forms, a nursing history form and a nursing care plan, were added to the nursing records on the three experimental wards, to facilitate this problem-solving process. On the experimental and control wards a pretest and posttest had been performed to estimate sleep quality, sleep quantity and the use of sleep medications. During the intervention, a period of 12 weeks, the problems nurses experienced in using the extra forms and the nursing process were discussed once a week with the investigator.

Study IV consisted out of secondary analysis of the extra forms added to the care plans on the experimental wards in Study 111.

The results of these studies were not presented seperately per study. The dissertation contains four parts, per part data were used from several studies.

A description of the content of the four parts follows.

Part I concerned a general introduction to the subject in which the quality of sleep and the measurement of sleep was emphasized. As appeared from the literature review biophysiological measurements correlated with self-reports on sleep, which was one of the reasons the Subjective Sleep Quality Scale (SSOS) was used to measure sleep quality of the hospitalized patients. The SSOS appeared to be a valid and reliable instrument although construct validation should be further tested. Suggested was to shorten the SSOS for future use.

What determines the quality of sleep is still not clear. In general it is stated that the waking period during sleep seems to be important in the appraisal of sleep. 
Part II answered the following problem statement: What is the extent of sleep problems in a general hospital and what are the determinants of these sleep problems.

Results were presented from Studies II and III. Sleep pattern clearly changes in hospital, bedtime and waking time are earlier, sleep latency is longer, sleep duration is shorter and patients are awakened more frequently and as a result sleep quality deteriorates in hospital. Almost 60 per cent of the patients in Study II stated that they had experienced one or more sleeping problems during their hospital stay. These findings supported the findings from the literature review on sleep in hospital settings.

The determinants estimated in Study II included environmental variables, personal characteristics, and disease-related variables as was found in the literature.

The most important factors explaining the variance in sleep quality in a general hospital were sleep at home, well-being, environmental changes and changes in normal sleep pattern such as sleeping habits and position in bed.

Sleep quality of a specific night was more explained by changes caused by the hospital environment while internal variables such as well-being explained the quality of sleep in general in hospital. In addition, environmental variables were not always expressed by patients as disturbing sleep although when asked for it directly, a majority of the patients were frequently awakened by nurses, roommates, and nursing care of roommates.

Awakenings were primarily caused by nurses, roommates, or the nursing care of roommates. Fixed environmental variables were mentioned less frequently as causes of patients' awakenings. Suggested was that these fixed environmental conditions were accepted as a consequence of a hospital admission.

Oider people experienced less changes in personal habits while hospitalized than younger people.

Sleep medications, prescribed or administered correlated only with a few variables, an indication that there was no clear policy on the ward regarding the use of sleep medications. Therefore it was not possible to correct for the influence of sleep medications on sleep.

Part III emphasized the problem statement: What decisions do nurses make on sleep problems. For this part data were used from all four studies.

From the literature review it became obvious that providing sleep medications is still the intervention most frequently instituted in case of sleep problems. In the first three studies data were gathered on the amount of sleep medications prescribed and offered in a general hospital. Although the amount of sleep medications prescribed varied considerably between the hospitals the administration of sleep medications didn't differ significantly when the minor tranquilizers were included, indicating that nurses decide on the provision of sleep medication regardless in what form the sleep medications are prescribed.

The number of patients receiving sleep medications ranged from 14 per cent (hospital A) to 38 per cent (hospital E) for a specific night. However the latter figure included the use of minor tranquilizers.

Because sleep medications are not always the most appropriate interventions for sleep problems it was expected that the implementation of the nursing process would improve the nursing care provided in case of sleep problems. The nursing 
process is in general accepted as a guide in decision-making in nursing as became clear from the literature review on the nursing process. Nursing interventions are expected to be based on the nursing diagnosis formulated. Therefore it was expected that the implementation of the nursing process would lead to an improvement of sleep quality and quantity and a decrease in use of sleep medications. Neither of the expectations were supported by the results of Study III.

It was concluded that the lack of results may be due to methodological problems. The interventions nurses perform or would like to perform in practice, which was estimated in a throughput evaluation, didn't change in the posttest compared to the pretest.

The diagnoses nurses formulated in the extra care plans were poorly formulated, often without mentioning the cause of the problem, and as a result the interventions were often limited to sleep medications.

Only half of the sleep problems patients stated in the interviews in Study III, were reported in the nursing care plans. Concluded was that nurses had problems in diagnosing sleep problems of patients accurately.

In Part IV the conclusions were presented and discussed and a conceptual model was presented based on Part II of this dissertation. In this conceptual model it is shown that the more people actively cope with problems and the more they worry, the worse they sleep at home and the worse they did sleep during previous admission, the more changes they experienced, such as environmental changes and changes in sleeping habits and the worse they felt during their admission. In addition the worse their sleep was during the present admission. This conceptual model needs to be tested further. 



\section{Samenvatting}

Door een opname in het ziekenhuis is er een aantal dingen dat verandert voor mensen, met name wat betreft de dagelijkse routines. Een verandering in het slaapwaak patroon tijdens een ziekenhuisopname is hiervan een voorbeeld.

Hoewel aan slaap in het algemeen een herstellende functie wordt toegeschreven en slaap erkend wordt als behorende tot het domein van de verpleging, hetgeen onderstreept wordt door het feit dat de NANDA (North American Nursing Diagnosis Association) de diagnose "Sleep pattern disturbance" (verstoring van het slaappatroon) geaccepteerd heeft, is nog weinig verplegingswetenschappelijk onderzoek uitgevoerd naar die veranderingen in het slaap-waakpatroon tijdens een ziekenhuisopname.

Het doel van het promotie-onderzoek "Slaapkwaliteit in het ziekenhuis", was te exploreren welke slaapproblemen patiënten ondervinden in het ziekenhuis en welke verpleegkundige zorgverlening plaatsvindt om slaapproblemen van ziekenhuispatiënten te voorkomen. Centrale vraagstellingen van dit onderzoek waren: "Hoe ervaren patiënten hun slaap in het ziekenhuis" en "Wat doen verpleegkundigen aan de slaap van patiënten".

Om deze vraagstellingen te kunnen beantwoorden zijn vier onderzoeken verricht: Studie I tot en met IV waarin in totaal vijf ziekenhuizen participeerden.

Studie I betrof een inventarisatie van de hoeveelheid slaapmedicatie voorgeschreven en verstrekt op drie interne en drie chirurgische afdelingen van drie ziekenhuizen, gedurende drie weken een avond/nacht per week. Gegevens over slaapmedicatie waren beschikbaar van 1076 patiënten.

In Studie II werden 141 interne en chirurgische patiënten van drie ziekenhuizen, vrouwen tussen de 30 en 70 jaar, geïnterviewd over hun slaap in het ziekenhuis. Slaapkwaliteit en -kwantiteit, het gebruik van slaapmedicatie en mogelijk gerelateerde factoren werden door middel van die interviews gemeten.

Gebaseerd op de resultaten van Studie II is in Studie III een quasi-experimenteel design toegepast om de effecten te bepalen van de introductie van het verpleegkundig proces ten aanzien van slaap op de kwaliteit en kwantiteit van de slaap en het gebruik van slaapmedicatie door patiënten. Om het hanteren van het verpleegkundig proces door de verpleegkundige te ondersteunen, zijn extra formulieren, een anamneseformulier en een verpleegplan, toegevoegd aan het verpleegkundig dossier op de drie experimentele afdelingen. Zowel op de experimentele als op de controle-afdelingen hebben een voor-en een nameting plaatsgevonden van de slaapkwaliteit en -kwantiteit en het gebruik van slaapmedicatie. Gedurende de gehele interventie, de introductie van het verpleegkundig proces, zijn de problemen die verpleegkundigen ondervonden in het gebruik van die toegevoegde formulieren en het hanteren van het verpleegkundig proces een keer per week besproken met de onderzoeker.

Tijdens Studie IV is een inhoudsanalyse uitgevoerd op de formulieren die toegevoegd waren aan het verpleegkundig dossier op de experimentele afdelingen in Studie III. 
Dit proefschrift bestaat uit vier delen, per deel zijn gegevens gebruikt van de verschillende studies.

Deel I betreft een algemene introductie van het onderwerp waarbij, de nadruk gelegd is op de kwaliteit van de slaap en het meten van slaapkwaliteit en kwantiteit. Uit de literatuurstudie bleek dat biophysiologische metingen van de slaap correleerden met zelfrapportage, hetgeen een van de redenen was om een subjectieve slaapkwaliteitsschaal te gebruiken, de Subjective Sleep Quality Scale (SSQS), om de slaapkwaliteit van ziekenhuispatiënten te meten. De SSOS bleek een valide en betrouwbaar instrument alhoewel de begripsvaliditeit nog verder onderzocht moet worden. Voorgesteld is om de SSQS in te korten voor verder gebruik.

Wat nu de kwaliteit van de slaap bepaalt, is nog steeds onduidelijk. In het algemeen wordt gesteld dat waakperiodes gedurende de slaap belangrijk zijn in de beoordeling van de slaap.

Deel II heeft de volgende probleemstelling: Wat is de omvang van slaapproblemen in een algemeen ziekenhuis en wat zijn de determinanten van deze slaapproblemen? resultaten worden gepresenteerd van de Studies II en III.

Het slaappatroon verandert zeer zeker in het ziekenhuis: bedtijd en het tijdstip van opstaan liggen vroeger, inslaapduur is langer, slaapduur is korter en patiënten worden vaker wakker met als gevolg dat de slaapkwaliteit afneemt in het ziekenhuis. Bijna 60 procent van de patiënten in Studie II gaven aan dat ze één of meer slaapproblemen ondervonden tijdens hun opname. Deze gegevens bevestigen de resultaten van de literatuurstudie naar slaap in het ziekenhuis.

De determinanten, gemeten in Studie II, waren omgevingsfactoren, persoonskenmerken en ziekte-gerelateerde factoren zoals ook aangetroffen in de literatuurstudie.

De factoren die de meeste variantie verklaarden van de slaapkwaliteit in het ziekenhuis waren: slaap thuis, welbevinden, omgevingsveranderingen en veranderingen in het normale slaappatroon zoals slaapgewoontes en de houding in bed. De slaapkwaliteit van een specifieke nacht werd meer verklaard door veranderingen veroorzaakt door de ziekenhuisomgeving, terwijl interne variabelen zoals welbevinden de slaapkwaliteit in het algemeen in het ziekenhuis verklaarden. Omgevingsfactoren worden bovendien door de patiënten niet altijd als slaapverstoorders gezien terwijl toch, als daarnaar werd gevraagd, de meerderheid van de patiënten aangaf frequent wakker te worden door bijvoorbeeld verpleegkundigen, kamergenoten of de verzorging van kamergenoten.

Patiënten werden in hoofdzaak wakker door verpleegkundigen, medepatiënten of tengevolge van de verzorging van die medepatiënten. Vaste omgevingsfactoren, zoals bijvoorbeeld apparatuur, werden minder vaak als slaapverstoorders genoemd. Als mogelijke verklaring werd genoemd dat die vaste omgevingsfactoren geaccepteerd werden als een consequentie van een ziekenhuisopname. Oudere patiënten gaven minder veranderingen aan in persoonlijke gewoontes tengevolge van een ziekenhuisopname dan jongere patiënten.

Slaapmedicatie voorgeschreven of verstrekt correleerde maar met een klein aantal variabelen, hetgeen erop kan duiden dat er geen duidelijk afdelingsbeleid was voor het gebruik van slaapmedicatie. Daarom was het niet mogelijk te corrigeren voor de invloed die slaapmedicatie heeft op de slaap. 
Deel III behandelt de probleemstelling: Welke beslissingen nemen verpleegkundigen ten aanzien van slaapproblemen? Gegevens van alle vier de studies zijn gebruikt voor dit deel.

Uit de literatuurstudie werd duidelijk dat het verstrekken van slaapmedicatie nog steeds de interventie is die het meest toegepast wordt door verpleegkundigen bij slaapproblemen. In de eerste drie studies werden gegevens verzameld over het aantal recepten voor en verstrekkingen van slaapmedicatie in een algemeen ziekenhuis. Hoewel het aantal recepten aanzienlijk varieerde tussen de ziekenhuizen, was dit niet het geval voor het aantal verstrekkingen hetgeen erop duidt dat de verpleegkundige uiteindelijk beslist over het al dan niet verstrekken van slaapmedicatie ongeacht de manier van voorschrijven. Het aantal patiënten dat slaapmedicatie ontvangen heeft, varieerde van 14 procent (ziekenhuis A) tot 38 procent (ziekenhuis E). Het laatste cijfer was wel inclusief de minor tranquilizers. Omdat slaapmedicatie niet in alle gevallen de meest geschikte interventie is voor slaapproblemen, afhankelijk van de oorzaak van het probleem, werd verwacht dat door de introductie van het verpleegkundig proces de verpleegkundige zorgverlening ten aanzien van slaapproblemen zou verbeteren. Uit de literatuurstudie over het verpleegkundig proces bleek dat het verpleegkundig proces in het algemeen beschouwd wordt als leidraad voor het beslissingsproces in de verpleging. Van verpleegkundige interventies wordt verondersteld dat ze gebaseerd zijn op de geformuleerde verpleegkundige diagnose. Daarom werd verwacht dat de introductie van het verpleegkundig proces ten aanzien van slaap zou leiden tot een verbetering van de slaapkwaliteit en -kwantiteit en tot een daling van het gebruik van slaapmedicatie. Geen enkele verwachting werd bevestigd door de resultaten van Studie III.

Geconcludeerd werd dat het uitblijven van resultaten mogelijk veroorzaakt is door methodologische problemen. De interventies die verpleegkundigen uitvoeren of zouden willen uitvoeren in de praktijk, hetgeen gemeten is in de "throughput evaluation", waren niet veranderd van de voormeting naar de nameting.

De diagnosen die verpleegkundigen formuleerden in de toegevoegde verpleegplannen waren slecht geformuleerd, vaak zonder vermelding van de oorzaak van het probleem, met als gevolg dat de interventies vaak beperkt bleven tot slaapmedicatie.

Slechts de helft van de slaapproblemen die patiënten uitten tijdens de interviews in Studie III waren vermeld in de verpleegplannen. Geconcludeerd werd dat verpleegkundigen problemen hebben met het nauwkeurig diagnostiseren van slaapproblemen van patiënten.

In Deel IV worden de conclusies gepresenteerd en besproken. Bovendien wordt een conceptueel model gepresenteerd, gebaseerd op Deel II van dit proefschrift. In dit model wordt weergegeven dat hoe actiever mensen met hun problemen omgaan en hoe meer ze piekeren, des te slechter hun slaap thuis is en des te slechter zij sliepen tijdens voorgaande opnames, des te meer veranderingen ze aangaven, zoals omgevingsveranderingen en veranderingen in slaapgewoontes en hoe slechter zij zich voelden tijdens de opname. Bovendien was hun slaap tijdens de huidige opname des te slechter. Dit conceptuele model moet wel nog verder getest worden. 


\section{References}

Abu-Saad, H. (1990). Assessment of pain in children: The school aged child. In: Proceedings round table nursing research conference, Utrecht.

Aggleton, P. \& Chalmers, H. (1985a). Models and theories. Defining the terms. Nursing Times, (sept.5), 24-28.

Aggleton, P. \& Chalmers, H. (1985b). Models and theories. Critical examination. Nursing Times, (april 3), 38-39.

Agnew, H.W. \& Webb, W.B. (1971). Sleep latencies in human subjects: Age, prior wakefulness, and reliability. Psychonomic Science, 24, 253-254.

Akerstedt, T. \& Gillberg, M. (1981). The circadian variation of experimentally displaced sleep. Sleep, 4, 159-169.

Anch, A.M., Browman, C.P., Mitler, M.M., \& Walsh, J.K. (1988). Sleep. A scientific perspective. Englewood Cliffs, Prentice Hall.

Aschoff, J. (1965). Circadian rhythms in man. Science, 148, 1427-1432.

Association of Sleep Disorders Centers (1979). Diagnostic classification of sleep and arousal disorders. Sleep, 2, 1-137.

Baekeland, F. \& Hoy, P. (1971). Reported vs. recorded sleep characteristics. Archives of General Psychiatry, 24, 548-551.

Baker, C.F. (1984). Sensory overload and noise in the ICU: Sources of environmental stress. Critical Care Quarterly, 6(4), 66-80.

Bayer, A.J. \& Pathy, M.S. (1985). Requests for hypnotic drugs and placebo response in elderly hospital in-patients. Postgraduate Medical Journal, 61, 317-320.

Beck, S.L. (1988). Measuring sleep. In: M. Frank-Stromborg, Instruments for clinical nursing research (pp.255-267). London, Appleton \& Lange.

Benner, P. (1982). From novice to expert. American Journal of Nursing, 82, 402-407.

Benner, P. (1984). From novice to expert. Menlo Park, Addison-Wesley.

Benner, P. \& Tanner, C. (1987). How expert nurses use intuition. American Journal of Nursing, $87,23-31$

Berk, H.A.A. De 11988). Over het gebruik van benzodiazepinepreparaten in de huisartsenpraktijk (Benzodiazepines prescribed by the general practioner). Doctoral dissertation. Helmond, Wibro dissertatiedrukkerij.

Berlin, R.M. (1984). Management of insomnia in hospitalized patients. Annals of Internal Medicine, 100, 398-404.

Beyerman, K. (1987). Etiologies of sleep pattern disturbance in hospitalized patients. In: A.M. McLane (Ed.), Classification of nursing diagnoses. Proceedings of the seventh conference. North American Nursing Diagnosis Association (pp. 193-198). St. Louis, The C.V. Mosby Company.

Bongers, A. (1989). Slaapinterventies in het ziekenhuis (Sleep interventions in hospital). Unpublished Master's thesis. Maastricht, University of Limburg.

Brewer, M.J. (1985), To sleep or not to sleep: The consequences of sleep deprivation. Critical Care Nurse, 5(6), 35-41.

Brinberg, D. \& McGrath, J.E. (1985). Validity and the research process. Newbury Park, Sage publications.

Browman, C.P. \& Tepas, D.I. (1976). The effects of presleep activity on all-night sleep. Psychophysiology, 13, 536-540.

Bruggen, H. Van der, (1991). Patiënt, privaat en privacy (Patient, privy and privacy). Doctoral dissertation. Lochem, De Tijdstroom.

Bruyneel, P. (1986). Slaap en medikatiegebruik (Sleep and medication). Verpleegkundigen en Gemeenschapszorg, (5), 238-249.

Bulechek, G.M. \& McCloskey, J.C. (1985). Nursing interventions: Treatments for nursing diagnoses. Philadelphia, W.B. Saunders Company. 
Buckwalter, K., Hartsock, J., \& Gaffney, J. (1985). Music therapy. In: G.M. Bulechek, \& J.C. McCloskey. Nursing interventions: Treatments for nursing diagnoses (pp. 58-74). Philadelphia, Saunders.

Canavan, T. (1984). The psychobiology of sleep. Nursing, 23, 682-683.

Capuano, T.A., Hitchings, K.S., \& Johnson, S. (1990). Respiratory nursing diagnoses: Practicing nurses' selection of defining characteristics. Nursing Diagnosis, 1, 169-174.

Cardellino, H. (1986). Quality assurance from a process audit approach. Nursing Management, $17,55-58$.

Carmines, E.G. \& Zeller, R.A. (1981). Reliability and validity assessment. Beverly Hills: Sage Publications, Inc.

Carpenito, L.J. (1991). The NANDA definition of nursing diagnosis. In: R.M. Carroll-Johnson (Ed.). Classification of nursing diagnoses. Proceedings of the ninth conference (pp.65-71). Philadelphia, J.B. Lippincott Company.

Carrascal, E., Allona, A., Oroz, A., \& Beorlegui, B. (1982). Study of factors disturbing nocturnal sleep in hospitalized patients. An attempt to modify them. In: Proceedings 5 th workgroup meeting (189-193). Workgroup of European Nurse Researchers. Research-a challenge for nursing practice. Uppsala, Sweden.

Carroll, J.S., Bliwise, D.L., \& Dement, W.C. (1989). A method for checking interobserver reliability in observational sleep studies. Sleep, 12, 363-367.

Carroll-Johnson, R.M. (1989). Classification of nursing diagnoses: Proceedings of the eighth conference. Philadelphia, J.B. Lippincott, Co.

Carskadon, M.A. \& Dement, W.C. (1982). The Multiple Sleep Latency Test: What does it measure? S/eep, 5, S67-S72.

Carskadon, M.A., Dement, W.C., Mitler, M.M., Guilleminault, C., Zarcone, V.P., \& Spiegel, R. (1976). Self-reports versus sleep laboratory findings in 122 drug-free subjects with complaints of chronic insomnia. American Journal of Psychiatry. 133, 1383-1388.

C.B.S. (1986). Compendium Gezondheidsstatistiek Nederland. Ministerie van Welzijn, Volksgezondheid en Cultuur. Staatsuitgeverij.

Chinn, P.L. \& Jacobs, M.K. (1987). Theory and nursing. A systematic approach. St. Louis, The C.V. Mosby Company.

Clapin-French, E. (1986). Sleep patterns of aged persons in long-term care facilities. Journal of Advanced Nursing, 11, 57-66.

Clift, A.D. 11975$\}$. Dependence on hypnotic drugs in general practice. In: A.D. Clift. S/eep disturbance and hypnotic dependence (p. 89). Amsterdam, Excerpta Medica.

Closs, S.J. (1988a). Assessment of sleep in hospital patients: A review of methods. Journal of Advanced Nursing, 13, 501-510.

Closs, S.J. (1988b). A nursing study of sleep on surgical wards. Report prepared for the Scottish Home and Health Department. University of Edinburgh, Department of nursing studies.

Coates, T.J., Killen, J.D., George, J., Marchini, E., Silverman, S., Hamilton, S., \& Thoresen, C.E. (1982). Discriminating good sleepers from insomniacs using all-night polysomnograms conducted at home. The Journal of Nervous and Mental Diseases, 170, 224-230.

Colling, J. (1983). Sleep disturbances in aging: A theoretic and empiric analysis. Advances in Nursing Science, 5(oct.), 36-44.

Corcoran, S.A. (1986). Task complexity and nursing expertise as factors in decision making. Nursing Research, 35, 107-112.

Cottrell, B.H., Cox, B.H., Kelsey, S.J., Ritchie, P.J., Rumph, E.A., \& Shannahan, M.K. (1986). A clinical evaluation tool for nursing students based on the nursing process. Journal of Nursing Education, 25, 270-274.

Cox, K., Senten, M.C.M., \& Halfens, R. (1988). Slapen in het ziekenhuis bezien vanuit een verpleegkundig perspectief: Een literatuurstudie ISleep in hospital from a nursing perspective: $A$ literature review). Verpleegkunde, 3, 84-93.

Craft, C.A. (1991a). Issues pertinent to implementation of nursing diagnosis. In: J.H. Carlson, C.A. Craft, A.D. McGuire, S. Popkess-Vawter. Nursing diagnosis. A case study approach (pp. 20-38). Philadelphia, W.B. Saunders Company.

Craft, C.A. (1991b). The diagnostic process. In: J.H. Carlson, C.A. Craft, A.D. McGuire, S. 
Popkess-Vawter. Nursing diagnosis. A case study approach (pp. 39-61). Philadelphia, W.B. Saunders Company.

Cuesta, C. De la (1983). The nursing process: From development to implementation. Journal of Advanced Nursing, 8, 365-371.

Curtis, B.J. \& Simpson, L.J. (1985). Auditing. A method for evaluating quality of care. JONA, 15(10), 14-21.

Czeisler, C.A., Weitzman, E.D., Moore-Ede M.C., Zimmerman, J.C., \& Knauer, R.S. 11980) Human sleep: Its duration and organization depend on its circadian phase. Science, 210, 1264-1267.

Davignon, D. \& Bruno, P. (1982). Insomnia: Causes and treatment, particularly in the elderly. Journal of Gerontological Nursing, 8, 333-336.

DeDiana, 1. (1976). Two stochastic sleep quality scales for self-rating of subjects' sleep. Sleep, 5, 101

Dement, W.C., Miles, L.E., \& Carskadon, M.A. (1982). "White paper" on sleep and aging. Journal of the American Geriatrics Society, 30 (1), 25-50.

Dotson, C.H. (1986). Perception of sleep following burn injury, JBCR, 7, 105-108.

Ellis, 8.W., Johns, M.W., Lancaster, R., Raptopoulos, P. Angelopoulos, N., \& Priest, R.G. (1981). The St. Mary's hospital sleep questionnaire: A study of reliability. S/eep, 4, 93-97.

Farmacotherapeutisch Kompas (Farmacotherapeutic guide) (1989). Centrale Medisch Pharmaceutische Commissie van de Ziekenfondsraad. Amstelveen, De Toorts.

Farr, L., Keene, A., Samson, D., \& Michael, A. (1984). Alterations in circadian excretion of urinary variables and physiological indicators of stress following surgery. Nursing Research, 33, 140-146.

Felton, G. (1987). Human biologic rhythms. In: J.J. Fitzpatrick, R.L. Tauton (Eds.). Annual review of nursing research, (pp. 45-77). New York, Springer Publishing Company.

Floyd, J.A. (1984). Interaction between personal sleep-wake rhythms and psychiatric hospital rest activity schedule. Nursing Research, 33, 255-259.

Fontaine, D.K. (1989). Measurement of nocturnal sleep patterns in trauma patients. Heart \& Lung, 18, 402-410.

Frankel, B.L., Coursey, R.D., Buchbinder, R., \& Snyder, F. (1976). Recorded and reported sleep in chronic primary insomnia. Archives of General Psychiatry, 33, 615-623.

Fräser, M. (1990). Using conceptual nursing in practice. London, Harper \& Row.

Gordon, M. (1987). Nursing diagnosis. Process and application. New York, McGraw-Hill.

Graaf, W. De (1984). Huisarts en s/aapgedrag (General practioner and sleep). Doctoral dissertation, Lisse, Swets \& Zeitlinger.

Gress, L.D., Bahr, R.T., \& Hassanein, R.S. (1981). Nocturnal behavior of selected institutionalized aldults. Journal of Gerontological Nursing, 7(2), 86-92.

Halfens, R., Drop, M.J., \& Philipsen, H. (1984). Leefwijzen en subjectieve gezondheid van een panel uit de Nederlandse bevolking (Way of living and appraisal of health of a cohort from the Dutch population). Nederland Oké, Maastricht.

Hammond, K.R. (1966). Clinical inference in nursing II. A psychologist's viewpoint. Nursing Research, 15, 27-38.

Hammond, K.R., Kelly, K.J., Schneider, R.J., \& Vancini, M. (1966a). Clinical inference in nursing: Analyzing cognitive task representative of nursing problems. Nursing Research, 15, 134-138

Hammond, K.R., Kelly, K.J., Schneider, R.J., \& Vancini, M. (1966b). Clinical inference in nursing: Information units used. Nursing Research, 15, 236-243.

Hammond, K.R., Kelly, K.J., Castellan, D.J., Schneider, R.J., \& Vancini, M. (1966c). Clinical inference in nursing: Use of information seeking strategies by nurses. Nursing Research, 15, 330-336.

Hammond, K.R., Kelly, K.J., Schneider, R.J., \& Vancini, M. (1967). Clinical inference in nursing: Revising judgements. Nursing Research, 16(1), 38-45.

Harris, E. (1981). Sedative-hypnotic drugs. American Journal of Nursing, 81, 1329-1334.

Hartmann, E. (1973). Sleep requirement: Long sleepers, short sleepers, variable sleepers, and insomniacs. Psychosomatics, XIV, 95-103. 
Hartmann, E., Baekeland, F., \& Zwilling, G.R. (1972). Psychological differences between long and short sleepers. Archives of General Psychiatry, 26, 463-468.

Hartmann, E., Baekeland, F., Zwilling, G., \& Hoy, P. (1971). Sleep need: How much sleep and what kind? The American Journal of Psychiatry, 127, 1001-1008.

Haussmann, R.K.D., \& Hegyvary, S.T. (1976). Field testing the nursing quality monitoring methodology. Phase II. Nursing Research, 25, 324-331.

Hawthorn, P.J. (1984). Measuring change in nursing practice. Journal of Advanced Nursing, 9 , 239-247.

Haynes, S.N., Follingstad, D.R., \& McGowan, W.T. (1974). Insomnia: Sleep patterns and anxiety level. Journal of Psychosomatic Research, 18, 69-74.

Hayter, J. (1980). The rhythm of sleep. American Journal of Nursing, 80, 457-461.

Henderson, V. (1966). The nature of nursing. New York, Macmillan.

Henderson, V. (1982). The nursing process-is the title right? Journal of Advanced Nursing, 7 , 103-116.

Hengeveld, M.W. (1982). Gebruik van benzodiazepinen in algemene ziekenhuizen (The use of benzodiazepines in general hospitals). In: H.G. Rooymans, F.G. Zitman. Benzodiazepinen. Alphen aan de Rijn, Stafleu.

Herbert, M. (1978). Studies of sleep in the elderly. Age and Ageing, 7 ( S), 41-45.

Herbert, M., Johns, M.W., \& Dore, C. (1976). Factor analysis of analogue scales measuring subjective feelings before and after sleep. British Journal of Medical Psychology, 49, 373. 379.

Hilton, B.A. (1976). Quantity and quality of patient's sleep and sleep disturbing factors in a respiratory intensive care unit. Journal of Advanced Nursing, 1, 453-468.

Hilton, B.A. (1985). Noise in acute patient care settings. Research in Nursing and Health, 8 , 283-291.

Hoch, C. \& Reynolds III, C. (1986). Sleep disturbances and what to do about them. Geriatric Nursing, (1), 24-27

Hoch, C.C., Reynolds III, C.F., Kupfer, D.J., Berman, S.R., Houck, P.R., \& Stack, J.A. (1987). Empirical note: Self-report versus recorded sleep in healthy seniors. Psychophysiology, 24, 293-299.

Hoddes, E., Zarcone, V., Smythe, H., Phillips, R., \& Dement, W.C. (1973). Quantification of sleepiness: A new approach. Phychophysiology, 10, 431-436

Horne, J. (1989). Why we sleep: The functions of sleep in humans and other mammals. Oxford, Oxford University Press.

Horne, J.A. \& Ostberg, O. (1976). A self-assessment questionnaire to determine morningnesseveningness in human circadian rhythms. International Journal of Chronobiology, 4, 97-110.

Hyman, R.B., Feldman, H.R., Harris, R.B., Levin, R.F., \& Mallory, G.B. (1989). The effects of relaxation training on clinical symptoms: A meta-analysis. Nursing Research, 38, 216-220.

Itano, J.K. (1989). A comparison of the clinical judgement process in experienced registered nurses and student nurses. Journal of Nursing Education, 2813), 120-126.

James, D.S. (1985). Survey of hypnotic drug use in nursing homes. Journal of the American Geriatrics Society, 33, 436-439.

Jenkins, C.D., Stanton, B.A., Niemcryk, S.J., \& Ross, R.M. 11988). A scale for the estimation of sleep problems in clinical research. Journal of Clinical Epidemiology, 41, 313-321.

Johns, M.W. (1971). Methods for assessing human sleep. Archives of Internal Medicine, 127, 484-492.

Johns, M.W. (1975). Factor analysis of subjectively reported sleep habits and the nature of insomnia. Psychological Medicine, 5, 83-88.

Johns, M.W. \{1977\}. Validity of subjective reports of sleep latency in normal subjects. Ergonomics, 20, 683-690.

Johns, M.W., Bruce, D.W., \& Masterton, J.P. (1974). Psychological correlates of sleep habits reported by healthy young adults. British Journal of Medical Psychology, 47, 181-187.

Johnson, J. (1985). Drug treatment for sleep disturbances: Does it really work? Journal of Gerontological Nursing, 11(8), 8-12.

Johnson, S.E. (1989). Sleep pattern disturbance: Defining characteristics observable in practi- 
ce. In: R.M. Carroll-Johnson (Ed.). Classification of nursing diagnoses. Proceedings of the eighth conference (pp. 368-370). Philadelphia, J.B. Lippincott Company.

Kales, A. (1969). Psychophysiological studies of insomnia. Annals of Internal Medicine, 71 , 625-629.

Kales, A., Caldwell, A.B., Preston, T.A., Healy, S., \& Kales, J.D. (1976). Personality patterns in insomnia. Archives of General Psychiatry, 33, $1128-1134$.

Kales, A., Caldwell, A.B., Soldatos, C.R., Bixler, E.O., \& Kales, J.D. (1983). Biopsychobehavioral correlates of insomnia. II Pattern specificity and consistency with the Minnesota Multiphasic Personality Inventory. Psychosomatic Medicine, 45, 341-356.

Kales, A. \& Kales, J. (1970). Evaluation, diagnosis, and treatment of clinical conditions related to sleep. JAMA, 213, 2229-2235.

Kales, A. \& Kales, J.D. (1974). Sleep disorders, recent findings in the diagnosis and treatment of disturbed sleep. New England Journal of Medicine, 290, 487-499.

Kales, A., Wilson, T., Kales, J.D., Jacobson, A., Paulson, M.J., Kollar, E., \& Walter, R.D. (1967). Measurements of all-night sleep in normal elderly persons: Effects of aging. Journal of the American Geriatrics Society, XV, 405-414.

Kampman, R. (1981). Een onderzoek naar de kwaliteiten van een subjectieve slaapkwaliteitsschaal (A study on the qualities of a subjective sleep quality scale). Instituut Preventieve en Sociale Psychiatrie, Erasmus Universiteit, Rotterdam.

Karacan, I., Green, J.R., Taylor, W.J., William, J.C., Elliot, R.S., Thornby, J.I., \& Sales, P.J (1973). Sleep characteristics of acute myocardial infarct patients in an ICU. S/eep Research, 2, 159 .

Karacan, I., Thornby, J.l., \& Williams, R.L. (1983). Sleep disturbance: A community survey. In: C.Guillemenault, E. Lugaresi (Eds.). Sleep/wake disorders: Natural history, epidemiology, and long-term evolution. New York, Raven Press.

Kerkhof, G.A. (1984). Een Nederlandse vragenlijst voor de selectie van ochtend- en avondmensen (A Dutch questionnaire to determine morning types and evening types). Nederlands Tijdschrift voor de Psychologie, 39, 281-294.

Klop, R. (1984). Angstbeleving van cardiologische patiënten en de herkenning hiervan door verpleegkundigen (Anxiety of cardiac patients and the recognition of anxiety by nurses). In: Nieuwe wetenschappers voor de gezondheidszorg (pp.40-48). Maastricht, University of Limburg.

Knab, B. \& Engel-Sittenfeld, P. (1983). The many facets of poor sleep. Neuropsychobiology, $10,141-147$.

Knab, B. \& Engel, R.R. (1988). Perception of waking and sleeping: Possible implications for the evaluation of insomnia. Sleep, 11, 265-272.

Kripke, D.F., Hauri, P., Ancoli-Israel, S., \& Roth, T. (1990). Sleep evaluation in chronic insomniacs during 14-day use of flurazepam and midazolam. Journal of clinical Psychopharmacology, 1014 suppl. 1, 32S-43S.

Ladwig, K.H. (1979). Nachtschafanamnese in der internistischen Klinik (Anamnesis of sleep in the internal medicine hospital(author's transl)). Med. Klin.. 74, 1957-1961.

Lamb, M.A. (1982). The sleeping patterns of patients with malignant and non-malignant diseases. Cancer Nursing, 5, 389-396.

Lampe, S.S. \& Hitchock, A. (1987). Documenting nursing diagnosis using focus charting. In: A.M. McLane (Ed.), Classification of nursing diagnoses. Proceedings of the seventh conference. North American Nursing Diagnosis Association (pp. 377-382). St. Louis, The C.V. Mosby Company.

Lendfers, M.L.H.G. (1988). Slaapmedikatiegebruik in het algemene ziekenhuis en hoeveelheid bepalende verpleegkundige factoren (Sleep medication usage in the general hospital and related nursing characteristics). Unpublished master's thesis. Maastricht, University of Limburg.

Lerner, R. (1982). Sleep loss in the aged: Implications for nursing practice. Journal of Gerontological Nursing, 8, 323-326

Leuenberger, F., Voegeli, M., \& Wingeier, M. (1983). Wie erleben Patienten die Nacht im Spital (How do patients experience nights in the hospital). Krankenpflege, (4), 30-32. 
Lewis, H.E. \& Masterton, J.P. (1957). Sleep and wakefulness in the arctic. Lancet, 1, 1262 1266

Lewis, S.A. (1969). Subjective estimates of sleep: An EEG evaluation. The British Journal of Psychology, 60, 203-208.

Lillisand, K.M. \& Korff, S. (1983). Nursing process evaluation: A quality assurance tool. Nursing Administration Quarterly, 7(3), 9-14.

Lo, C.K. \& Kim, M.J. (1986). Construct validity of sleep pattern disturbance: A methodological approach. In: M.E. Hurley (Ed.). Classification of nursing diagnoses. Proceedings of the sixth conference (pp.197-206). St.Louis, The C.V. Mosby Company.

Mamelak, M., Csima, A., \& Price, V. (1990). The effects of a single night's dosing with triazolam on sleep the following night. Journal of Clinical Pharmacology, 30, 549-555.

Marks, R.M. \& Sachar, E.J. (1973). Undertreatment of medical inpatients with narcotic analgesics. Annals of Internal Medicine, 78, 173-181.

Marriner, A. (1979). The nursing process. St. Louis, The C.V. Mosby Company.

Maslow, A. (1970). Motivation and personality. New York, Harper \& Row.

Mayfield, D.G. \& Morrison, D. (1973). The use of minor tranquilizers in a teaching hospital. Southern Medical Journal, 66, 589-592.

McCaffery, M. (1979). Nursing management of patients in pain. Philadelphia, J.B. Lippincott Co.

McFarland, G.K. \& McFarlane, E.A. (1989). Nursing diagnosis \& intervention. St. Louis, The C.V. Mosby Company.

McFarlane, J.K. \& Castledine, G. (1983). A guide to the practice of nursing using the nursing process. St. Louis, The C.V. Mosby Company.

McGhie, A. \& Russel, M.S. (1962). The subjective assessment of normal sleep patterns. Journal of Mental Science, 108, 642-654.

McGhie, A. (1966). The subjective assessment of sleep patterns in psychiatric illness. British Journal of Medical Psychology, 39, 221-230.

McGonigal, K.S. (1986). The importance of sleep and the sensory environment to critically ill patients. Intensive Care Nursing, 2(2), 73-83.

McGuire, C.H. (1985). Medical problem solving. A critique of the literature. Journal of Medical Evaluation, 60, 587-595.

McLane, A. (1987). Classification of nursing diagnoses: Proceedings of the seventh conference. St. Louis, The C.V. Mosby Company.

McNeil, B.J., Padrick, K.P., \& Wellman, J. (1986). 'I didn't sleep a wink'. American Journal of Nursing, 86(1), 26-27.

Meddis, R. (1977). The sleep instinct. London, Routledge \& Kegan Paul.

Mendelson, W.B. (1989). Human s/eep. Research and clinical care. New York, Plenum Medical Book Company.

Merica, H. \& Gaillard, J.M. (1985). Standard description and evaluation of the interrelationships of standard sleep variables for normal subjects. Sleep, 8, 261-273.

Merwijk, A.C.J.M. Van (1990). Gebruik van slaapmedicatie in het ziekenhuis en het daarop volgende gebruik in de thuissituatie (Use of sleep medications in the hospital and the use of it at home after discharge). Unpublished master's thesis. Maastricht, University of Limburg.

Metzger, K.L. \& Hiltunen, E.F. (1987). Diagnostic content validation of ten frequently reported nursing diagnoses. In: A.M. McLane (Ed.), Classification of nursing diagnoses. Proceedings of the seventh conference. North American Nursing Diagnosis Association (pp. 144-153). St. Louis, The C.V. Mosby Company.

Miles, L.E. \& Dement, W.C. (1980). Biological rhythm aspects of sleep-wake function in the aged. Sleep, 3, 163-170.

Miller (1985a). Does the process help the patient? Nursing Times, (june 26), 24-27.

Miller, A. (1985b). The relationship between nursing theory and nursing practice. Journal of Advanced Nursing, 10, 417-424.?

Milne, B. (1982). Sleep-wake disorders and what can we do about them. Canadian Nurse. 78(4), 24-27.

Milne, D. (1985). 'The more things change the more they stay the same': Factors affecting the 
implementation of the nursing process. Journal of Advanced Nursing, 10, 39-45.

Monroe, L.J. (1967). Psychological and physiological differences between good and poor sleepers. Journal of Abnormal Psychology, 72, 255-264.

Moore, M.N. (1989). Development of a sleep-awake instrument for use in a chronic renal population. ANNA Journal, 16, 15-19.

Morgan, K. \& Oswald, I. (1981). Anxiety caused by a short-life hypnotic. British Medical Journal, $284,942$.

Morgan, K., Healy, D.W., \& Healy, P.J. (1989). Factors influencing persistent subjective insomnia in old age. A follow-up study of good and poor sleepers aged 65 to 74. Age and Ageing, 18, 117.122.

Morrison, D. \& Mayfield, D.G. (1972). Sleep insurance: A valid use of hypnotics? N.C.M.J., 33. 862-865.

Moses, J., Lubin, A., Naitoh, P., \& Johnson, L.C. (1972). Reliability of sleep measures. Psychophysiology, 9(1), 78-82.

Mulder-Hajonides van der Meulen, W.R.E.H., Wijnberg, J.R., Hollander, J.J., DeDiana, I.P.F., \& Hoofdakker, R.H. van den (1980, September). Measurement of subjective s/eep quality. Paper presented at the 5th European Congress on Sleep Research, Amsterdam, The Netherlands.

Mulhearn, S. (1989). The nursing process: Improving psychiatric admission assessment? Journal of Advanced Nursing, 14, 808-814.

Murphy, F., Bentley, S., Ellis, B.W., \& Dudley, H. (1977). Sleep deprivation in patients undergoing operation: A factor in the stress of surgery. British Medical Journal, 2(6101), 1521 1522

Musch, B. \& Maillard, F. (1990). Zoplicone, the third generation hypnotic: a clinical overview. International Clinical Psychopharmacology, 5, 147-158.

Newman, M.A. (1986). Health as expanding consciousness. St. Louis, The C.V. Mosby Company

Nightingale, F. $(1859,1947)$. Notes on nursing. What it is, and what it is not. Philadelphia, J.B. Lippincott Company.

Offerhaus, L. (1988). Nogmaals benzodiazepinen: Te veel, te lang en te sterk? (Once more benzodiazepines: Too many, too long, and too strong?). Nederlands Tijdschrift voor Geneeskunde, 132, 1921-1924.

Ogilvie, A.J. (1980). Sources and levels of noise on the ward at night. Nursing Times, 13631366.

Orem, D.E. (1985). Nursing. Concepts of practice. New York, McGraw-Hill Book Company.

Orlando, I.J. (1961). The dynamic nurse-patient relationship. New York, Putnam.

Oswald, I. (1980). Sleep studies in clinical pharmacology. British Journal of Pharmacology, 10 , 317-326.

Pacini, C.M. \& Fitzpatrick, J.J. (1982). Sleep patterns of hospitalized and non-hospitalized aged individuals. Journal of Gerontological Nursing, 8, 327-332.

Parrot, A.C. \& Hindmarch, I. (1978). Factor analysis of a sleep evaluation questionnaire. Psychological Medicine, 8, 325-329.

Perry, S.W. \& Albert, W.W. 11984). Rationale for the use of hypnotic agents in a general hospital. Annals of Internal Medicine, 100, 441-446.

Ploeg, H.M. Van der, Defares, P.B., \& Spielberger, C.D. (1980). Handleiding bij de Zelf-Beoordelings Vragenlijst. Een Nederlandse bewerking van de Spielberger State-Trait Anxiety Inventory. Lisse, Swets \& Zeitlinger.

Polit, D.F. \& Hungler, B.P. (1987). Nursing research. Principles and methods, Philadelphia: J.B. Lippincot Company.

Price, M.R. (1980). Nursing diagnosis. Making a concept come alive. American Journal of Nursing. 80, 668-671.

Prokop, M. (1982). Insomnia: From a nursing perspective. In: C.M. Norris. Concept clarification in nursing (pp. 301-308). Rockville, Aspen.

Putzier, D.J., Padrick, K., Westfall, U.E., \& Tanner, C.A. (1985). Diagnostic reasoning in critical care nursing. Heart \& Lung, 14, 430-437. 
Radwin, L.E. (1990). Research on diagnostic reasoning in nursing. Nursing Diagnosis, 112), 70 77.

Regestein, Q.D., \& Barbiasz, J.E. (1980). Sleep disorders: Recognizing them in patients. The Journal of Practical Nursing, 30(nov/dec), 21-22, 62.

Reimer, M. (1987). Sleep pattern disturbance: Nursing interventions perceived by patients and their nurses as facilitating nocturnal sleep in hospital. In: A.M. McLane (Ed.), Classification of nursing diagnoses. Proceedings of the seventh conference. North American Nursing Diagnosis Association (pp. 372-376). St. Louis, The C.V. Mosby Company.

Reynolds III, C.F., Coble, P.A., Black, R.S., Holzer, B., Caudl, R., \& Kupfer, D.J. (1980). Sleep disturbances in a series of elderly patients. Polysomnographic findings. Journal of the American Geriatric Society, 28(4), 164-170.

Reynolds III, C.F., Kupfer, D.J., Hoch, C.C., \& Sewitch, D.E. 11985). Sleeping pills for the elderly: Are they ever justified? J. Clin. Psychiatry, 46(2), 9-12.

Richards, K. (1987a). Techniques for measurement of sleep in critical care. Focus an critical care, 1414), 34-40.

Richards, D.A. (1987b). The nursing process: The effect on patients' satisfaction with nursing care. Journal of Advanced Nursing, 12, 559-562.

Robinson, C. (1986). Impaired sleep. In: V.K. Carrieri, A.M. Lindsey, and C.M. West. Pathophysiologica phenomena in nursing (pp. 390-417). Philadelphia, W.B. Saunders Company

Roeder, M.A. (1980). Patient care plans and the evaluation of nursing process. Supervisor Nurse, 11, 57-58.

Rogers, M.E. (1970). An introduction to the theoretical basis of nursing. Philadelphia, F.A. Davis Company.

Rosekind, M.K. \& Schwartz, G.E. (1988). The perception of sleep and wakefulness I: Accuracy and certainty of subjective judgements. Sleep Research, 17,89.

Ross, M.M., Hare, K., \& McPherson, M. (1986). When sleep won't come: Helping our elderly clients. Canadian Nurse, 82(9), 14-18.

Rossi, L., Fitzmaurice, J.B., Glynn, M.A., \& Connors, K. (1987). Validation of the defining characteristics for sleep pattern disturbance. In: A.M. McLane (Ed.), Classification of nursing diagnoses. Proceedings of the seventh conference. North American Nursing Diagnosis Association (p. 279). St. Louis, The C.V. Mosby Company.

Roy, C. (1984). Introduction to nursing. An adaptation model. Englewood Cliffs, Prentice Hall Inc.

Ruler, A. \& Lack, L. (1988). Gender differences in sleep. Sleep Research, 17, 244.

Salzman, C. (1981). Psychotropic drug use and polypharmacy in a general hospital. General Hospital Psychiatry, 3, 1-9.

Scandrett, S. \& Uecker, S. (1985). Relaxation training. In: G.M. Bulechek \& J.C. McCloskey Nursing interventions. Treatments for nursing diagnoses (pp.22-48). Philadelphia, W.B. Saunders Company.

Schirmer, M.S. (1983). 'When sleep won't come.' Journal of Gerontological Nursing, 9(1), 16. 21.

Schmele, J.A. (1985). A method for evaluating nursing practice in a community setting. ORB, (april), 115-122.

Schmidt-Kessen, W. \& Kendel, K. (1973). Einfluss der Raumtemperatur auf den Nachtschlaf (Influence of room temperature on sleep). Res. Exp. Med.(Berlin), 160, 220-233.

Schneider-Helmert, D. \& Kumar, A. (1986). Subjective and objective measures of awakening among normals and insomniacs. Sleep Research, 15, 166.

Schreurs, P.J.G., Tellegen, B., \& Willige, G. Van de (1984). Gezondheid, stress, coping: De ontwikkeling van de Utrechtse Coping-lijst (Health, stress, coping: The development of the Utrecht Coping Questionnaire). Gedrag-Tijdschrift voor Psychologie, 12, 101-117.

Schulkens, Y. (1987). De herkenning van angstbeleving van de patiënt door de verpleegkundige en de factoren die hierbij een rol spelen (Recognition of patient's anxiety by nurses and related factors). Unpublished master's thesis. Maastricht, Universtiy of Limburg.

Seidl, E. \& Walter, J. (1984). Der Schlaf der Kranken im Spital (Patients' sleep in hospital). In: E. Seidl \& J. Walter, Der Patient und das Krankenhaus (pp. 56-92). Wien: Verlag Wilhelm 
Maudrich.

Seidlitz, P.R. (1981). Excessive noise levels detrimental to patients, staff. Hospital Progress, (febr.), 54-56, 64 .

Sharpley, A.L., Solomon, R.A., \& Cowen, P.J. (1990). Sleep stability with home sleep recording and automatic sleep stage analysis. Sleep, 13, 538-540.

Shea, H.L. (1986). A conceptual framework to study the use of nursing care plans. International Journal of Nursing Studies, 23, 147-157.

Simon, C. (1983). Benzodiazepine hypnotics for insomnia. Nurses' Drug Alert, 7(9), 68-70.

Smith, S. (1985). Drugs and sleep. Nursing Times, 82(6), 36-37.

Snyder, F., Hobson, J.A., Moneson, D.F., \& Goldfrank, F. (1964). Changes in respiration, heart rate, and systolic blood pressure in human sleep. J. Appl. Physiol., 19, 417-422.

Snyder-Halpern, R. (1985). The effect of critical care unit noise on patient sleep cycles. Critical Care Ouarterly, 7(4), 41-50.

Snyder-Halpern, R. \& Verran, J.A. (1987). Instrumentation to describe subjective sleep characteristics in healthy subjects. Research in Nursing and Health, 10, 155-163.

Stanton, M. (1985). Nursing theories and the nursing process. in: J.B. George (Ed.). Nursing theories. The base for professional nursing practice (pp. 319-337). London, Prentice-Hall International.

Stanton, M., Paul, C., \& Reeves, J.S. (1985). An overview of the nursing process. In: J.B. George (Ed.). Nursing theories. The base for professional nursing practice (pp. 14-33). London, Prentice-Hall International.

Stead, W. (1985). One awake. All awake! Quality and quantity of hospital patients' sleep. Nursing Mirror, 160(16), 20-1.

Stevens, B.J. (1984). Nursing theory. Analysis, application, evaluation. Boston, Little, Brown \& Company.

Tabachnick, B.G. \& Fidell, L.S. (1989). Using multivariate statistics. New York, Harper \& Row.

Tanner, C.A., Padrick, K.P., Westfall, U.E., \& Putzier, D.J. (1987). Diagnostic reasoning strategies of nurses and nursing students. Nursing Research, 36, 358-363.

Taub, J.M. \& Berger, R.J. (1976). The effects of changing the phase and duration of sleep. Journal of Experimental Psychologv, 2(1), 30-41.

Thomas, C.D. (1987). Insomnia, identification and management. Seminars in Oncology Nursing, 3. $263-266$.

Thornby, J.I., Karacan, I., Beutler, L.E., Booth, G.H., Anch, A.M., Williams, R.L., Salis, P.J., \& Backburn, A.B. (1974). Once more thrice: Objective-subjective correlations in sleep. S/eep Research, 3, 91.

Todd, B. (1982). Drugs and the elderly. Precautions with hypnotics. Geriatric Nursing, 3, 343346.

Torres, G. 11985). The place of concepts and theories within nursing. In: J.B. George (Ed.). Nursing theories: The base for professional nursing practice (pp.1-13). London, Prentice-Hall International.

Torres, G. \{1986\}. Theoretical foundations of nursing. London, Prentice-Hall International.

Tune, G.S. (1968). Sleep and wakefulness in normal human adults. British Medical Journal, 2, 269-271.

Tune, G.S. (1969). Sleep and wakefulness in 509 normal human adults. British Journal of Medical Psychology, 42, 75-80.

Turner, A.G., King, C.H., \& Craddock, J.G. (1975). Measuring and reducing noise. Hospitals, 49, $85-90$.

Vandenbosch, T.M., Bentley, C.L., Jones, K.A., \& Blake, D. (1986). Tailoring care plans to nursing diagnoses. American Journal of Nursing, 86, 313-314

Verran, J.A. \& Snyder-Halpern, R. (1988). Do patients sleep in the hospital. Applied Nursing Research, $1(2), 95$.

Visser, A.Ph. (1984a). De beleving van het verblijf in het algemeen ziekenhuis (The experience of a general hospital admission). Assen, Van Gorcum.

Visser, A.Ph. (1984b). Het gebruik van rustgeende en pijbestrijdingsmiddelen door chirurgische patiënten (Usage of tranquillizers and pain medications by surgical patients). T.A/c. Drugs, 
$10(1), 28-36$

Visser, P., Hofman, W.F., Kumar, A., Cluydts, R., DeDiana, I.P.F., Marchant, P., Bakker, H.J., Diest, R. Van, \& Poelstra, P.A.M. (1978). Sleep and mood: Measuring the sleep quality. In: R.G. Priest, A. Pletscher, \& J. Ward, Proceedings of the Northern European Symposium on Sleep Research (pp. 135-145). Basle, Switzerland, MTP

Webb, W.B. \& Agnew, H.W. (1971). Stage 4 sleep: Influence of time course variables. Science, 174, 1354-1356.

Webster, R.A. \& Thompson, D.R. (1986). Sleep in hospital. Journal of Advanced Nursing. 11 , 447-457.

Westfall, U.E., Tanner, C.A., Putzier, D., \& Padrick, K.P. (1986). Activating clinical inferences: A component of diagnostic reasoning in nursing. Research in Nursing and Health, 9, 269277.

White, M., Wear, E., \& Stephenson, G. (1983). A computer-compatible method for observing falling asleep behavior of hospitalized children. Research in Nursing \& Health, 6, 191-198.

Williams, R.L., Karacan, I., \& Hursch, C.J. (1974). Electroencephalography (EEG) of human sleep: Clinical applications. New York, Wiley.

Woods, N.F., \& Falk, S.A. (1974). Noise stimuli in the acute care area. Nursing Research, 23. 144-150.

Woolley, N. (1990). Nursing diagnosis: Exploring the factors which may influence the reasoning process. Journal of Advanced Nursing, 15, 110-117.

Young, M.S. \& Lucas, C.M. (1984). Nursing diagnosis: Common problems in implementation. Topics in Clinical Nursing, 5(4), 68-77.

Yura, H. \& Walsh, M.B. (1983). The nursing process. Assessing, planning, implementing, evaluating. Norwalk, Appleton-Century-Crofts.

Yura, H. \& Walsh, M.B. (1988). The nursing process. Assessing, planning, implementing, evaluating. Norwalk, Appleton \& Lange.

Zitman, F.G. (1988). Kort- en langwerkende benzodiazepinen (Short and long-acting benzodia. zepines). Nederlands Tijdschrift voor Geneeskunde, 132, 1917-1921. 


\section{Appendix A}

Table 1 The SSOS at night 1 and night 2 in hospital: Factor loadings without rotation.

\begin{tabular}{lcc}
\hline & $\begin{array}{c}\text { Night 1 } \\
\text { factor 10 }\end{array}$ & $\begin{array}{c}\text { Night 2 } \\
\text { factor } 1^{\dagger}\end{array}$ \\
\hline I feel that I slept good last night. & .82 & .85 \\
I feel that I only had a couple of hours sleep last night. & .81 & .81 \\
After awakening last night it was difficult to fall asleep again. & .76 & .76 \\
I didn't sleep more than 5 hours last night. & .74 & .74 \\
I feel that I had a poor sleep last night. & .72 & .76 \\
I feel that I didn't get enough sleep last night. & .71 & .80 \\
I felt rested after awaking this morning. & .69 & .78 \\
I did fall asleep easily last night. & .67 & .52 \\
I tossed and turned all night. & .64 & .64 \\
It took more than half an hour to fall asleep last night. & .58 & .51 \\
I think I had a deep sleep last night. & .54 & .66 \\
I felt tired and exhausted after awaking this morning. & .51 & .64 \\
I did awake several times last night. & .50 & .67 \\
I didn't sleep a wink last night. & .42 & .40 \\
I got up in the middle of the night. & .22 & .30 \\
\hline
\end{tabular}

eigenvalue 6.2 variance $41 \%$

1 eigenvalue 6.8 variance $45 \%$

Table 2 The SSOS at home: Factor loadings without rotation.

\begin{tabular}{lc}
\hline & $\begin{array}{c}\text { At home } \\
\text { factor } 1\end{array}$ \\
\hline I feel that I mostly sleep well. & .84 \\
I feel that I don't get enough sleep most of the time. & .80 \\
I feel that I sleep poorly most of the time. & .78 \\
I often fall asleep easily. & .76 \\
I feel that I often get only a couple of hours sleep during the night. .75 \\
After awaking at night it is difficult to fall asleep again. & .74 \\
Mostly I feel rested after awaking in the morning. & .71 \\
It often takes longer than half an hour to fall asleep. & .68 \\
Often I awake several times a night. & .67 \\
I often feel tired and exhausted after awaking in the morning. & .65 \\
Often I don't sleep a wink. & .64 \\
Mostly I toss and turn all night. & .64 \\
I think I have a deep sleep most of the nights. & .63 \\
Often I get up in the middle of the night. & .60 \\
I don't sleep more than 5 hours. & .60
\end{tabular}

eigenvalue 7.4 variance $50 \%$ 
Table 3

Cronbach's alphas of the shortened SSaS for Study II $(n=141)$ and Study III ( $n=482$ ).

Study II Study III

\begin{tabular}{lll}
\hline At home & .87 & .83 \\
Night 1 & .85 & $\cdots-$ \\
Night 2 & .88 & $-\ldots$ \\
Hospital in general & .87 & .85 \\
\hline
\end{tabular}

Table 4 Correlation coefficients (Pearson) between the scores on the 5-point scales and the shortened SSaS in Study II $(n=141)$.

\section{5-Point scales}

\section{ssas}

\begin{tabular}{ll}
\hline At home & $.74 *$ \\
Night 2 & .82 \\
Hospital in general & $.67 *$
\end{tabular}

$* 0.001$

Table 5 Correlation coefficients (Pearson) between qualitative, quantitative sleep characteristics and the scores on the shortened SSOS in Study II $(n=141)$ and Study III $(n=482)$.

\begin{tabular}{lccc}
\hline & \multicolumn{2}{c}{ Study II } & $\begin{array}{c}\text { Study III } \\
\text { Hospital in general }\end{array}$ \\
\cline { 2 - 4 } & At home & Night 2 & $.55^{*}$ \\
\hline $\begin{array}{l}\text { Duration of sleep } \\
\text { Number of awakenings }{ }^{\dagger}\end{array}$ & $.49^{*}$ & $.66^{*}$ & $-.44^{*}$ \\
Sleep latency, & & & $-.37^{*}$ \\
\hline
\end{tabular}

not measured in Study II

${ }^{*} p \leq .001$ 
Table 6 The mean shortened SSOS scores for three age groups in Studies II and III.

\begin{tabular}{lccccccc}
\hline & \multicolumn{4}{c}{ Study II } & & \multicolumn{2}{c}{ Study III } \\
\cline { 2 - 5 } \cline { 6 - 7 } & At home & $\begin{array}{c}\text { Night 1 } \\
\text { hospital } \\
\text { Mean }\end{array}$ & $\begin{array}{c}\text { Night 2 } \\
\text { hospital } \\
\text { Mean }\end{array}$ & $\begin{array}{c}\text { In general } \\
\text { hospital } \\
\text { Mean }\end{array}$ & & At home & $\begin{array}{c}\text { In general } \\
\text { hospital } \\
\text { Mean }\end{array}$ \\
\hline $20-35$ & 4.3 & 4.1 & 3.8 & 3.7 & 4.8 & 4.0 \\
$36-50$ & 4.3 & 4.1 & 4.0 & 3.6 & 4.4 & 3.7 \\
older than 50 & 4.2 & 4.2 & 4.1 & 3.9 & 4.2 & 3.9 \\
\hline
\end{tabular}

${ }^{+} \mathrm{F}=3.19 \mathrm{p} \leq .05$

Table 7 The mean shortened SSOS scores for men and women in Study III.

\begin{tabular}{lcc}
\hline & $\begin{array}{c}\text { At home } \\
\text { Mean }\end{array}$ & $\begin{array}{c}\text { In general in hospital } \\
\text { Mean }\end{array}$ \\
\hline Men & 4.4 & 3.9 \\
Women & 4.3 & 3.9 \\
\hline
\end{tabular}




\section{Appendix B}

Table 1 The Utrecht Coping Questionnaire: Factor loadings after varimax rotation with five factors.

fac1 fac2 fac3 fac4 fac5

Using a direct approach in order to solve the problem. .88

Making several alternative plans for handling a problem. .79

Considering different sollutions to the problem. $\quad .77$

Finding out all about the problem. $\quad .67$

Telling oneself that other people also have problems. $\quad .57$

Making a direct intervention, when problems occur. $\quad .52$

Realising that every cloud has a silver lining. $\quad .51$

Considering problems as a challenge. $\quad .42$

88

$-.31$

22

.26

$\begin{array}{lll}.25 & .25 & .24\end{array}$

$\begin{array}{ll}.35 & -.27\end{array}$

Seeking sympathy and comfort from somebody. $\quad 84$

Showing that there are things, which are bothering you. $\quad .80$

Showing one's feelings. $\quad .70$

Asking someone to help. $\quad .64$

Sharing one's worries with someone. $\quad .21 \quad .52 \quad .42$

Showing one's annoyance.

$21 \quad .42$

.23

Worrying about the past.

Taking a gloomy view of the situation.

.66

Feeling unable to do anything.

Looking for distraction.

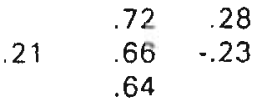

Trying to make oneself feel better one way or another.

Trying to dispel one's worries temporarily

by taking a break.

$.62 \quad .29$

Resigning oneself to the sitution.

Showing one's anger with those 


\section{Appendix C}

Table 1 Factor analysis of the satisfaction list without rotation: Factor loadings.

factor $1^{\prime}$

The clarity of the information provided by the nurses on medication,

treatment, examinations, results of these examinations etc.

.89

The interactions between nurses and patients.

The rules and the routines of the ward. $\quad .87$

The personal attention of physicians for the patients. $\quad .87$

$\begin{array}{ll}\text { Support with potential problems. } & .87\end{array}$

Opportinity to discuss personal problems. $\quad .86$

$\begin{array}{ll}\text { The interactions between physicians and patients. } & .86\end{array}$

$\begin{array}{ll}\text { Activities concerning waking time. } & 86\end{array}$

The extent to which being independent and active is stimulated. $\quad .86$

The medical rounds. $\quad .85$

$\begin{array}{ll}\text { The possibility to act independently (straigthening bed, washing yourself). } & .85\end{array}$

The clarity of the information provided by the physicians on medication,
treatment, examinations, results of these examinations etc.

Activities concerning bed time. $\quad .84$

The personal attention of the nurse for the patients.

Possibility to feel free, your privacy.

The nursing care received. $\quad .82$

The introduction to the ward. $\quad .81$

Information you received on the rules of the wards, the ward routines

an information leaflet. $\quad .74$

The way you are assisted when you ask for help. $\quad .67$

'eigenvalue 13.4 variance $70 \%$ 


\section{Appendix D}

Table 1 F-values for sleep quality in the hospital measured by the SSaS by independent variables including use of sleep medication in hospital $(n=141)$.

In general in hospital

Night 1 in hospital

\begin{tabular}{lcc}
\hline 1 Sleep at home & $13.99^{* * *}$ & 3.31 \\
2 Well-being & $7.29^{* *}$ & $8.71^{* *}$ \\
3 Sleeping habits & $8.29^{* *}$ & .03 \\
4 Environmental changes & $5.96 *$ & 3.08 \\
5 Use of sleep medication & .17 & 1.00 \\
$1 \times 2$ & .35 & $4.51^{*}$ \\
$1 \times 3$ & .06 & 1.13 \\
$1 \times 4$ & .12 & .23 \\
$1 \times 5$ & .34 & .19 \\
$2 \times 3$ & .04 & .71 \\
$2 \times 4$ & .01 & $5.97 *$ \\
$2 \times 5$ & .09 & .52 \\
$3 \times 4$ & .09 & .93 \\
$3 \times 5$ & 1.82 & .21 \\
$4 \times 5$ & 1.79 & .92 \\
\hline
\end{tabular}

$* p \leq .05 * * p \leq .01 * * p \leq .001$ 
Table 2 F-values for sleep quality in the hospital measured by the SSOS by independent variables including morningness/eveningness $(n=141)$.

In general in hospital Night 1 in hospital

\begin{tabular}{|c|c|c|}
\hline 1 Sleep at home & $13.49 * *$ & $4.36 *$ \\
\hline 2 Well-being & $6.76^{* *}$ & $9.72^{* *}$ \\
\hline 3 Sleeping habits & $8.41^{* *}$ & .01 \\
\hline 4 Environmental changes & $5.03^{*}$ & 2.78 \\
\hline 5 Morningness/eveningness & 1.41 & .37 \\
\hline $1 \times 2$ & .72 & 2.85 \\
\hline $1 \times 3$ & .07 & .09 \\
\hline $1 \times 4$ & 1.32 & .15 \\
\hline $1 \times 5$ & .13 & 1.28 \\
\hline $2 \times 3$ & .00 & .91 \\
\hline $2 \times 4$ & .29 & $5.67 * *$ \\
\hline $2 \times 5$ & .31 & 1.10 \\
\hline $3 \times 4$ & 2.04 & .96 \\
\hline $3 \times 5$ & .21 & .73 \\
\hline $4 \times 5$ & .34 & 2.51 \\
\hline $1 \times 2 \times 3$ & 1.24 & .22 \\
\hline $1 \times 2 \times 4$ & .50 & .27 \\
\hline $1 \times 2 \times 5$ & .01 & .43 \\
\hline $1 \times 3 \times 4$ & .06 & .82 \\
\hline $1 \times 3 \times 5$ & .92 & .00 \\
\hline $1 \times 4 \times 5$ & 1.30 & .91 \\
\hline $2 \times 3 \times 4$ & .63 & 2.58 \\
\hline $2 \times 3 \times 5$ & .41 & .19 \\
\hline $2 \times 4 \times 5$ & 2.01 & 2.09 \\
\hline $3 \times 4 \times 5$ & .42 & .73 \\
\hline
\end{tabular}

$* p \leq .05 * p \leq .01 * * p \leq .001$ 


\begin{tabular}{|c|c|c|c|c|c|c|c|c|c|c|c|c|c|c|c|}
\hline & & 1 & 2 & 3 & 4 & 5 & 6 & 7 & 8 & 9 & 10 & 11 & 12 & 13 & 14 \\
\hline 1 & age & $-\cdot$ & & & & & & & & & & & & & \\
\hline 2 & $\begin{array}{l}\text { environmental } \\
\text { changes }\end{array}$ & -.10 & -- & & & & & & & & & & & & \\
\hline 3 & bed & -.11 & .07 & -- & & & & & & & & & & & \\
\hline 4 & privacy & $-.21^{\bullet}$ & $.20^{\bullet}$ & -.02 & -. & & & & & & & & & & \\
\hline 5 & worry & -.15 & .10 & -.12 & .10 & -- & & & & & & & & & \\
\hline 6 & cope & -.11 & .06 & .11 & $.23^{\bullet}$ & .11 & -. & & & & & & & & \\
\hline 7 & well-being & .15 & -.06 & -.01 & $-.17^{\bullet}$ & $-37^{\circ}$ & -.07 & -- & & & & & & & \\
\hline 8 & $\begin{array}{l}\text { sleep quality } p \\
\text { admissions }\end{array}$ & $\begin{array}{l}\text { previous } \\
.06\end{array}$ & Is $-.20^{\circ}$ & .07 & -.12 & $-.31^{\square}$ & $-.28^{\bullet}$ & $.16^{\circ}$ & -- & & & & & & \\
\hline 9 & $\begin{array}{l}\text { sleep medicati } \\
\text { admissions }\end{array}$ & $\begin{array}{l}\text { tions pre } \\
.11\end{array}$ & $\begin{array}{c}\text { evious } \\
.15^{\circ}\end{array}$ & $-.28^{\circ}$ & .06 & $.27^{\bullet}$ & -.03 & $-.23^{\bullet}$ & $-.19^{\bullet}$ & -- & & & & & \\
\hline 10 & sleeping habits & $\mathrm{ts}-.34$ & $.13^{\circ}$ & .01 & $.15^{\circ}$ & .07 & -.03 & -.02 & -.11 & -.12 & -- & & & & \\
\hline 11 & position in bed & $d \cdot .13^{\circ}$ & -.08 & $.13^{\circ}$ & .10 & .06 & $.15^{\circ}$ & .07 & -.00 & -.09 & .00 & $-\cdot$ & & & \\
\hline 12 & $\begin{array}{l}\text { being awaken } \\
\text { too early }\end{array}$ & $\begin{array}{l}\text { hed } \\
-.21\end{array}$ & .14 & .08 & $.25^{\square}$ & $.17=$ & .03 & $-.37^{\square}$ & .07 & -.10 & .10 & .10 & -- & & \\
\hline 13 & alone in bed & $-.19^{\bullet}$ & .10 & -.11 & -.01 & .00 & -.00 & -.03 & -.10 & .04 & $.13^{2}$ & .08 & .03 & -- & \\
\hline 14 & $\begin{array}{l}\text { morningness/ } \\
\text { eveningness }\end{array}$ & .02 & .08 & .01 & -.00 & .07 & .09 & .09 & -.06 & .06 & -.03 & .08 & .12 & .11 & -- \\
\hline 15 & $\begin{array}{l}\text { sleep quality } \\
\text { at home }\end{array}$ &. .06 & -.12 & .06 & -.05 & $-.49^{\square}$ & $-.15^{\bullet}$ & $.18^{\circ}$ & $.33^{\circ}$ & $-.40^{\square}$ & .02 & $.21^{\bullet}$ & .00 & -.03 & .06 \\
\hline
\end{tabular}

$0 \leq .05^{\bullet} p \leq .01^{\square} p \leq .001$ 


\section{Appendix $\mathrm{E}$}

Table 1 Description of the population of nurses on the experimental and control wards in the pretest and posttest.

\begin{tabular}{|c|c|c|c|c|c|c|c|c|c|}
\hline & \multicolumn{2}{|c|}{ Gender } & \multicolumn{6}{|c|}{ Education } & \multirow{2}{*}{$\begin{array}{c}\text { Years of } \\
\text { experience } \\
\text { mean }\end{array}$} \\
\hline & $M$ & $F$ & $\begin{array}{l}\text { pract } \\
\text { grad. }\end{array}$ & $\begin{array}{l}\text { nurse } \\
\text { stud. }\end{array}$ & $\begin{array}{l}\text { dipl } \\
\text { grad }\end{array}$ & $\begin{array}{l}\text { urse } \\
\text { tud. }\end{array}$ & BSN & $\begin{array}{c}\text { post basic } \\
\text { degree }\end{array}$ & \\
\hline \multicolumn{10}{|c|}{ EXPERIMENTAL WARDS } \\
\hline $\begin{array}{l}\text { Pretest } \\
(n=19)\end{array}$ & 8 & 10 & -- & - & 11 & 2 & 1 & 5 & 10 \\
\hline $\begin{array}{r}\text { Posttest } \\
(n=19) \\
\text { CONTROL WARDS }\end{array}$ & 7 & 9 & -- & -- & 11 & 1 & - & 6 & 12 \\
\hline $\begin{array}{l}\text { Pretest } \\
(n=29)\end{array}$ & 12 & 11 & 1 & - & 18 & 4 & 2 & 4 & 11 \\
\hline $\begin{array}{l}\text { Posttest } \\
(n=48)\end{array}$ & 11 & 32 & 1 & 3 & 28 & 7 & 2 & 7 & 10 \\
\hline
\end{tabular}


Table 2 Frequencies of interventions nurses use in practice on sleep problems during the pretest $(t 1)$ and during the posttest $(t)$ in the control group and experimental group.

\begin{tabular}{|c|c|c|c|c|c|c|c|c|}
\hline & & & $t_{1}$ & & & $t_{3}$ & & $F$ \\
\hline & & never & $\begin{array}{l}\text { Some- } \\
\text { times }\end{array}$ & always & never & $\begin{array}{l}\text { some- } \\
\text { times }\end{array}$ & always & \\
\hline paying no attention & $\begin{array}{l}\text { con } \\
\exp \end{array}$ & $\begin{array}{l}22 \\
14\end{array}$ & $\begin{array}{l}4 \\
2\end{array}$ & $\begin{array}{l}3 \\
2\end{array}$ & $\begin{array}{l}36 \\
15\end{array}$ & $\begin{array}{l}8 \\
3\end{array}$ & $\begin{array}{l}4 \\
1\end{array}$ & ns \\
\hline no time to pay & con & 20 & 9 & - & 27 & 21 & - & ns \\
\hline attention & $\exp$ & 9 & 9 & - & 9 & 9 & - & \\
\hline consult physician & con & 5 & 17 & 7 & 9 & 27 & 12 & $6.57^{* *}$ \\
\hline & & & & & & & & \\
\hline try to discover cause & con & - & 5 & 24 & 1 & 9 & 38 & ns \\
\hline $\begin{array}{l}\text { of sleep problem in } \\
\text { conversation }\end{array}$ & $\exp$ & - & 6 & 12 & - & 6 & 13 & \\
\hline sleep medication & $\operatorname{con}$ & 1 & 18 & 9 & 10 & 27 & 9 & $8.07^{* * *}$ \\
\hline & $\exp$ & - & 9 & 9 & - & 6 & 12 & \\
\hline glas of warm milk & con & 1 & 11 & 17 & 5 & 17 & 24 & ns \\
\hline & $\exp$ & 2 & 12 & 4 & 2 & 9 & 7 & \\
\hline pain & $\operatorname{con}$ & 4 & 20 & 3 & 16 & 24 & 6 & $4.56^{* *}$ \\
\hline medication & $\exp$ & 3 & 10 & 4 & - & 13 & 6 & \\
\hline tranquilizer & con & 10 & 17 & - & 27 & 19 & - & $\mathrm{ns}$ \\
\hline & $\exp$ & 11 & 6 & 1 & 6 & 13 & - & \\
\hline put patient & con & - & 8 & 20 & 1 & 10 & 36 & $12.05 \cdots$ \\
\hline at ease & $\exp$ & 2 & 9 & 8 & - & 13 & 6 & \\
\hline straighten bed & con & 3 & 8 & 15 & 2 & 12 & 32 & $3.00^{\circ}$ \\
\hline & $\exp$ & 2 & 9 & 8 & 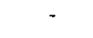 & 10 & 8 & \\
\hline washing face, & $\operatorname{con}$ & 20 & 6 & 3 & 22 & 12 & 12 & $7.06 * *$ \\
\hline brushing teeth & $\exp$ & 15 & 3 & 1 & 13 & 5 & - & \\
\hline decrease noise & con & 2 & 14 & 13 & 8 & 22 & 16 & $4.29^{*}$ \\
\hline & $\exp$ & 8 & 10 & 1 & 5 & 10 & 3 & \\
\hline adjust care & $\operatorname{con}$ & 7 & 12 & 9 & 3 & 22 & 21 & $\mathrm{~ns}$ \\
\hline routines & $\exp$ & - & 17 & 2 & & 15 & 4 & \\
\hline activate pa- & con & - & 12 & 17 & 1 & 19 & 28 & $4.60^{*}$ \\
\hline tient during day & $\exp$ & 1 & 8 & 10 & 1 & 7 & 11 & \\
\hline educate patient on & con & 2 & 12 & 13 & 8 & 22 & 19 & ns \\
\hline sleep/sleep problems & $\exp$ & 2 & 7 & 8 & 1 & 5 & 12 & \\
\hline
\end{tabular}

${ }^{*} \mathrm{p} \leq .05 *{ }^{*} \mathrm{p} \leq .01 *{ }^{*} \mathrm{p} \leq .001$ 
Table 3 Frequency of interventions nurses would actually use and prefer to use in practice for the 10 cases during the pretest $(t 1)$ and posttest $(t 2)$ in the control and experimental group.

\begin{tabular}{|c|c|c|c|c|c|}
\hline & & \multicolumn{2}{|c|}{$\mathrm{t1}$} & \multicolumn{2}{|c|}{$\mathrm{t} 3$} \\
\hline & & actually do & prefer to do & actually do & prefer to do \\
\hline paying no & con & $\cdot$ & $\cdot$ & - & - \\
\hline attention & $\exp$ & - & - & - & - \\
\hline no time to pay & $\operatorname{con}$ & - & - & 3 & 1 \\
\hline attention & $\exp$ & 1 & - & 1 & 1 \\
\hline consult & con & 84 & 87 & 149 & 135 \\
\hline physician & $\exp$ & 18 & 17 & 14 & 20 \\
\hline try to discover cause & $\operatorname{con}$ & 142 & 121 & 272 & 230 \\
\hline $\begin{array}{l}\text { of sleep problem } \\
\text { in conversation }\end{array}$ & $\exp$ & 87 & 73 & 70 & 75 \\
\hline sleep & $\operatorname{con}$ & 48 & 43 & 64 & 49 \\
\hline medication & $\exp$ & 34 & 24 & 33 & 31 \\
\hline glas of warm & con & 67 & 54 & 68 & 65 \\
\hline milk & $\exp$ & 19 & 12 & 18 & 18 \\
\hline pain & $\operatorname{con}$ & 19 & 15 & 36 & 36 \\
\hline medication & $\exp$ & 10 & 5 & 17 & 15 \\
\hline tranquilizer & $\operatorname{con}$ & 9 & 6 & 19 & 16 \\
\hline & $\exp$ & 4 & 3 & 13 & 7 \\
\hline put patient & $\operatorname{con}$ & 90 & 75 & 141 & 112 \\
\hline at ease & $\exp$ & 37 & 42 & 28 & 39 \\
\hline straighten bed & con & 42 & 33 & 48 & 42 \\
\hline & $\exp$ & 3 & 2 & 4 & 5 \\
\hline washing face, & $\operatorname{con}$ & 8 & 8 & 19 & 16 \\
\hline brushing teeth & $\exp$ & - & - & - & 1 \\
\hline decrease noise & con & 3 & 3 & 12 & 10 \\
\hline & $\exp$ & - & - & - & - \\
\hline adjust care & $\operatorname{con}$ & 7 & 7 & 10 & 14 \\
\hline routines & $\exp$ & 5 & 5 & - & 3 \\
\hline activate patient & con & 4 & 5 & 5 & 10 \\
\hline during day & $\exp$ & - & - & 1 & 3 \\
\hline educate patient on & $\operatorname{con}$ & 31 & 25 & 59 & 58 \\
\hline sleep/sleep problems & $\exp$ & 15 & 13 & 10 & 10 \\
\hline
\end{tabular}


Table 4 (Dis)agreements of nurses with statements on sleep problems in hospital for the control and experimental wards during the pretest (t 1$)$ and posttest (t2).

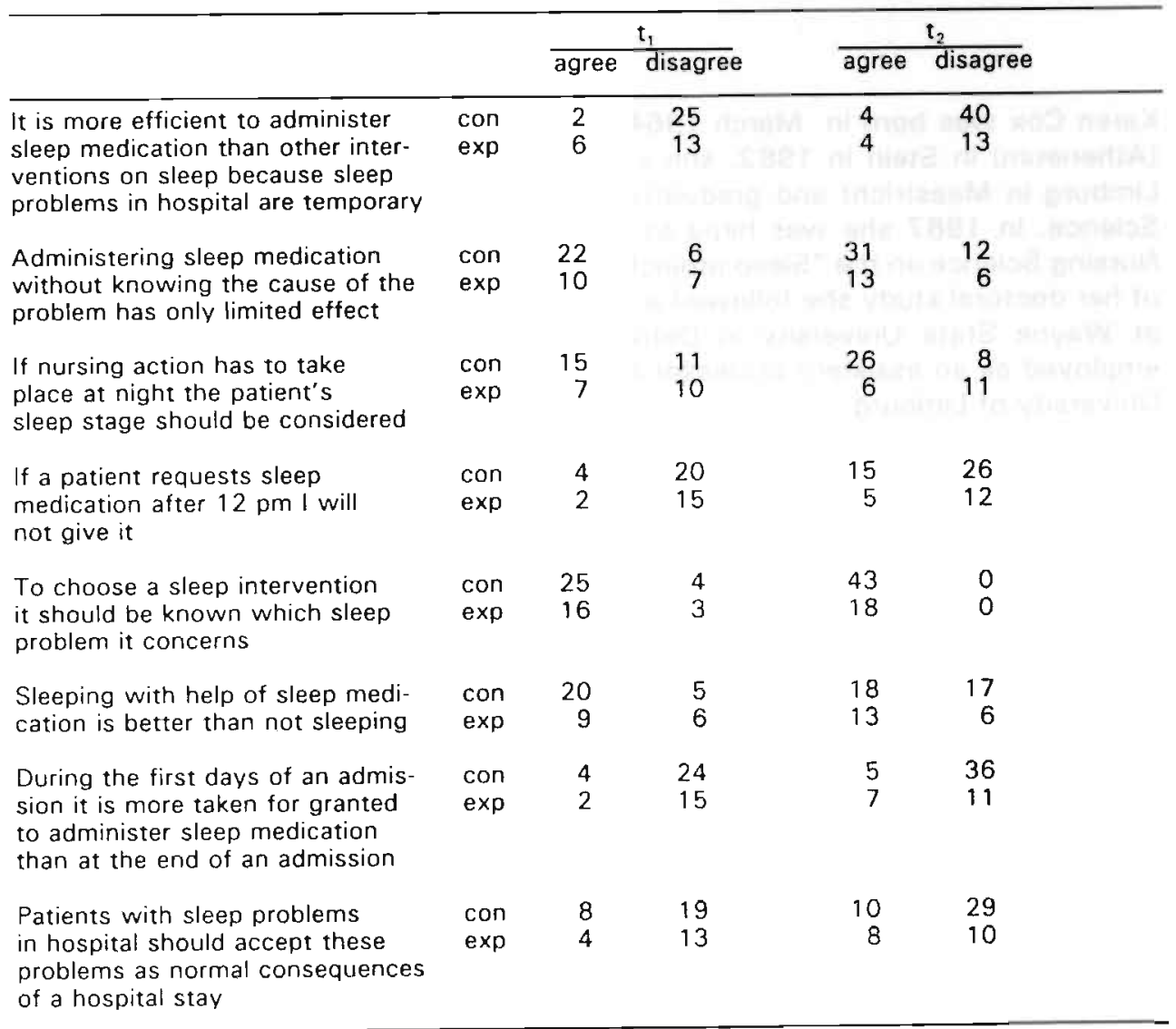




\section{Curriculum Vitae}

Karen Cox was born in March 1964 in Sittard. After completion of highschool (Atheneum) in Stein in 1982, she studied Health Sciences at the University of Limburg in Maastricht and graduated in 1986 with a specialization in Nursing Science. In 1987 she was hired as a research associate at the Department of Nursing Science on the "Sleep project" funded by the "Praeventie fonds". As part of her doctoral study she followed a number of courses at the College of Nursing at Wayne State University in Detroit. Since September 1990 she has been employed as an assistant professor at the department of Nursing Science at the University of Limburg. 

